\title{
A FRAMEWORK TO DESIGN AND OPTIMIZE CHEMICAL FLOODING PROCESSES
}

Third Annual and Final Report for the Period

September 1, 2005 - August 31, 2006

\author{
by \\ Mojdeh Delshad, Gary A. Pope, Kamy Sepehrnoori
}

Nov. 2006

Work Performed under Contract No. DE-FC-26-03NT15412

Betty Felber, Contracting officer Representative

U.S. Dept of Energy

National Energy Technology Laboratory

One West Third Street, Suite 1400

Tulsa, OK 74103-3159

Prepared by

Center for Petroleum and Geosystems Engineering

The University of Texas at Austin

Austin, TX 78712 


\section{DISCLAIMER}

This report was prepared as an account of work sponsored by an agency of the United States Government. Neither the United States Government nor any agency thereof, nor any of their employees, makes any warranty, express or implied, or assumes any legal liability or responsibility for the accuracy, completeness, or usefulness of any information, apparatus, product, or process disclosed, or represents that its use would not infringe privately owned rights. Reference herein to any specific commercial product, process, or service by trade name, trademark, manufacturer, or otherwise does not necessarily constitute or imply its endorsement, recommendation, or favoring by the United States Government or any agency thereof. The views and opinions of authors expressed herein do not necessarily state or reflect those of the United States Government or any agency thereof. 


\begin{abstract}
The goal of this proposed research is to provide an efficient and user friendly simulation framework for screening and optimizing chemical/microbial enhanced oil recovery processes. The framework will include (1) a user friendly interface to identify the variables that have the most impact on oil recovery using the concept of experimental design and response surface maps, (2) UTCHEM reservoir simulator to perform the numerical simulations, and (3) an economic model that automatically imports the simulation production data to evaluate the profitability of a particular design. Such a reservoir simulation framework is not currently available to the oil industry.

The objectives of Task 1 are to develop three primary modules representing reservoir, chemical, and well data. The modules will be interfaced with an already available experimental design model. The objective of the Task 2 is to incorporate UTCHEM reservoir simulator and the modules with the strategic variables and developing the response surface maps to identify the significant variables from each module. The objective of the Task 3 is to develop the economic model designed specifically for the chemical processes targeted in this proposal and interface the economic model with UTCHEM production output. Task 4 is on the validation of the framework and performing simulations of oil reservoirs to screen, design and optimize the chemical processes.
\end{abstract}




\section{TABLE OF CONTENTS}

DISCLAIMER ....................................................................................... ii

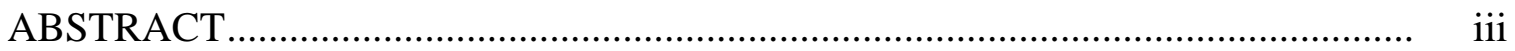

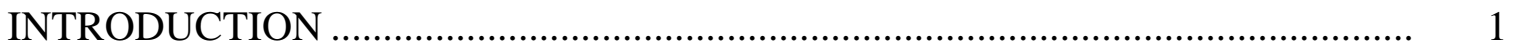

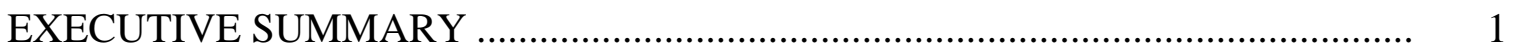

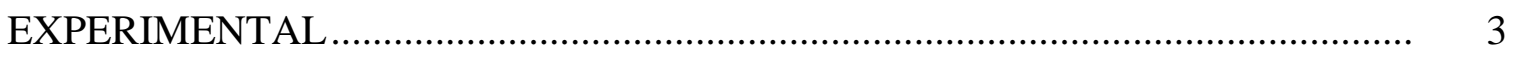

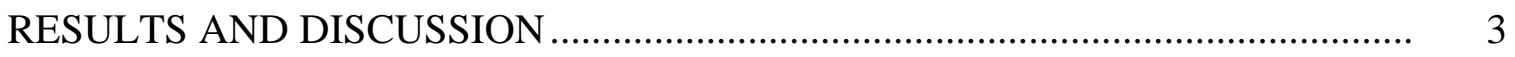

Task 1: Development of Uncertainty Modules and Experimental Design

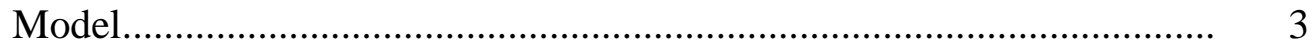

Task 2: Reservoir Simulation and Response Surface Model.............................. 5

Task 3: Economic Analysis ........................................................................ 7

Task 4: Validation and Field Scale Studies .................................................... 8

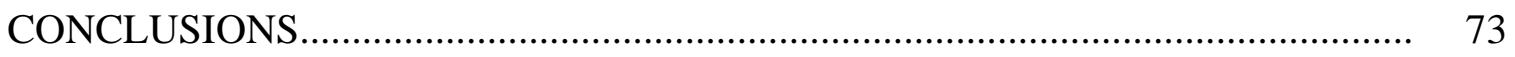

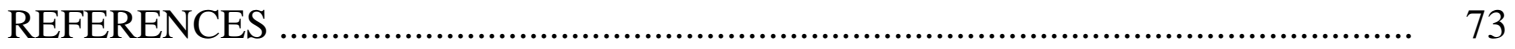




\section{LIST OF TABLES}

Table A-1 $\quad$ Reservoir and fluid properties................................................................. 15

Table A-2 Input parameters for the base case simulation ....................................... 15

Table A-3 Summary of sensitivity parameters...................................................... 16

Table A-4 Summary of UTCHEM surfactant flood simulations ............................ 17

Table A-5 Summary of oil recovery results ...................................................... 18

Table B-1 Reservoir and simulation model properties .......................................... 56

Table B-2 Fluid properties ............................................................................ 56

Table B-3 Base case SP design ................................................................. 57

Table B-4 Economic analysis input parameters.................................................... 57

Table B-5 Sensitivity simulation designs and results .......................................... 58

Table B-6 Sensitivity simulation economic analysis ............................................ 59 


\section{LIST OF FIGURES}

Fig. A-1 Comparison of average reservoir pressure (day zero corresponds to Aug. 1996, surfactant injection starts in Jan. 2007, and the end corresponds to Jun 2020).

Fig. A-2 Comparison of total injection rate.......................................................... 19

Fig. A-3 Comparison of total production rate. ....................................................... 20

Fig. A-4 Comparison of oil production rate .......................................................... 21

Fig. A-5 Comparison of overall oil cut. .............................................................. 22

Fig. A-6 Comparison of cumulative water injected. ................................................. 23

Fig. A-7 Comparison of cumulative fluid production............................................. 24

Fig. A-8 Comparison of cumulative surfactant injection......................................... 25

Fig. A-9 Comparison of cumulative surfactant production....................................... 26

Fig. A-10 Cumulative polymer injection................................................................ 27

Fig. A-11 Cumulative oil production as a percentage of original oil in place. ........... 28

Fig. A-12 Comparison of cumulative oil production in bbls....................................... 29

Fig. A-13 Overall aqueous phase cut as a function of cumulative oil production in bbls. ............................................................................ $\quad 30$

Fig. A-14 Comparison of pore volumes water injected. ........................................... 31

Fig. A-15 Final average oil saturation................................................................... 31

Fig. A-16 Average oil saturation in each layer at the end of simulation..................... 32

Fig. A-17 Average permeability, initial water saturation, and porosity per layer............................................................................................ 33

Fig. A-18 Chemical incremental oil recovery ……………...................................... 33

Fig. A-19 Chemical incremental oil recovery ......................................................... 34

Fig. B-1 Simulation model permeability (md).................................................... 60

Fig. B-1 Simulation model initial oil saturation.................................................... 60

Fig. B-3 Comparison of measured and UTCHEM surfactant phase behavior.......... 61

Fig. B-4 Comparison of measured and UTCHEM polymer viscosity vs. shear rate.

Fig. B-5 Comparison of measured and UTCHEM polymer viscosity vs. salinity.

Fig. B-6 Comparison of measured and UTCHEM polymer viscosity vs. concentration.................................................................................... 62

Fig. B-7 Base case simulation injection rate and bottomhole pressure...................... 63 
Fig. B-8 Base case simulation production rates and produced surfactant concentration (volume fraction)....................................................... 63

Fig. B-9 Base case oil saturation after 0.2 pv injected....................................... 64

Fig. B-10 Base case oil saturation after 0.35 pv injected....................................... 64

Fig.B-11 Base case oil saturation after 1.75 pv injected....................................... 64

Fig. B-12 Base case surf. conc. (vol. frac.) after 0.2 pv injected............................. 65

Fig. B-13 Base case surf. conc. (vol. frac.) after 0.35 pv injected........................... 65

Fig. B-14 Base case surf. conc. (vol. frac.) after 1.75 pv injected............................ 65

Fig. B-15 Base case polymer conc. (wt\%) after 0.2 pv injected.............................. 66

Fig. B-16 Base case polymer conc. (wt\%) after 0.35 pv injected............................. 66

Fig. B-17 Base case polymer conc. (wt\%) after 1.75 pv injected............................. 66

Fig. B-18 Base case ift (dynes/cm) after 0.2 pv injected .................................... 67

Fig. B-19 Base case ift (dynes/cm) after 0.2 pv injected....................................... 67

Fig. B-20 Base case ift (dynes/cm) after 1.75 pv injected. .................................... 67

Fig. B-21 Cumulative oil recovery for surfactant concentration simulations............ 68

Fig. B-22 Economic results for surfactant concentration simulations. ...................... 68

Fig. B-23 Cumulative oil recovery for surfactant slug size simulations................... 69

Fig. B-24 Economic results for surfactant slug size simulations.............................. 69

Fig. B-25 Cumulative oil recovery for polymer mass simulations. .......................... 70

Fig. B-26 Economic results for polymer mass simulations. .................................. 70

Fig. B-27 Cumulative oil recovery for surfactant adsorption simulations................. 71

Fig. B-28 Economic results for surfactant adsorption simulations......................... 71

Fig. B-29 Comparison of npv for design optimization simulations ......................... 72

Fig. B-30 Comparison of npv for uncertainty simulations....................................... 72 


\section{INTRODUCTION}

In this report, we detail our progress on Tasks 1 through 4 for the final year of the project. We previously reported on the development and testing of the framework with modules for uncertainty and optimization of reservoir properties, well placement, chemical data, and economics. We reported on surfactant flooding simulations with different permeability and permeability heterogeneities, surfactant concentration and slug size to identify the key variables that control the project life and oil recovery using the experimental design and a simple discounted cash flow analysis. The experimental design module was then used to design the simulations varying the primary variables such as reservoir permeability and heterogeneity, surfactant, and polymer concentration and slug size and the provided range for each.

Here we report on design and optimization of surfactant flooding for two field applications.

\section{EXECUTIVE SUMMARY}

An efficient approach to obtain the optimum design under uncertainty for a wide range of reservoir simulation applications has been developed and successfully implemented. The approach discussed here significantly reduces the time required to evaluate optimum designs for improved oil recovery (IOR) processes.

Determining the optimum combination of design variables for an IOR process is a complex problem that depends on the crude oil price, reservoir and fluid properties, 
process performance, and well specifications. Due to the large number of design variables, numerical simulation is often the most appropriate tool to evaluate the feasibility of such a process. Our innovative simulation approach has the capability to determine an economically optimum design that includes the following variables for surfactant/polymer flooding projects:

- $\quad$ The duration of water injection prior to the surfactant flooding

- $\quad$ Surfactant concentration and slug size

- $\quad$ Polymer concentration injected with the surfactant

- $\quad$ The concentration and duration of the polymer drive

- $\quad$ The electrolytes concentration in different stages of the flood

In order to efficiently perform these complex design processes, the platform developed as part of this project distributes multiple simulations on a cluster of computer processors.

The objectives of Task 1 are to develop three primary modules representing reservoir, chemical, and well data. The modules are interfaced with an already available experimental design model. The objective of the Task 2 is to incorporate UTCHEM reservoir simulator and the modules with the strategic variables and developing the response surface maps to identify the significant variables from each module. The objective of Task 3 is to incorporate an economic model that automatically imports the simulation production data to evaluate the profitability of a particular design. The objective of the Task 4 is to perform a certain number of flow simulations using UTCHEM. Here we report on our efforts on Task 4. 


\section{EXPERIMENTAL}

This project does not include an experimental component. The published laboratory data are used in the design of field scale simulations presented later.

\section{RESULTS AND DISCUSSION}

We performed simulations to help determine whether a surfactant flood could be economically attractive in two US reservoirs, given typical performance and consumption of the surfactant. UTCHEM simulations were performed using typical values of interfacial tension reduction, oil mobilization using capillary desaturation concept, surfactant consumption, etc. We performed sensitivity simulations to determine physical parameters that are critical to the success of the surfactant flood in these reservoirs, including optimum size and concentration of surfactant slug.

\section{Task 1: Development of Uncertainty Modules and Experimental Design Model}

Integrated reservoir simulation system (IRSS) is a compilation of software and hardware on a single processor running Linux or a cluster of processors to solve numerous oil reservoir problems where multiple reservoir simulations are simultaneously performed, either in sequential, distributed or parallel mode (Zhang 2005). The reservoir simulators incorporated are UTCHEM, ECLIPSE from Geoquest, (Schlumberger) and VIP from Landmark (Landmark). Stochastic distributions of reservoir properties are generated using Matrix Decomposition Method (Yang, 1990), and Sequential Gaussian Simulation module of GSLIB (Geostatistical Software Library) (Deutsch and Journel, 1998). The framework uses two different job schedulers to submit the jobs either in 
sequential, distributed or parallel mode. The two job schedulers are Portable Bath System (PBS) (Altair Grid Technologies) and Load Sharing Facility (LSF) (Platform Computing Corporation).

Upon successful completion of the simulations, UT_IRSP will summarize the results and generates statistical summary files and statistical map files according to the purpose of the study.

There are many Window-based softwares for data post-processing. DesignExpert and Crystal Ball are the most critical components of the platform. Surfer is used to generate variogram for the $3 \mathrm{D}$ geostatistical data. Tecplot RS is used to plot the 3D map files from UTCHEM and ECLIPSE.

The framework is designed using the object-oriented concept and is written in $\mathrm{C}^{++}$. Ideally, it works on a cluster of computers with LINUX as the operating system. The framework can be divided into three modules. Main program works as the front end to the framework. Once the framework is launched, the user needs to provide the study name and select the numerical model of interest.

- $\quad$ Pre-processing group contains ten classes. This section of the code reads the instruction and/or stochastic files first. Multiple simulation input files are then generated according to the user's specification. All the simulation jobs are then submitted to the processors either as sequential (one simulation at a time), distributed (multiple simulations to a cluster of PCs) or parallel mode. The simulation output files are saved hierarchically on a 
storage device. The instruction file contains the following data as (1) the number of the simulations, (2) the run number, (3) the execution mode, and (4) the factors that are under investigation and how these factors are varied for each simulation. The stochastic input file is also needed to generate the single or spatial stochastic fields from the distributions. Sequential Gaussian (sgsim) model from GSLIB (Deutsch and Journel, 1998) is one of the two geostatistical modules available in the framework.

- Post-processing module contains eight classes. The output of the simulations will be collected and summarized either for further data manipulation or graphical presentations.

\section{Task 2: Reservoir Simulation and Response Surface Model}

Design of Experiments (DOE) is a method to select simulations to maximize the information gained from each simulation and to evaluate statistically the significance of the different factors. An experimental design study is used to generate response surfaces that identify the various factors that cause changes in the responses and also predicting these variations in a simple mathematical form. The purpose of Response Surface Methodology (RSM) (Myers and Montgomery, 1995) is to approximate a process over a region of interest, often called operating region. The components of the operating region include objectives, requirements, state parameters (with or without uncertainty), decision variables, and constraints. An objective is the statement of the goal, and requirement can be imposed. State parameters are those that cannot be controlled and most of the times 
have uncertainties associated with them. They can be discrete or continuous. Discrete parameters are also referred to as "scenarios". Decision variables are those that are controllable and are usually choices available to the decision-maker. Constraints are boundary conditions, which restrict values available for the decision variables.

RSM provides tools for (1) identifying the variables that influence the responses (screening) and (2) building regression models relating the responses to the strategic variables (modeling). The final models are used to make predictions of the process over the domain.

In order to compute the regression model, the process has to be sampled over the operating region through experimentation. Design of Experiment is the use of mathematical and statistical methods to determine the number and the location of the experiments in order to get most information at the lowest experimental cost.

We will not describe the detailed mathematical and statistical theories behind response surface and experimental design. More detailed information can be found in related literature (Myers and Montgomery, 1995). A commercial package, DesignExpert from Stat-Ease, Inc., is used for performing experimental design analysis.

The steps to perform RSM and DOE in conjunction with our framework are listed as the following:

- $\quad$ Select the response and identify the settings for the state parameters and decision variables.

- $\quad$ Select the corresponding method of DOE according to the study objective.

- Include the experimental plan from DOE in the instruction and/or stochastic and/or economic file. 
- $\quad$ Run the numerical simulations using the framework. The simulations are executed sequentially, distributed or in a parallel mode.

- Export the results of the response to the DOE and perform statistical analysis.

- Use the response model results to screen the factors and/or to perform further optimization as discussed in the next section.

The optimization algorithm incorporates metaheuristics to guide its search algorithm toward better solutions. The approach uses a form of adaptive memory to store which solutions worked well before and recombines them into new improved solutions. Since this technique does not use the hill-climbing approach of ordinary solvers, it does not get trapped in local solutions, and it does not get thrown off course by noisy (uncertain) model data. Scatter and tabu searches are used to globally search the solution space. Neural network is used as a predictive model to help the system accelerate the search by screening the reference points that are likely to have inferior objective function values. The optimizer is described in detail in the references (April et al., 2003).

OptQuest from OptTek Systems, Inc. is the commercial optimizer that implements the above stated optimization algorithm and has been integrated in Crystal Ball, a risk analysis software package from Decisioneering, Inc. We use Crystal Ball and OptQuest to perform the optimization under uncertainty. Figure 4 shows the workflow of OptQuest in the Crystal Ball environment.

\section{Task 3: Economic Analysis}

A simple discounted cash flow model is implemented in the framework (Vaskas, 1996). The discounted cash flow (DCF) method of economic analysis allows individual projects to be evaluated and/or compared with other projects. DCF analysis gives less 
weight to future incomes by applying a discount rate to the predicted cash flows, thereby taking into account the time value of money.

\section{Task 4: Field Scale Studies}

Previously we reported on the application of the developed framework to several field scale examples (Zhange et al., 2005). IN this report we give the results on design and optimization of surfactant EOR process for two heterogeneous, mixed wet dolomite reservoirs in US.

\section{Field A - US dolomite reservoir}

This field is characterized as a dolomite formation with layered description with two units separated by "hard streak" barrier that limits the vertical flow between the units. The reservoir temperature is about $220^{\circ} \mathrm{F}$ with the initial reservoir pressure of $4000 \mathrm{psi}$. The wettability is characterized as mixed wet. Oil has an API of about 33 with the viscosity in the range of 1.5 to $2.5 \mathrm{cp}$. The formation volume factor of oil is about 1.2 rb/stb. There are 5 injection wells and 4 producers. The wells are deviated wells completed in the top three layers primarily. The effective well spacing is about $930 \mathrm{ft}$ between each pair of injection and infill production wells. The wells are all operated under a constant pressure with a gradient of about 5700 psi between each well pair. The total injection rate was about 2000 STB/d during the waterflood and surfactant injection period. The pressure gradient is about $6 \mathrm{psi} / \mathrm{ft}$. Table A-1 gives the reservoir model and fluid properties.

Surfactant flood simulations were performed following the initial primary production and waterflood. Water injection was extended to Jan. 2007 (3980 days from 
the onset of primary production shown on the $\mathrm{x}$ axis of all the figures). Several simulations were performed to find the optimum surfactant concentration, slug size, and the salinity. The list of parameters used in base case simulation is given in Table A-2. Since the adsorption of surfactant on dolomite rock is not well known and due to uncertainty in microemulsion viscosity and surfactant micelle concentration (CMC), we also performed sensitivity simulations to these parameters as given in Table A-3. Tables A-4 and A-5 summarize the results of these simulations.

The base case simulation (run no. UTS-02) included a 7-year surfactant slug with a concentration of 1.7 vol\%. The simulation was performed at a constant optimum salinity of $0.225 \mathrm{meq} / \mathrm{ml}$ where we assume salinity remains constant and at optimum throughout the simulation. The surfactant adsorption was about $0.08 \mathrm{mg} / \mathrm{g}$ in the base case simulation. However, we did perform sensitivity simulations to surfactant adsorption. Laboratory data are crucial to get a better handle on the surfactant retention on the dolomite formation and the possible need of an alkali agent such as sodium carbonate of sodium hydroxide to reduce the adsorption.

Simulation UTS-03 had a higher surfactant concentration of 2.5 vol\% in the chemical slug. To investigate the effect of salinity on the chemical flood performance, simulation UTS-04 was performed using the same amount of chemical as that of UTS-02 but at a salinity corresponding to a Type II(-) under optimum condition $(0.15 \mathrm{meq} / \mathrm{ml}$ of salt). Simulation UTS-05 was performed with a salinity gradient design where the initial formation water, injected pre chemical water, and surfactant slug has a salinity at 
optimum of $0.225 \mathrm{meq} / \mathrm{ml}$ and it was then dropped to under optimum Type II(-) in the water post flush $(0.15 \mathrm{meq} / \mathrm{ml})$. The sensitivity to the surfactant slug size was performed in Simulation UTS-07 by reducing the slug size from that of the base case of 7 years to only 4 years. Effect of mobility control and enhanced sweep efficiency is demonstrated in simulation UTS-07 by adding 250 ppm polymer concentration to the surfactant slug. The increased viscosity in the injected water reduced the injectivity and thus the amount of surfactant injected but for the same amount of oil recovery. This simulation shows the benefit of a mobility control agent such as polymer during the surfactant flood. However, it may not be feasible to inject polymer in this low permeability formation. Reservoir coreflood experiments are required to test the injectivity of low molecular weight polymer. The sensitivity to microemulsion viscosity was explored by reducing the microemulsion viscosity by a factor of 1.5 from that in Simulation UTS-06. Due to lower microemulsion viscosity, the injectivity increased and thus the amount of surfactant injected which results a higher oil recovery. Simulation UTS-09 was performed to obtain the highest oil recovery possible under the most optimum conditions of surfactant flood. Surfactant concentration was increased to 2.5 vol\% and was injected for a period of five years. The surfactant properties were changed corresponding to a more efficient surfactant with a lower CMC of 0.0001 vol. fractions and higher oil solubilization ratio of about 25 compared to that of 10 used in the base case simulation. The details are given in Table A-3. The oil recovery in simulation UTS-09 increased to 0.725 for even less amount of surfactant injected of simulation UTS-03. The effect of surfactant adsorption on oil recovery was investigated in Simulation UTS-11 where the surfactant adsorption 
was increased a ten fold. Oil recovery reduced from 0.725 to 0.624 . Of course the surfactant adsorption can be reduced by addition of alkali agent to the water in the actual field application. Simulation UTS-15 was performed for a different surfactant phase behavior. Other parameters were similar to simulation UTS-08. The oil recovery is only slightly lower than that of UTS-08.

Figures A-1 through A-33 summarize the results of the sensitivity simulations.

The average reservoir pressure rises from less than 1000 psi during the primary production to about 3300 psi at the end of the continuing waterflood as shown in Fig. A1. The reservoir pressure increases about 1000 psi when surfactant was added to the injected water due to the higher injection rate as demonstrated in Fig. A-2. The reservoir pressure is lower than that of the waterflood when $250 \mathrm{ppm}$ polymer solution was added to the surfactant slug as simulation UTS-07 shown in Fig. A-1 due to the lower injection rate of the more viscous polymer solution (Fig. A-2). Waterflood injection rate is about $2000 \mathrm{~B} / \mathrm{D}$ prior the injection of chemicals and increases to as high as $8000 \mathrm{~B} / \mathrm{D}$ for Simulations UTS-09 and UTS-11 where the microemulsion viscosity was lowered to about 1.5 cp. These rates might be too high but we did not impose any constraints on the injection rate in these simulations. Total production rate shows very similar trend as shown in Fig. A-3.

The influence of surfactant in mobilizing the residual oil saturation is demonstrated in Fig. A-4 as the peak of the oil production rate started at about 5000 days. Corresponding history of the overall oil cut is given in Fig. A-5. The range of oil cut at 
the end of the surfactant simulations is between 2 to $6 \%$ with the exception of the case where polymer was added to the surfactant solution where the oil cut is still high and about 22\%. Figures A-6 and A-7 give the cumulative fluid production and water injected at the end of the simulations. The range of the amount of surfactant injected is given in Fig. A-8. The lowest amount was injected in Run UTS-07 where polymer was added and the injection rate was the lowest whereas the largest amount was injected in Run UTS-03. The history of cumulative surfactant produced is given in Fig. A-9. Cumulative polymer injection for Run UTS-07 is shown in Fig. A-10.

Oil recovery efficiency that is relative amount of oil production compared to the original oil in place at the beginning of the primary production (Aug. 1996) is plotted in Fig. A-11. Waterflood recovery is about $30 \%$ whereas the recovery is as high as $74 \%$ for the most optimistic simulation UTS-09. The cumulative oil production is given in Fig. A-12.

The overall aqueous phase cut which is defined as the sum of water and microemulsion phase cuts is plotted as a function of cumulative oil recovery in Fig. A-13. Figure A.14 demonstrates the range of pore volumes injected for different simulations. Since the wells are operating under a constant pressure drop, the resulting injection rates due to fluid mobilities in the gridblock containing the wells will be different. We have injected about 1.2 pore volumes during the waterflood whereas the majority of the simulations with similar microemulsion viscosity have about 1.2 to 1.4 PV throughput. 
The lowest pore volumes injected was in the case where high viscous polymer was injected and it was about $0.8 \mathrm{PV}$.

Average oil saturations at the end of the simulations are given in Fig. A.15. The lowest oil saturation remained in the reservoir of $10 \%$ was found for the very optimistic simulation of UTS-09 and the next lowest of 13\% is for Run UTS-03 where a large slug of surfactant was injected. The average oil saturation at the end of the waterflood is about $47 \%$ that is way above the residual oil saturation of $38 \%$.

The layer distribution of oil saturation at the end of the simulations is given in Fig. A-16. The average permeability, initial water saturation, and porosity per layer are shown in Fig. A-17. The remaining oil saturation shown in Fig. A-16 correlated well with the permeability and initial oil saturation as given in Fig. A-17. The incremental oil recovery due to chemical flooding that is the additional oil recovered compared to the waterflooding for the same period of time are given in Fig. A-18. The lowest is for the Run UTS-04 where the salinity is under optimum in Type II(-) and the highest is for the simulation UTS-09 where relatively high concentration of a very efficient surfactant is used.

Figure A-19 summarizes the results of these simulations in terms of the flood efficiency in lbs of surfactant injected per STB of oil produced along with the incremental oil recovered and the amount of surfactant injected. The most efficient floods are those under the conditions of simulations UTS-07, UTS-08, and UTS-09. The simulation UTS-07 with 250 ppm polymer in the chemical slug uses the least amount of 
surfactant and has the highest oil recovery per lbs of surfactant. The cost of polymer needs to be included as the total chemical cost.

The most sensitive parameters controlling the chemical flooding recovery in this reservoir are the amount of surfactant injected, the surfactant concentration, salinity, and the mobility control agent. The optimum designs are for the cases UTS-08 and UTS-07 as described below:

\begin{tabular}{|l|c|c|}
\hline \multicolumn{1}{|c|}{ Design } & UTS-07 & UTS-08 \\
\hline Salinity & Optimum & Optimum \\
\hline Surf. concentration, vol\% & 1.7 & 1.7 \\
\hline Surfactant slug size, years & 4 & 4 \\
\hline $\begin{array}{l}\text { Polymer concentration in the } \\
\text { surfactant slug, ppm }\end{array}$ & 250 & 0 \\
\hline Oil efficiency & 0.448 & 0.495 \\
\hline lb surf/STB oil & 15.73 & 16.82 \\
\hline
\end{tabular}


Table A-1: Reservoir and fluid properties

\begin{tabular}{|l|c|}
\hline Parameter & Value \\
\hline Number of gridblocks & $95 \times 192 \times 5$ \\
\hline Gridblock size, $\mathrm{ft}$ & $\Delta \mathrm{x}=40, \Delta \mathrm{y}=50$ \\
\hline Oil viscosity, $\mathrm{cp}$ & 2.0 \\
\hline Water viscosity, $\mathrm{cp}$ & 0.3 \\
\hline
\end{tabular}

Table A-2: Input parameters for the base case simulation

\begin{tabular}{|l|c|}
\hline \multicolumn{1}{|c|}{ Property } & Value \\
\hline Surfactant properties & $0.065,0.025$ \\
\hline Heights of binodal curve, vol. fraction & $0.16,0.29 \mathrm{meq} / \mathrm{ml}$ \\
\hline Salinity limits of Type III, meq/ml & 0.001 vol. fraction \\
\hline CMC, vol. fraction & $1 ., 0.5,1000$ \\
\hline Adsorption parameters & $2.0,2.0,0.0,0.9,0.7$ \\
\hline Viscosity & \\
\hline Relative permeability model & $0.075,0.382,0.075$ \\
\hline $\begin{array}{l}\text { Residual saturations at low trapping } \\
\text { number }\end{array}$ & $0.0,0.0,0.0$ \\
\hline $\begin{array}{l}\text { Residual saturations at high trapping } \\
\text { number }\end{array}$ & $0.2,1.0,0.2$ \\
\hline Endpoints at low trapping number & $1.0,1.0,1.0$ \\
\hline Endpoints at high trapping number & $1.5,2.5,1.5$ \\
\hline Exponents at low trapping number & $1.5,2.5,1.5$ \\
\hline Exponents at high trapping number & $1865,59074,364.2$ \\
\hline Trapping number parameters & \\
\hline Interfacial Tension & chuh = 0.3, ahuh $=9$ \\
\hline Huh Correlation & \\
\hline Fluid properties & 0.3 \\
\hline Water viscosity, cp & $1.04,0.8,1.0$ \\
\hline Oil viscosity, cp & \\
\hline Water and oil compressibility, 1/psi & \\
\hline Water, oil, surfactant density, g/cc & \\
\hline
\end{tabular}


Table A-3: Summary of sensitivity parameters

\begin{tabular}{|c|c|c|c|}
\hline Simulation & Surfactant properties & $\begin{array}{l}\text { Microemulsion } \\
\text { viscosity }\end{array}$ & $\begin{array}{l}\text { Surfactant } \\
\text { adsorption }\end{array}$ \\
\hline UTS-02 & Base case & Base case & Base case \\
\hline UTS-03 & /I & $/ /$ & // \\
\hline UTS-04 & // & /1 & $/ 1$ \\
\hline UTS-05 & // & // & // \\
\hline UTS-06 & /I & /I & /I \\
\hline UTS-07 & $/ /$ & /1 & /1 \\
\hline UTS-08 & $1 /$ & $/ 1$ & /1 \\
\hline UTS-09 & $\mathrm{CMC}=0.0001, \mathrm{HBNC71}=0.02$ & $\alpha_{1-5}=1,1,0,0,0$ & $1 /$ \\
\hline UTS-11 & $/ /$ & $/ /$ & $10,0.5,1000$ \\
\hline UTS-15 & $\begin{array}{c}\text { CMC }=0.001 \\
\text { HBNC70, HBNC71 = 0.0428, } \\
0.0401 \\
\text { CSEL, CSEU }=0.282,0.316 \\
\text { meq } / \mathrm{ml}\end{array}$ & // & Base case \\
\hline
\end{tabular}


Table A-4: Summary of UTCHEM surfactant flood simulations

\begin{tabular}{|c|c|c|c|c|c|c|c|c|c|}
\hline Simulation & Salinity & $\begin{array}{l}\text { Surf. } \\
\text { conc. } \\
\text { (vol\%) }\end{array}$ & $\begin{array}{c}\text { Polymer } \\
\text { conc. (wt \%) }\end{array}$ & $\begin{array}{l}\text { Slug size } \\
\text { (yrs) }\end{array}$ & $\begin{array}{l}\text { Water inj. } \\
\left(10^{6} \text { bbls }\right)\end{array}$ & $\begin{array}{l}\text { Surf. inj. } \\
\left(10^{6} \mathrm{lbs}\right)\end{array}$ & $\begin{array}{l}\text { Oil prod. } \\
\left(10^{6} \text { bbls }\right)\end{array}$ & $\begin{array}{l}\text { Oil prod. } \\
\left(10^{6} \mathrm{STB}\right)\end{array}$ & $\begin{array}{c}\text { Oil efficiency } \\
\text { (Fraction } \\
\text { OOIP) }\end{array}$ \\
\hline Water23 & --- & - & - & - & 11.7034 & 0.0 & 2.0953 & 1.7461 & 0.311 \\
\hline UTS-02 & $\begin{array}{c}\text { Opt. at } 0.225 \\
\mathrm{meq} / \mathrm{ml}\end{array}$ & 1.7 & 0.0 & 7 & 12.7934 & 29.70 & 3.5744 & 2.9787 & 0.5308 \\
\hline UTS-03 & $\begin{array}{c}\text { Opt. at } 0.225 \\
\text { meq/ml }\end{array}$ & 2.5 & 0.0 & 7 & 13.3741 & 43.95 & 4.2027 & 3.5023 & 0.62 \\
\hline UTS-04 & $\begin{array}{l}\text { Under opt. at } \\
0.15 \mathrm{meq} / \mathrm{ml}\end{array}$ & 1.7) & 0.0 & 7 & 12.1077 & 28.31 & 2.5604 & 2.1337 & 0.38 \\
\hline UTS- $05^{1}$ & $\begin{array}{l}\text { Salinity } \\
\text { gradient }\end{array}$ & 1.7 & 0.0 & 7 & 13.6519 & 29.71 & 3.6027 & 3.0023 & 0.535 \\
\hline UTS-06 & $\begin{array}{c}\text { Opt. at } 0.225 \\
\text { meq } / \mathrm{ml}\end{array}$ & 1.7 & 0.0 & 4 & 14.017 & 16.61 & 3.0555 & 2.5463 & 0.45 \\
\hline UTS-07 & $\begin{array}{c}\text { Opt. at } 0.225 \\
\text { meq } / \mathrm{ml}\end{array}$ & 1.7 & 0.025 & 4 & 7..9204 & 12.12 & 3.0198 & 2.5165 & 0.448 \\
\hline UTS- $08^{2}$ & // & 1.7 & 0.0 & 4 & 16.3413 & 17.38 & 3.3349 & 2.7791 & 0.495 \\
\hline UTS- $09^{2,3}$ & /1 & 2.5 & 0.0 & 5 & 23.9376 & 37.92 & 4.8824 & 4.0687 & 0.725 \\
\hline UTS- $11^{2,3,4}$ & /1 & 2.5 & 0.0 & 5 & 20.999 & 36.11 & 4.1978 & 3.4982 & 0.623 \\
\hline UTS- $15^{2,5}$ & $\begin{array}{c}\text { opt. at } 0.30 \\
\mathrm{meq} / \mathrm{ml}\end{array}$ & 1.7 & 0.0 & 4 & 13.5326 & 16.99 & 3.0322 & 2.5268 & 0.450 \\
\hline
\end{tabular}

1: Initial, water injection, and surfactant at optimum salinity of $0.225 \mathrm{meq} / \mathrm{ml}$ and water postflush at $0.15 \mathrm{meq} / \mathrm{ml}$ salt

2: Lowered the microemulsion viscosity

3: Lower CMC, lower HBNC71, High NC exponent of 1

4- Increase surfactant adsorption by a factor of 10

5- Different phase behavior parameters 
Table A-5: Summary of oil recovery results

\begin{tabular}{|l|c|c|c|}
\hline Simulation & $\begin{array}{c}\text { Produced } \\
\text { incremental oil } \\
\left(\mathbf{1 0}^{\mathbf{6}} \mathbf{S T B}\right)\end{array}$ & $\begin{array}{c}\text { Injected surfactant } \\
\mathbf{( 1 0} \mathbf{~ l b s )}\end{array}$ & $\begin{array}{c}\text { lbs of surf. per STB } \\
\text { oil } \\
\mathbf{( l b} / \text { STB })\end{array}$ \\
\hline UTS-02 & 1.2326 & 29.70 & 24.090 \\
\hline UTS-03 & 1.7562 & 43.95 & 25.025 \\
\hline UTS-04 & 0.3876 & 28.31 & 73.039 \\
\hline UTS-05 & 1.2562 & 29.71 & 23.650 \\
\hline UTS-06 & 0.8002 & 16.61 & 20.757 \\
\hline UTS-07 & 0.7704 & 12.12 & 15.732 \\
\hline UTS-08 & 1.0330 & 17.38 & 16.824 \\
\hline UTS-09 & 2.3226 & 37.92 & 16.318 \\
\hline UTS-11 & 1.7521 & 36.11 & 20.609 \\
\hline UTS-15 & 0.7807 & 16.98 & 21.749 \\
\hline
\end{tabular}

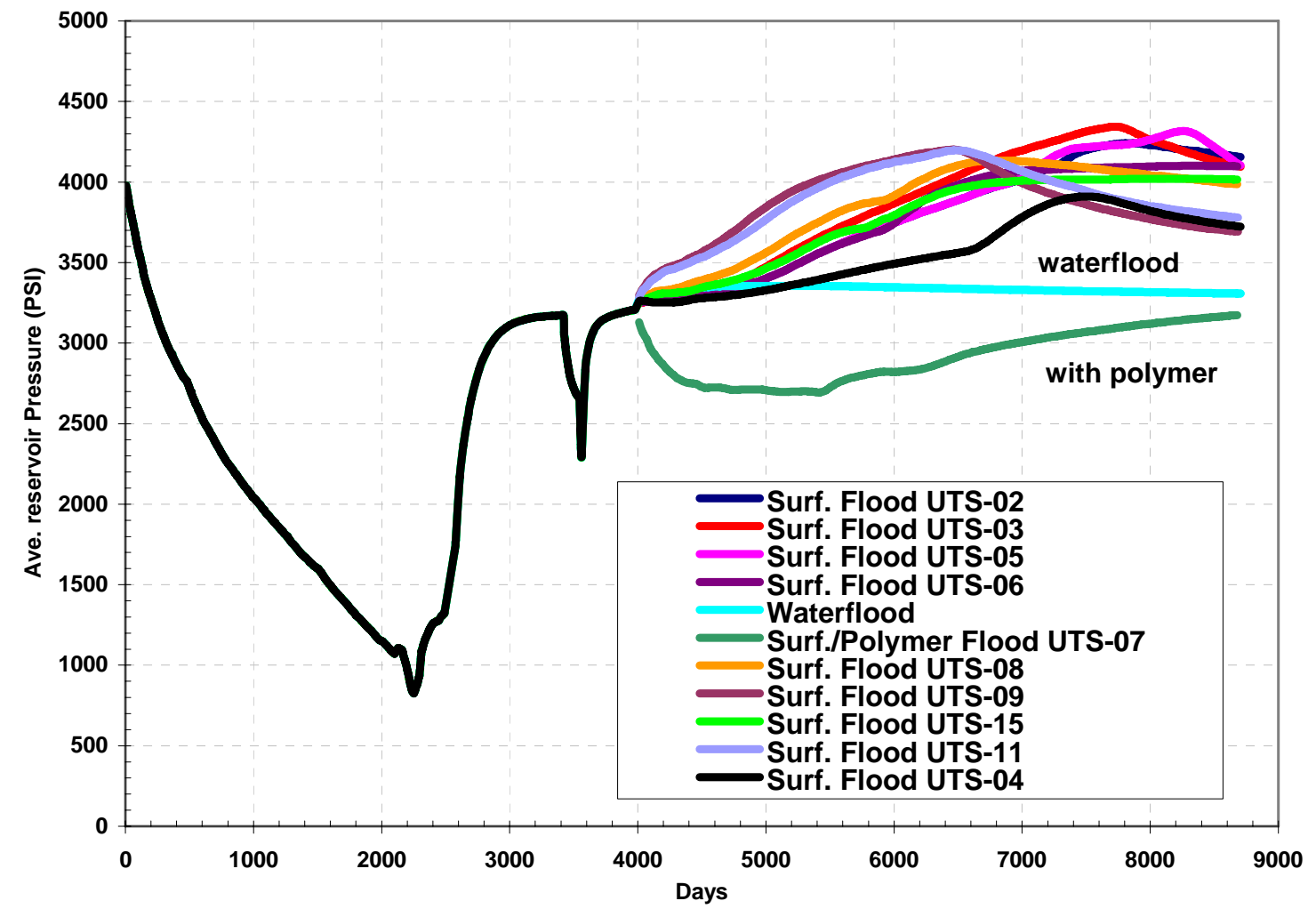

Fig. A-1: Comparison of average reservoir pressure (day zero corresponds to Aug. 1996, surfactant injection starts in Jan. 2007, and the end corresponds to Jun 2020) 


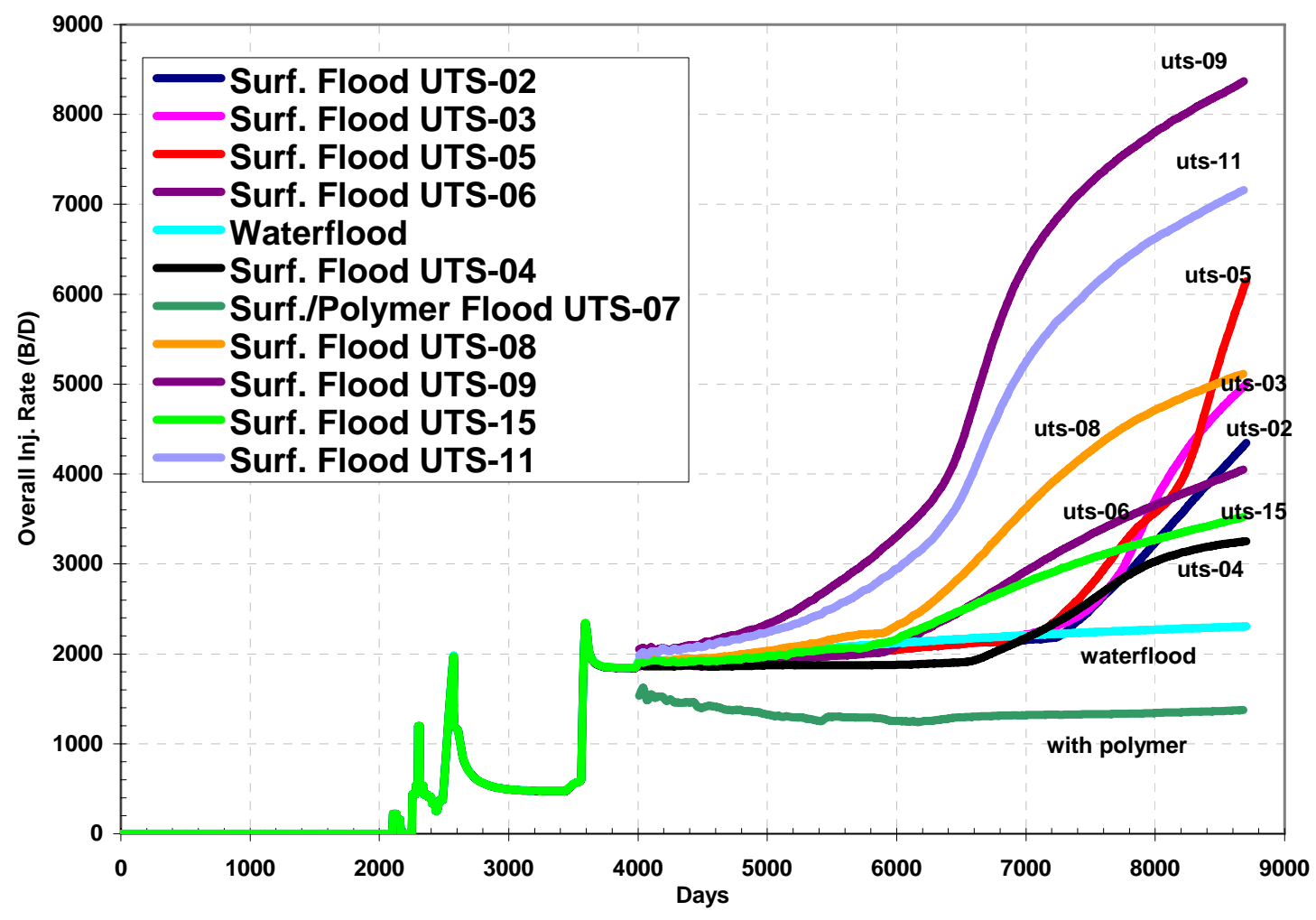

Fig. A-2: Comparison of total injection rate 


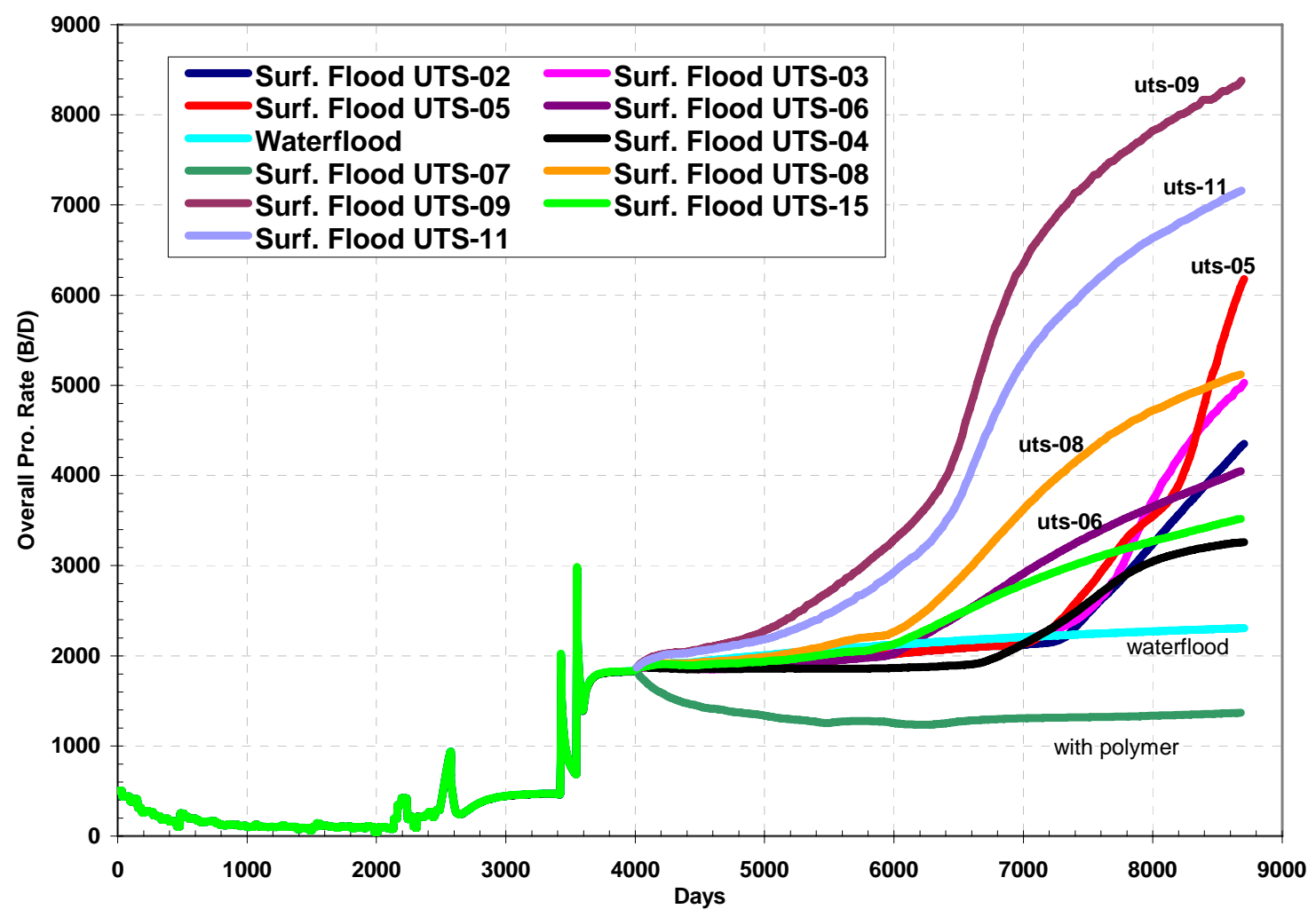

Fig. A-3: Comparison of total production rate 


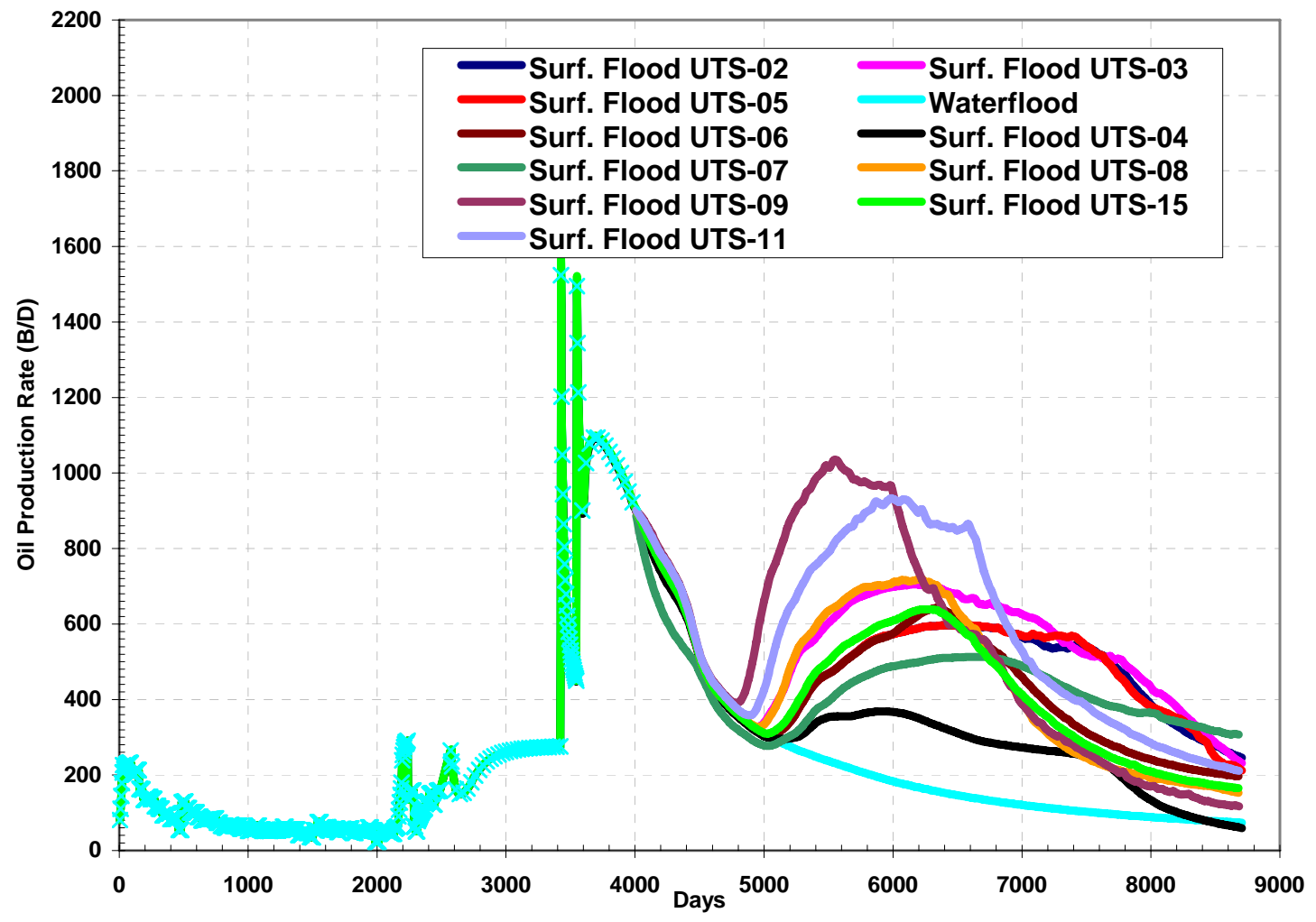

Fig. A-4: Comparison of oil production rate 


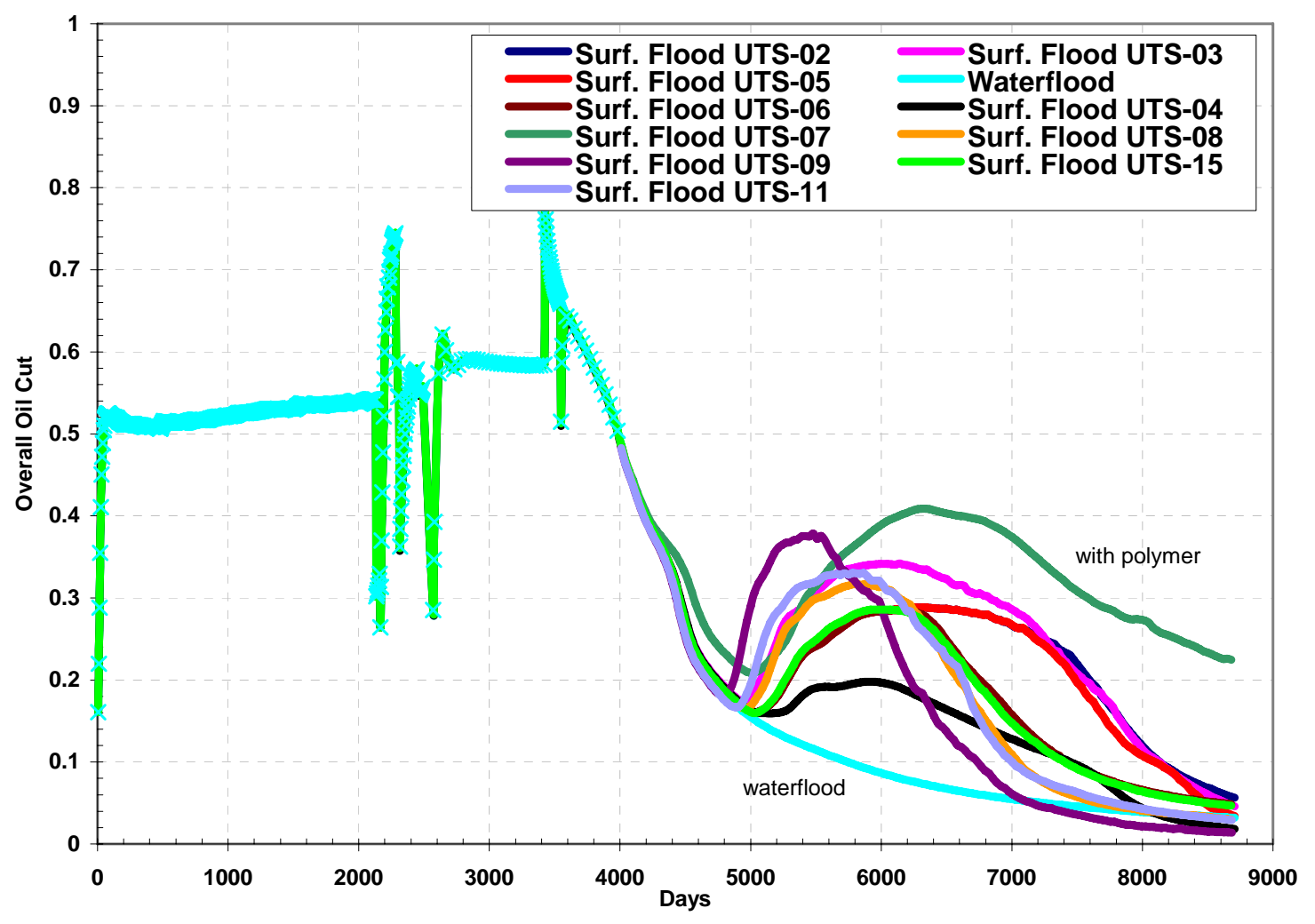

Fig. A-5: Comparison of overall oil cut 


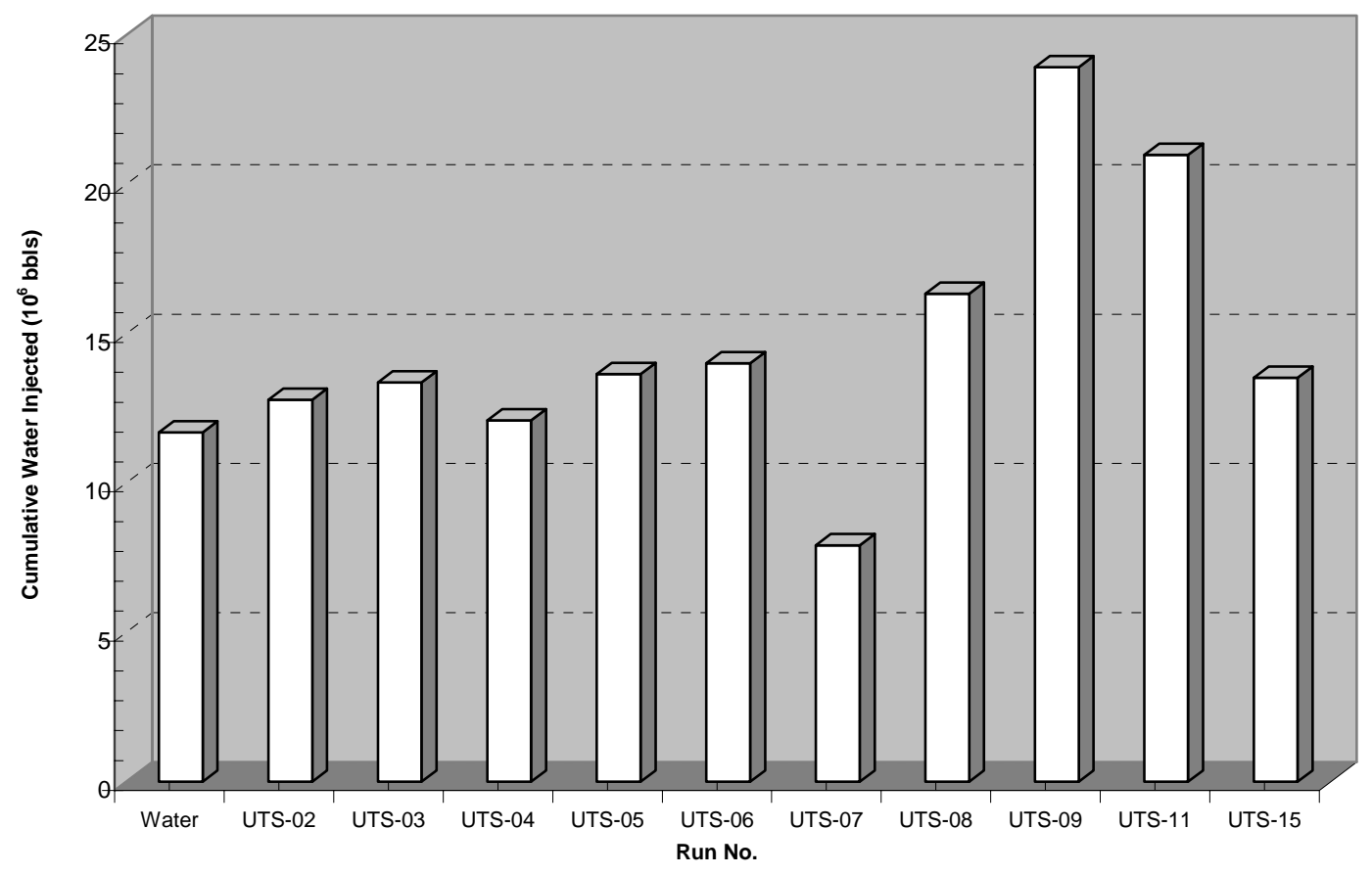

Fig. A-6: Comparison of cumulative water injected 


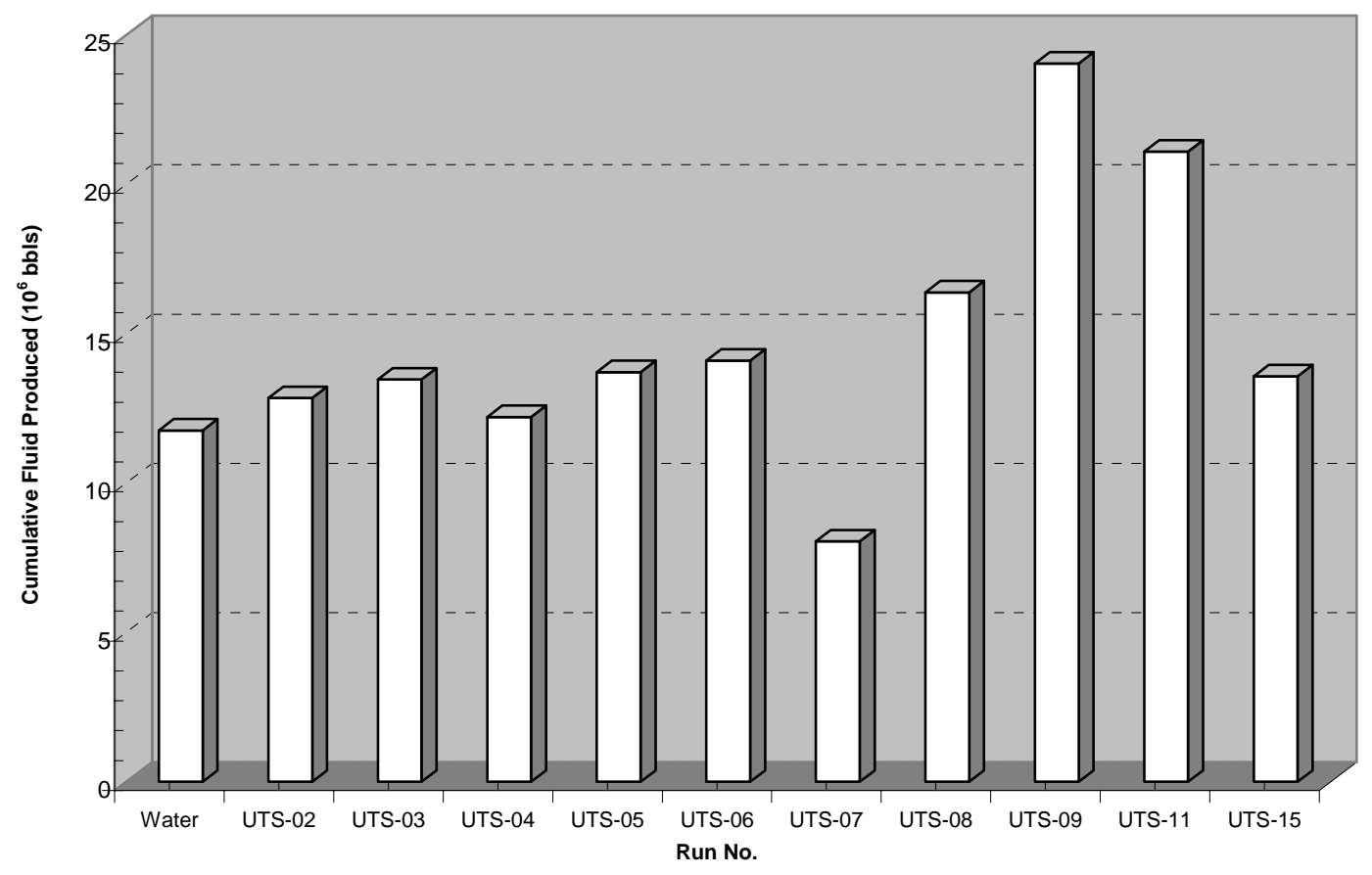

Fig. A-7: Comparison of cumulative fluid production 


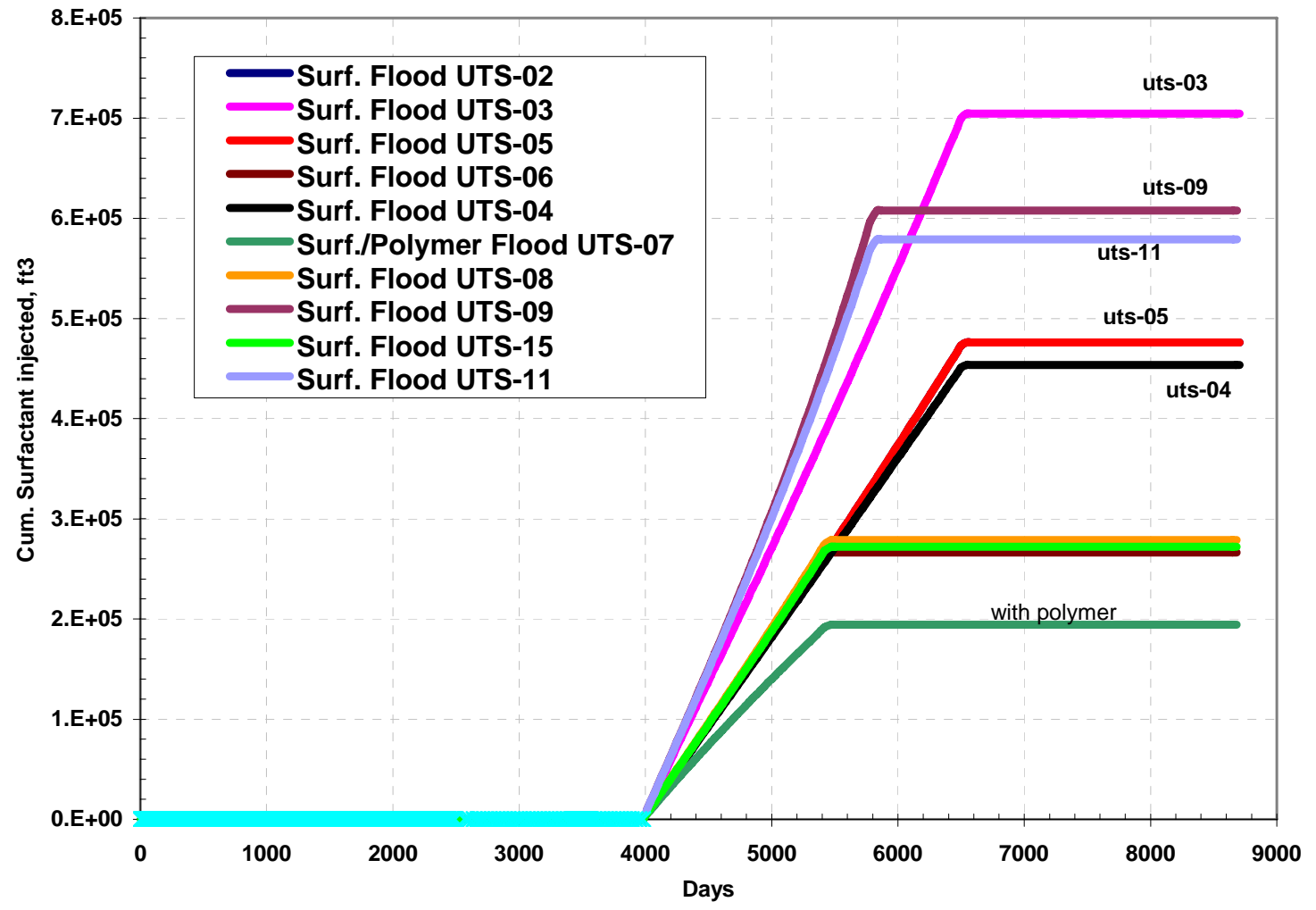

Fig. A-8: Comparison of cumulative surfactant injection 


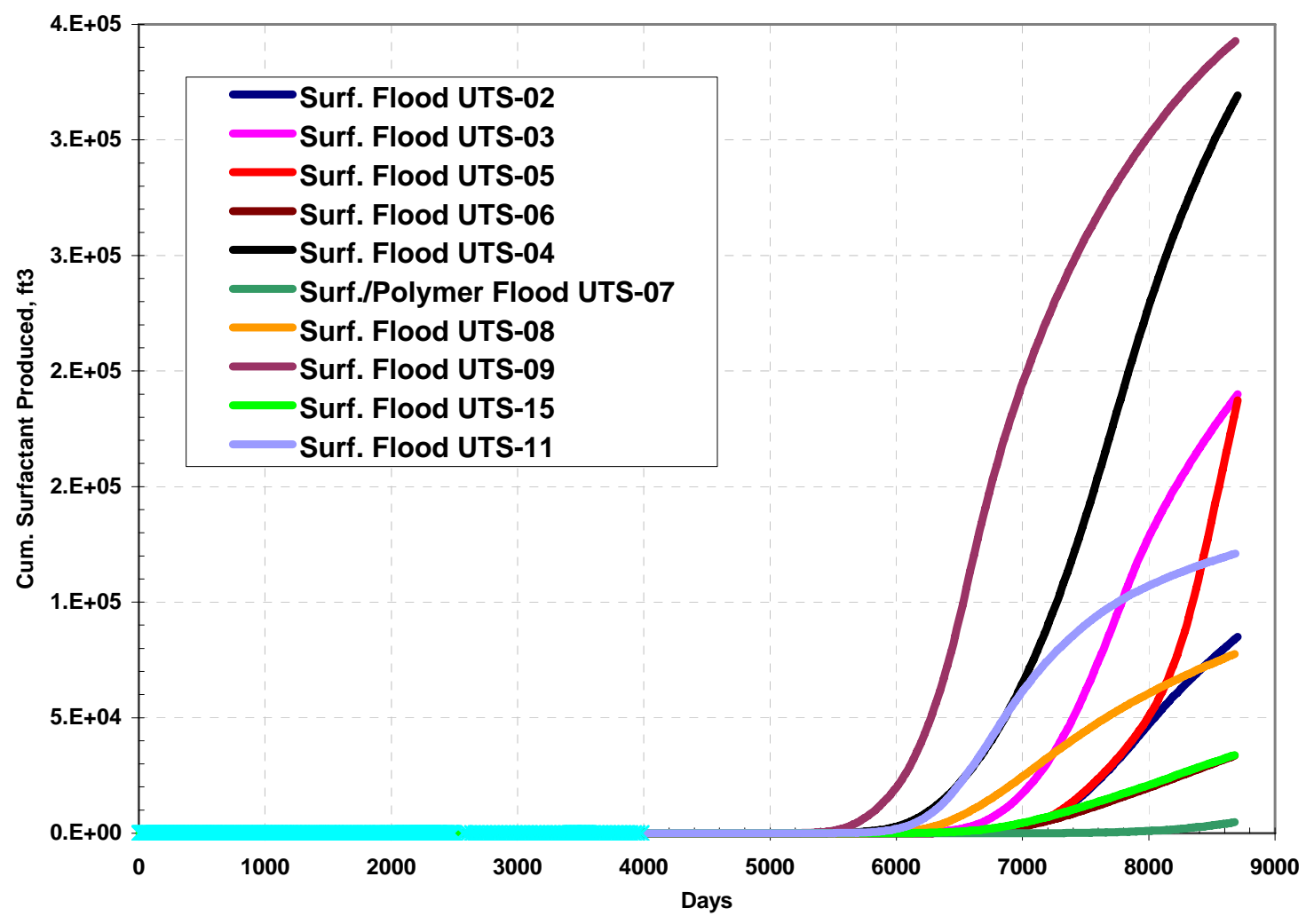

Fig. A-9: Comparison of cumulative surfactant production 


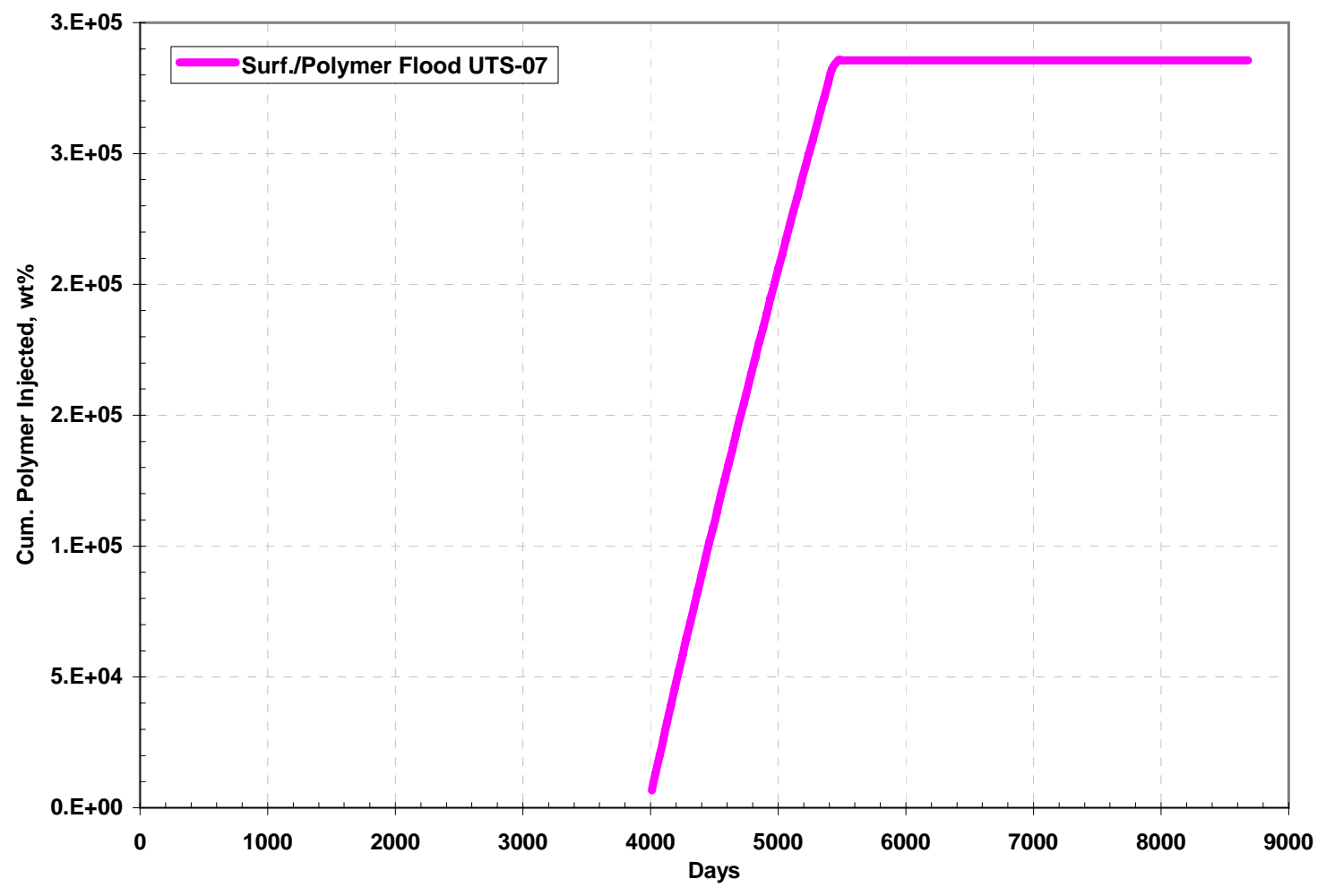

Fig. A-10: Cumulative polymer injection 


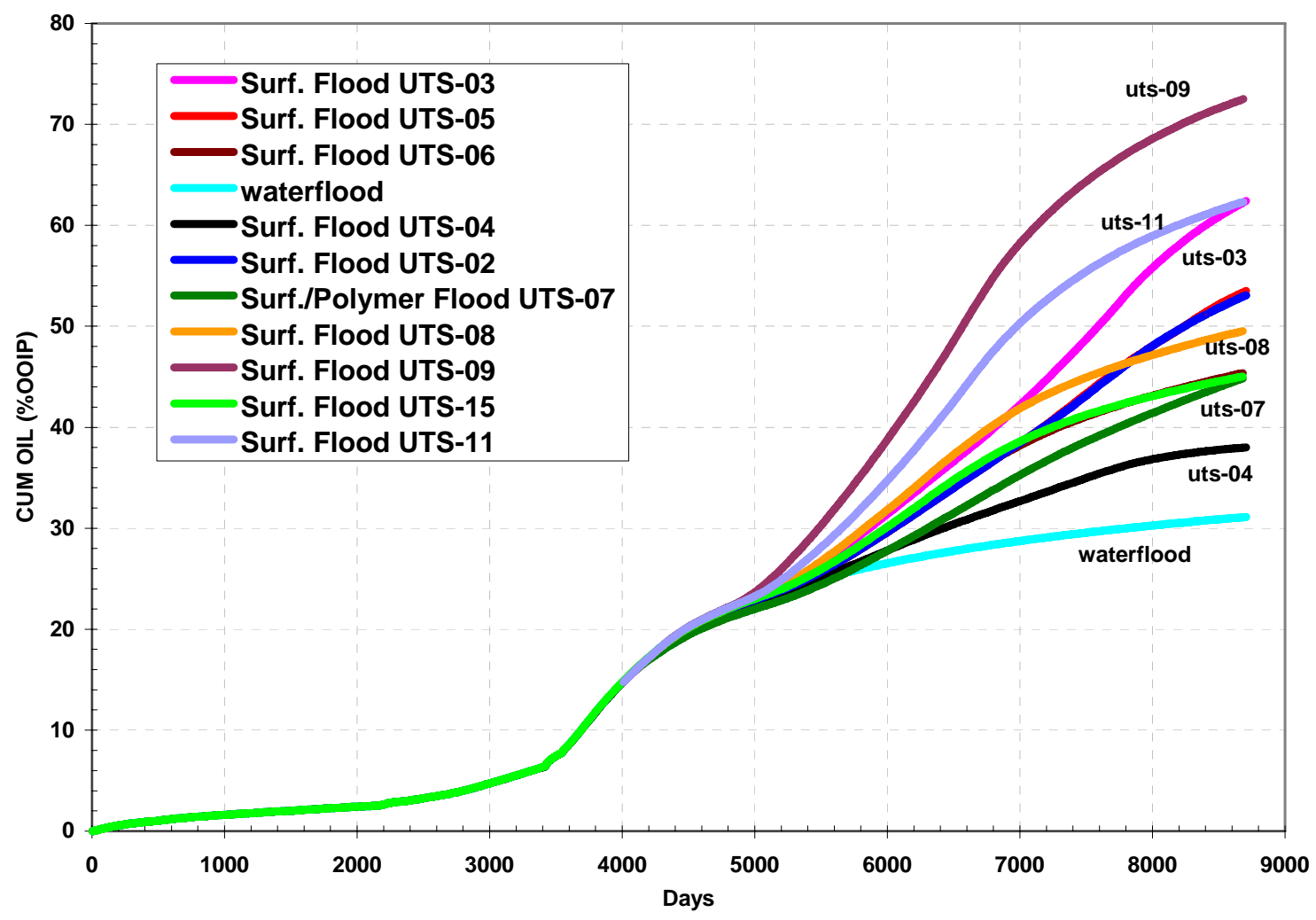

Fig. A-11: Cumulative oil production as a percentage of original oil in place 


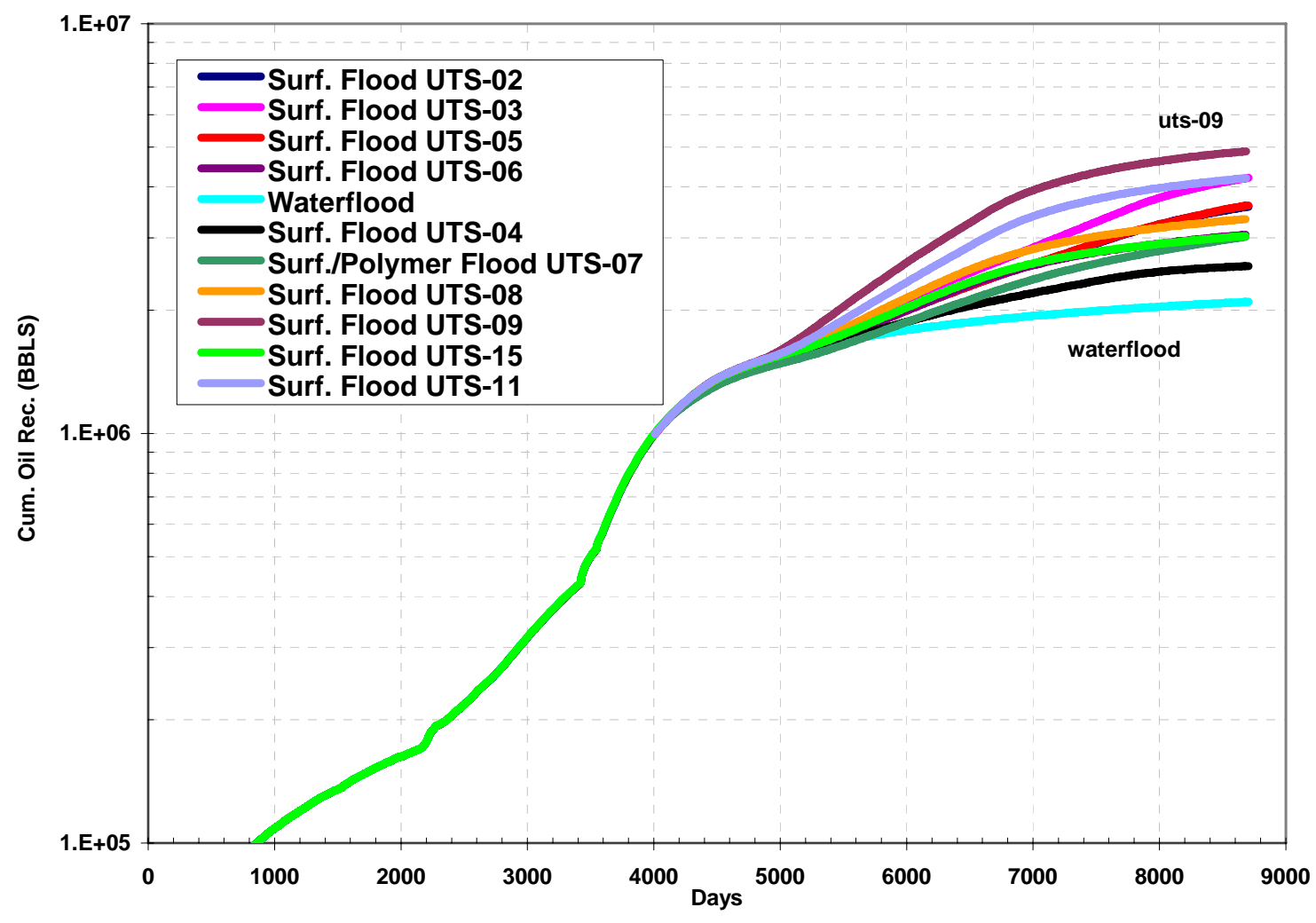

Fig. A-12: Comparison of cumulative oil production in bbls 


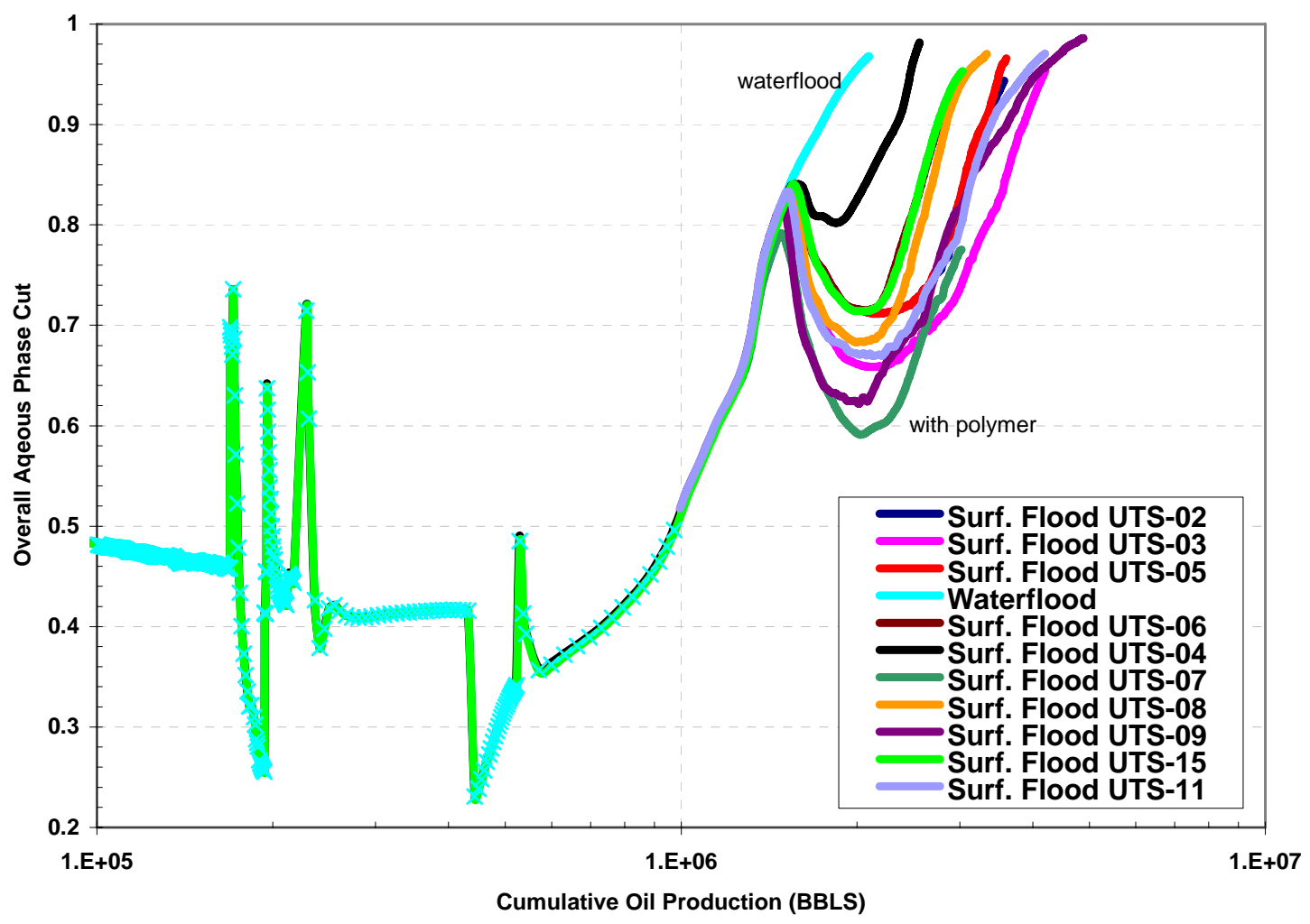

Fig. A-13: Overall aqueous phase cut as a function of cumulative oil production in bbls 


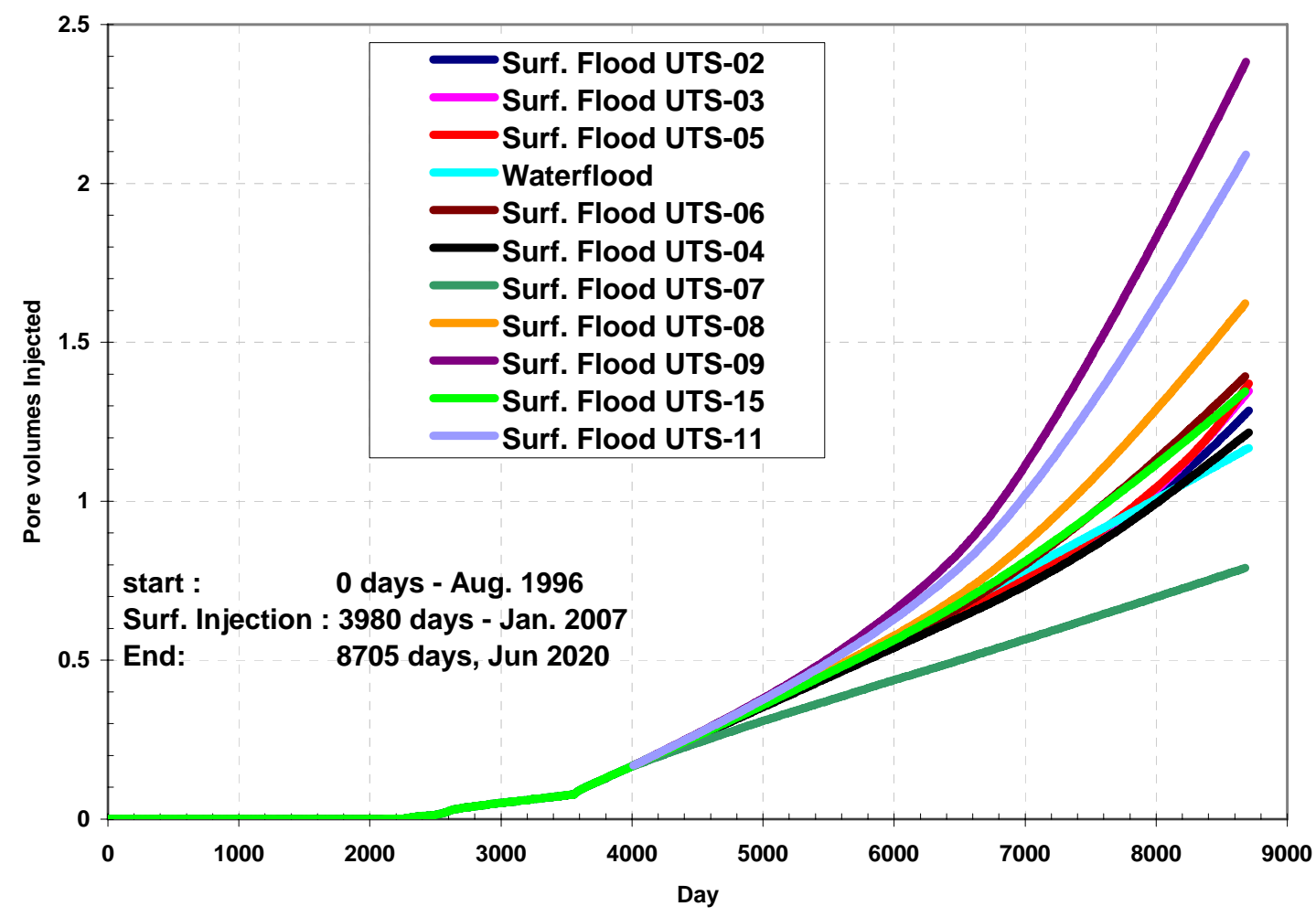

Fig. A-14: Comparison of pore volumes water injected

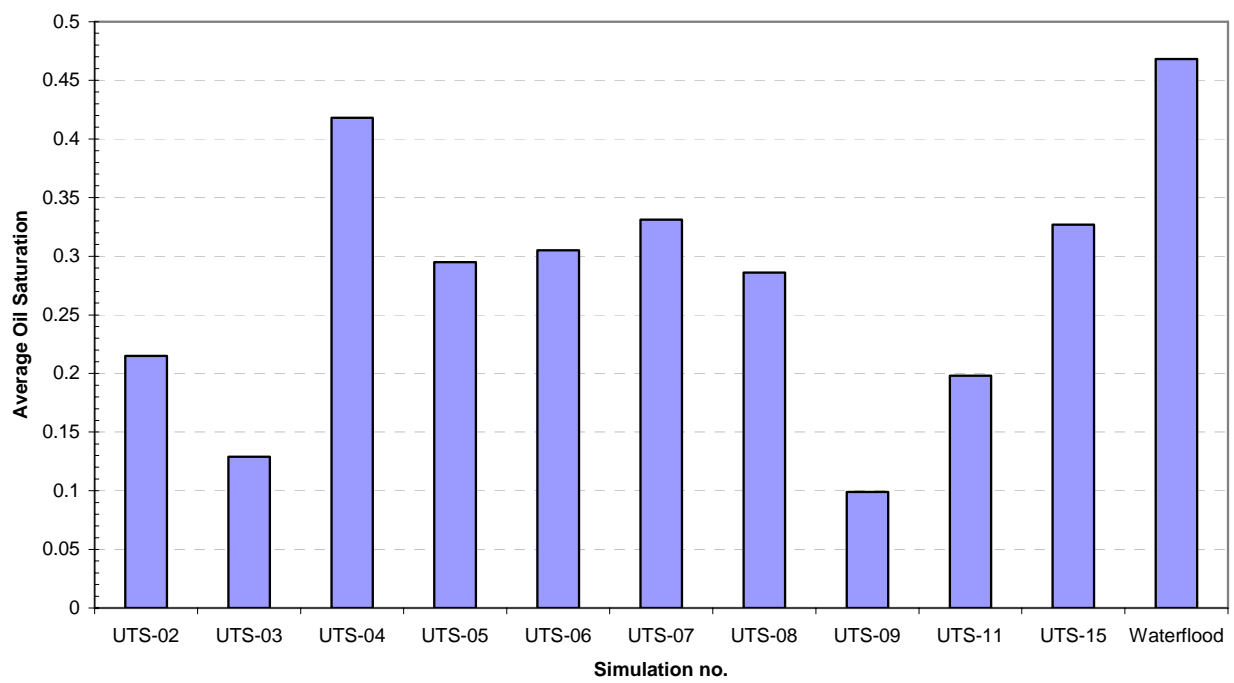

Fig. A-15: Final average oil saturation 


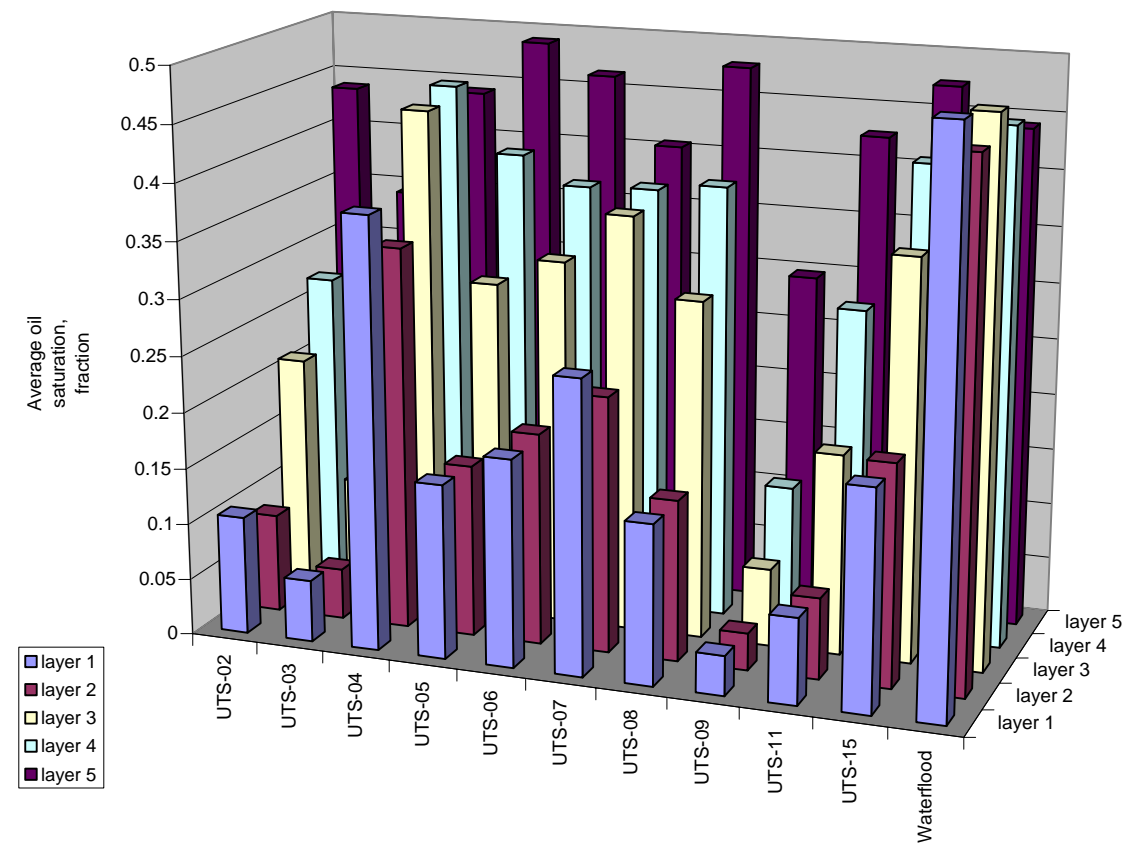

Fig. A-16: Average oil saturation in each layer at the end of simulation 


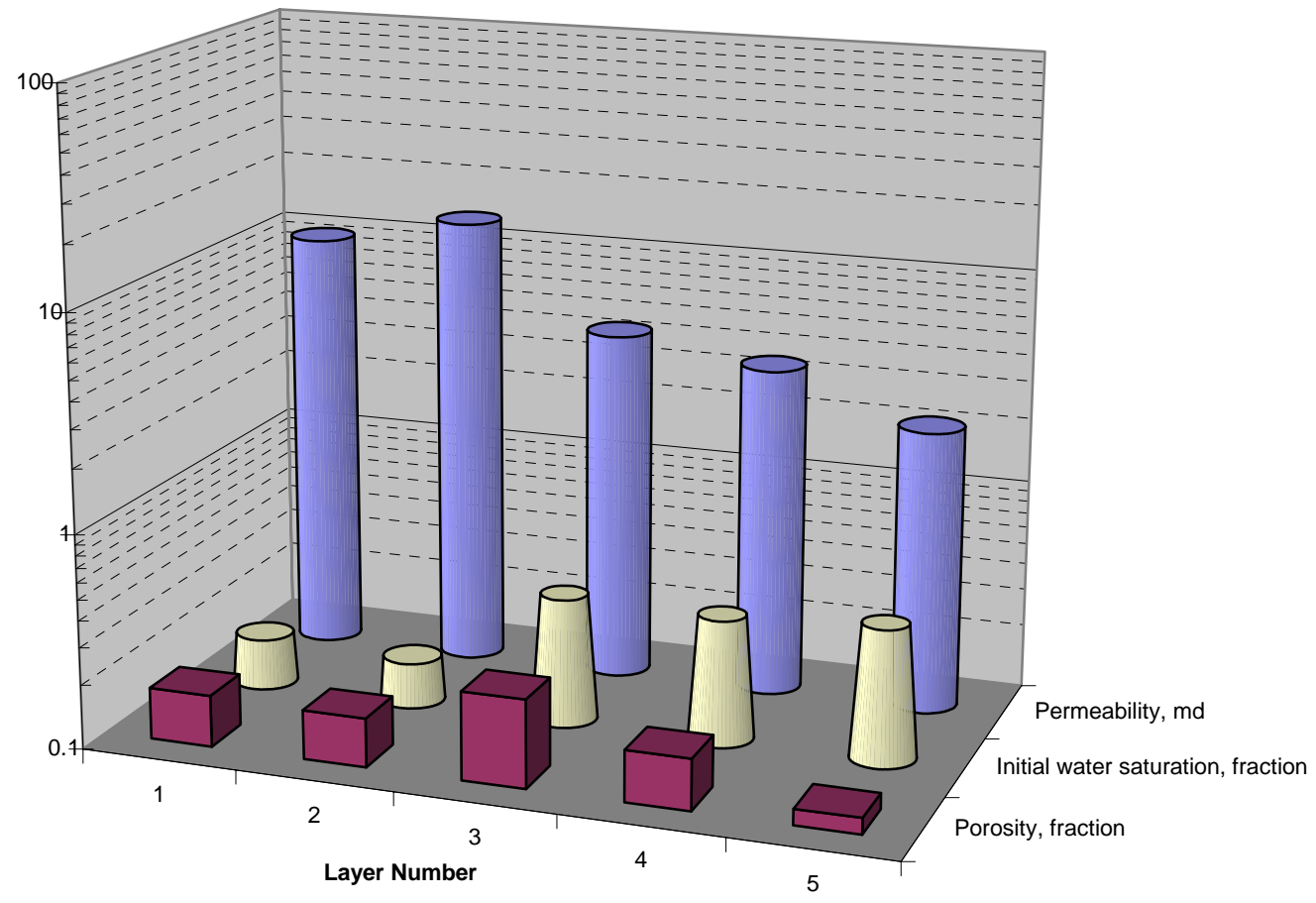

Fig. A-17: Average permeability, initial water saturation, and porosity per layer

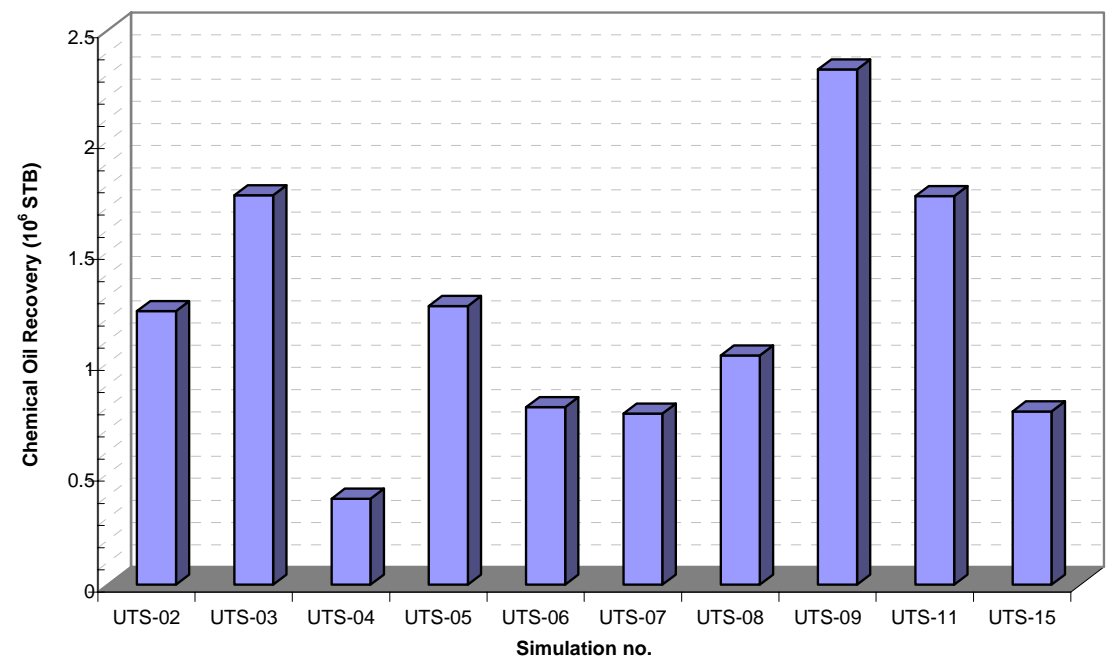

Fig. A-18: Chemical incremental oil recovery 


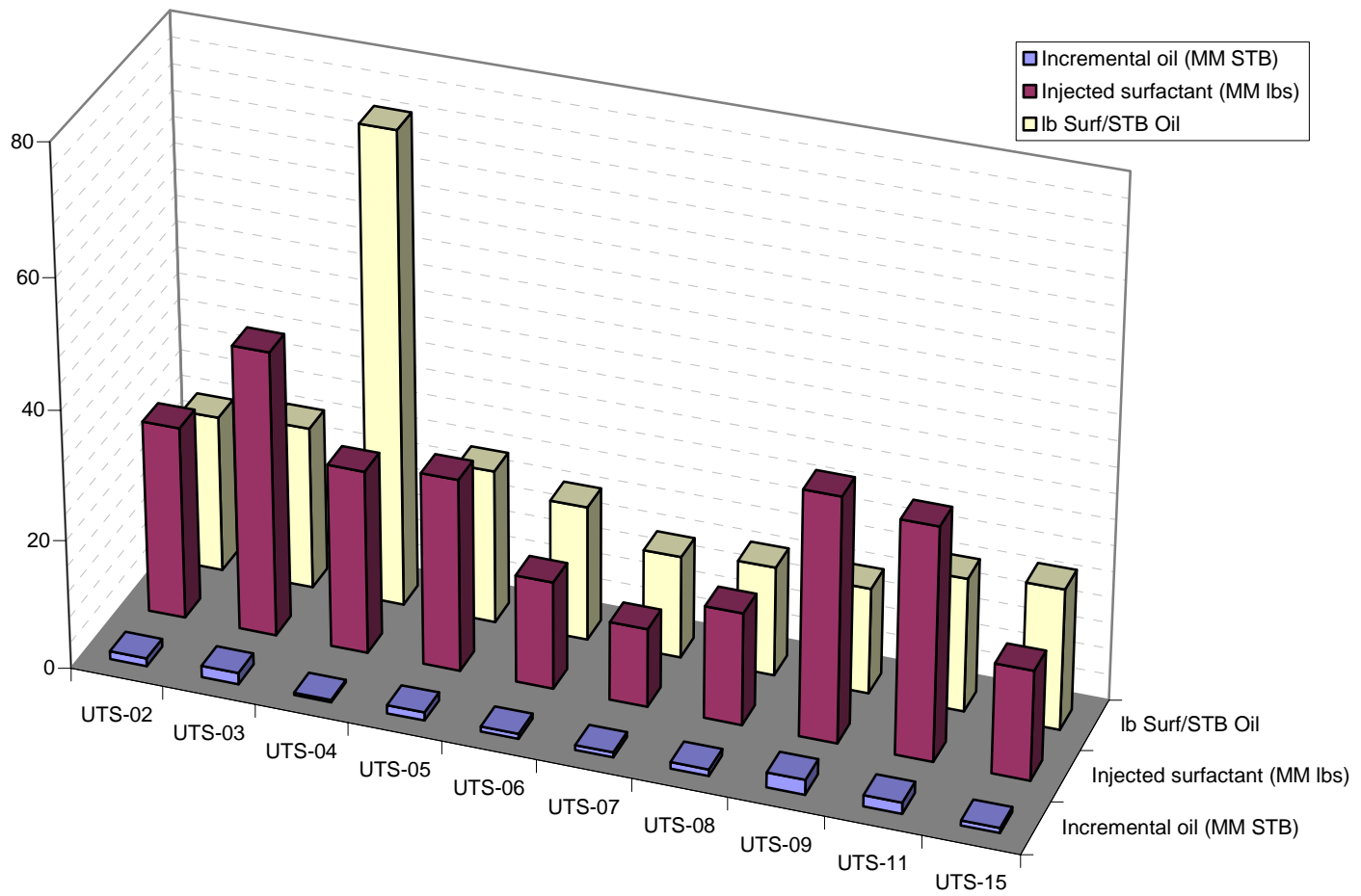

Fig. A-19: Chemical incremental oil recovery 


\section{Field B - West Texas reservoir}

The focus of this study is a West Texas Permian basin reservoir. The reservoir is a mixed-wet dolomite within the Grayburg formation (Anderson, 2006; Anderson et al., 2006). The reservoir is currently undergoing waterflood recovery at a very high water cut of about $98-99 \%$. The reservoir also has a high remaining oil saturation and low reservoir pressure. This makes the reservoir a target for tertiary recovery. The purpose of this study was to determine the feasibility of and the optimum design for a field-scale application in this carbonate reservoir. The study was performed in parallel with a laboratory study, which determined the surfactant and polymer compatibility with reservoir crude oil and cores. The results indicated that an surfactant/polymer (SP) flood is economically feasible and the key design parameters such as mass of chemicals and mobility control are critical.

Based on the positive result of the numerical optimization study and laboratory testing, the field operator for this reservoir made a decision to perform a single well pilot test with the intent of determining the waterflood residual oil saturation and the chemical flood residual oil saturation for assessing the performance of the chemical test. This study was supported by an economic analysis and a sensitivity study. The sensitivity study included a design optimization study and an uncertainty analysis. The economic analysis provided the basis for selecting the optimum design and determining the risk associated with this tertiary recovery technique. 


\section{Simulation Model}

The reservoir used in this study is 4,700 feet deep, $100^{\circ} \mathrm{F}, 100$ feet thick, and has petrophysical properties indicative of a mixed-wet rock. Table B-1 shows some of the petrophysical properties used in this study. The reservoir has uncharacteristically high residual oil saturation for a mixed-wet rock. However, studies like Tie and Morrow (2005) show that this range of residual oil saturation is common in a carbonate rock. The reservoir fluid properties were also obtained from the field operator. Table 4-2 shows the fluid properties used in this study.

A simulation model was developed according to these properties. The model was developed as a quarter 5-spot symmetry element with a pressure-constrained injector and producer. The symmetry element was based on a 40-acre well spacing, which is relatively large for chemical flooding. The field operator also provided the producer and injector well constraints (300 psi and 2,500 psi bottomhole, respectively), which were based on facility and reservoir fracture gradient limitations. The permeability field used in this model was developed by the field operator and is shown in Fig. B-1. As depicted in the figure, the reservoir is heterogeneous with high permeability layers in the middle and the top.

This reservoir has had a long history of primary recovery and secondary recovery. Therefore, a waterflood was simulated to obtain conditions similar to the current state of the reservoir. The simulation was run until a water cut of $98 \%$ was attained, resulting in 1.8 pore volumes injected. This simulation generated the initial oil saturation and 
pressure distribution for the chemical flooding simulations. The average post-waterflood saturations and pressure are listed in Table B-1. Figure B-2 shows the oil saturation distribution and the effect of the high permeability layers, which had the lowest postwaterflood oil saturation.

\section{Laboratory Data}

The surfactant and polymer parameters used in this study were based on laboratory data collected at The University of Texas at Austin laboratory (Levitt et al., 2006). Laboratory experiments were not part of this project and we just incorporated the results in our simulation study. We give an overview of the laboratory results. Several surfactants and two polymers were screened for compatibility with this reservoir's crude oil, formation brine, temperature, and rock type.

Levitt et al., 2006, developed a screening process for the surfactant phase behavior to determine the compatibility with the crude oil and the optimum surfactant/cosurfactant/solvent blend. These experiments were used to determine the optimum salinity and corresponding IFT. Following the laboratory's screening test, the optimum surfactant formulation and phase behavior was used in this simulation study. The UTCHEM surfactant phase behavior parameters were obtained by curve fitting the laboratory solubilization ratio for several salinities. The resulting curve fit is shown in Fig. B-3. The optimum salinity for this surfactant/crude oil/brine solution was relatively high. The surfactant blend was designed in this fashion since the reservoir salinity of $\sim 33,000 \mathrm{ppm}$ is high. In addition, the IFT at optimum salinity is quite low. Using the Chun Huh (1979) 
equation and the solubilization ratio at optimum salinity (18), an approximate value of $0.001 \mathrm{dynes} / \mathrm{cm}$ was expected.

The polymer type and physical property data were also obtained from the parallel laboratory study (Levitt et al., 2006). A hydrolyzed polyacrylamide was used in this study and the polymer viscosity data was provided for use in the UTCHEM model. Experiments were conducted to estimate the polymer viscosity dependence on shear rate. These data were curve fit using the UTCHEM model, zero shear rate viscosity, and infinite shear rate viscosity. Figure B-4 shows the results of the curve fit of the viscosity and shear rate data.

The next experiment was conducted to estimate the polymer viscosity dependence on salinity. These data were also matched using the zero shear rate viscosities at multiple salinities. Once the curve fit was completed, one parameter was obtained for the model. Fig. B-5 shows the polymer viscosity as a function of salinity.

The last experiment was conducted to estimate the polymer viscosity dependence on polymer concentration. These data were matched using the zero shear rate viscosities at multiple concentrations. This process could determine up to three parameters used in the UTCHEM model. Figure B-6 shows the polymer viscosity as a function of polymer concentration at a salinity of 8,000 ppm and zero shear rate.

In addition, Berea and reservoir core floods were conducted to measure the performance of the surfactant and polymer. In particular, the surfactant retention was 
measured in several core floods and ranged from 0.1 to $0.4 \mathrm{mg} / \mathrm{g}$ with an average value of $0.2 \mathrm{mg} / \mathrm{g}$.

\section{Base Case SP Design}

The base case simulation used the previously discussed well constraints and initial conditions. The well constraints are important for chemical flooding because they can affect the life of the project. The chemical flood design was partly based on the laboratory coreflood design. The laboratory design was used as the starting point but was scaled up for a field application. Table B-3 shows a summary of base case design including slug sizes, chemical concentrations, and salinity. This design consisted of a 0.25 PV surfactant-polymer slug and a 1 PV polymer drive. A water postflush was added to minimize the amount of polymer used, which is commonly performed in field projects but not in the laboratory corefloods. The salinity gradient was also derived from laboratory experiments and is a key parameter for the success of a chemical flood. The salinity gradient was important for this study because of the large changes in salinity during the chemical flood. It can be seen from Tables B-2 and B-3 that the salinity gradient design had the high initial reservoir salinity of $1 \mathrm{meq} / \mathrm{mL}$ in the reservoir brine and is reduced to $0.04 \mathrm{meq} / \mathrm{mL}$ in the water postflush following the polymer drive.

There were also several assumed values that went into the model. A value of surfactant adsorption was conservatively chosen within the range of values reported by the laboratory. The value used $(0.3 \mathrm{mg} / \mathrm{g})$ was slightly higher than the average lab value of $0.2 \mathrm{mg} / \mathrm{g}$. The value for polymer adsorption was unknown and was assumed to be 10 
$\mu \mathrm{g} / \mathrm{g}$. The capillary desaturation curve was also assumed using parameters as presented in Delshad, 1990. The last assumptions dealt with permeability. A ratio of vertical to horizontal permeability of 0.05 was used based on a recommendation from the field operator, but the actual value is unknown. The value for the average permeability was based on the best part of the field. There are other regions in the field that have significantly lower permeability. These assumptions will have a strong impact on the project life and polymer permeability reduction among other significant factors.

Figure B-7 shows the base case injection rate and pressure throughout the chemical flood. The injection rate was reduced by a factor of 2 by the end of the polymer flood and then rebounded during the water postflush. Note that all fluid rates, masses, and volumes were reported for a full five-spot pattern even though the simulation model was a quarter of a five-spot symmetry element. Figure B-8 shows the production rates and produced surfactant concentration during the chemical flood. For this simulation, a dramatic increase in oil production rate could be seen. The pre-chemical flood rate was $35 \mathrm{bbls}$ of oil per day and increased to a peak value of $720 \mathrm{bbls} / \mathrm{day}$. This corresponds to an increase in oil cut from $2 \%$ to $35 \%$. Another important result shown is the breakthrough time of oil and surfactant (0.25 PV and 0.35 PV, respectively). The surfactant concentrations were low ( $<0.001$ volume fraction) compared to the injected values ( 0.01 volume fraction). The cumulative oil recovery was $27.8 \%$ of the original oil in place and $42 \%$ of the remaining oil in place. 
Figures B-9 through B-11 show the base case oil saturation distribution at different times of the chemical flood. The figures show one three-dimensional profile of a slice through the wells and one $2 \mathrm{D}$ areal cross section of the high permeability middle layer. It is shown that the oil saturation was reduced to very low values in the high permeability layer at early times. One key result was the very low oil saturations near the injection well and in the high permeability layers. At the final time, a significant amount of oil was left in the low permeability layers (56\% oil saturation).

Figures B-12 through B-14 show the base case surfactant concentration distribution at different times. The profiles show that the surfactant moved very quickly through the high permeability layers resulting in early breakthrough. Due to adsorption and production, almost no surfactant was left at the final time.

Figures B-15 through B-17 show the base case polymer concentration distribution at different times. Similar to surfactant, polymer was primarily traveling through the high permeability layers. Conversely, the polymer was able to invade the low permeability layers due to a longer period of injection and lower adsorption. At the final time, a significant amount of polymer was left in the low permeability layers as a result of severe channeling during the water postflush and is shown in Figure B-17.

Figures B-18 through B-20 show the base case IFT distribution at different times. These figures depicted the same results as the surfactant concentration profiles. The IFT was reduced to very low values near the well and in the high permeability layers. 
This unoptimized base case simulation resulted in very promising oil recovery (27.8\% OOIP).

To provide support to this study, an economic analysis was performed. The economic analysis was completed using the discounted cash flow (DCF) method to determine the net present value (NPV), internal rate of return (IRR), and growth rate of return (GROR) for each project. The NPV and rates of return were calculated based on the discounted cash flows.

The optimum design could then be selected from a number of simulations by selecting the one with the highest NPV. If two cases had a similar NPV, it was possible to use the rates of return to determine optimum design.

Another key parameter is the oil bank breakthrough time, which determines the moment when the positive income starts. The peak oil production rate also determines how much money is made immediately after the oil bank breakthrough. Lastly, the magnitude of the tail of oil production rate has a minor impact on the economics late in the project's life.

In order to perform this economic analysis in this study, several assumptions had to be made. Table B-4 lists these assumptions. The capital cost was an assumed value including the installation of facilities to handle the chemical injection. The operating costs were based on expected injection and production costs. The surfactant cost may vary depending on the components of the blend. The surfactant used for this study is a non-commercial blend of surfactant, co-surfactant, and solvent. Therefore, the prices of 
each chemical can vary and a range of values was assumed. The polymer price was known because it is a readily available commercial product. Next, typical tax rates for a major oil company were assumed to be valid for this project. Lastly, the discount rate was assumed and was a typical value for this industry.

Table B-5 shows a summary of the simulation results and Table B-6 shows a summary of the economic analysis results. The economic limit for the base case simulation is 14 years. This relatively high value is due to the reservoir well spacing and wettability. The NPV for a full five-spot pattern was $\$ 2.28$ million assuming $\$ 30$ per barrel of oil and \$2.75 per pound of surfactant. For higher oil price and lower surfactant cost, the NPV increased to $\$ 11.2$ million. The simulation also had an IRR of $15.2 \%$ and a GROR of $11.3 \%$. This value was lower than expected due to the relatively high economic limit. It can be concluded that this unoptimized base case design looks promising based on these results.

\section{Sensitivity Analysis}

A sensitivity analysis was important because a chemical project has significant risks based on financial, process, and reservoir uncertainties. Chemical flood simulations are dependent on a large number of variables used for reservoir description, fluid and rock properties and process design. Following the assessment of the base case simulation, a method of testing the sensitivity of each key process variable was generated with the intent of obtaining the optimum SP design and observing the effects of uncertain design parameters. 
Table B-5 summarizes all of the sensitivity designs and their results. The key parameters are surfactant and polymer mass, which strongly control the oil recovery, mobility control, and economics. Therefore, more emphasis was placed on these parameters.

Listed in Table B-5 are the oil recovery, chemical efficiency, and simulation life. Chemical efficiency was calculated by dividing the mass of chemical injected (pounds) by the volume of oil recovered during the chemical flood (barrels). The result was a qualitative method for quickly assessing the project economics. However, this method does not consider oil breakthrough time and other important time derived criteria that impact the DCF method. The economic results for each simulation are shown in Table B-6. This table also lists values for chemical efficiency for each simulation. However, these values are different than the values presented in Table B-5 because they are reported at the economic limit, whereas the values in Table B-5 are reported at the simulation life.

Compared to past chemical flooding studies for water-wet rocks, the results were relatively different. First, a longer project life was simulated. This was primarily due to differences in relative permeability and residual oil saturation for this mixed-wet reservoir compared to a water-wet reservoir. For the base case simulation, the oil and surfactant breakthrough times were $0.25 \mathrm{PV}$ and $0.35 \mathrm{PV}$, respectively. If the reservoir was water-wet, the oil bank breakthrough time would be faster and the surfactant breakthrough time would be slower than in this mixed-wet case. This phenomenon is due 
to fractional flow effects based on differences in relative permeability for the different wettability conditions. The mobility ratio for the simulated SP flood in this mixed-wet reservoir was approximately 1.3. This mobility ratio for the same chemicals would have been about 0.6 for a water-wet reservoir, a much more favorable value. Therefore, the fact that these simulations have uncharacteristically long project lives affected the economics of each sensitivity case, which are shown in Table B-6.

The parameters used to obtain the optimum design were surfactant concentration, surfactant slug size, mass of polymer, and salinity. The value used for surfactant concentration affects the surfactant mass affecting both the oil recovery and economics of the project. Changes in surfactant concentration also affect the retardation factor of the surfactant slug. The retardation factor or frontal advance loss is defined as the loss of frontal velocity due to adsorption and has the units of pore volumes (Lake, 1989). The equation is as follows:

$$
D_{3}=\frac{(1-\phi) \rho_{S} \hat{C}_{3}}{\phi C_{3 J}}
$$

where $D_{3}$ is the retardation factor for surfactant, $\phi$ is porosity, $\rho_{\mathrm{s}}$ is the rock density, $C_{3}$ is the adsorbed surfactant concentration, $C_{3 J}$ is the injected surfactant concentration. A lower injected chemical concentration will have a higher retardation factor.

The surfactant slug size also affects the surfactant mass affecting both the oil recovery and economics. Changes in surfactant slug size will also result in slight changes 
in the salinity gradient. A longer surfactant slug will have a less steep salinity gradient compared to a shorter surfactant slug. This can also affect the flooding performance during the polymer drive.

The polymer concentration is important because it affects the mass of polymer injected. This in turn affects the quality of mobility control that is very important in this heterogeneous reservoir. The polymer drive design, particularly the drive length, can also affect the mass of polymer injected. The length will also affect the salinity gradient to a lesser extent. In some cases, strategies like tapering the polymer concentration during the polymer drive can help the economics.

Salinity gradient is the last parameter used for SP design optimization. The key effects of salinity gradient are the changes in surfactant phase behavior during the flood. Pope et al., 1979 presented results that show maximizing the region of ultra-low interfacial tension is optimum for SP flooding. Their conclusion was to design the salinity gradient so that the front of the surfactant slug has greater than optimum salinity, the middle of the slug is at optimum salinity, and the tail of the slug has lower than optimum salinity.

Surfactant concentration: A range of surfactant concentrations from 0.5 to $1.5 \mathrm{vol} \%$ were tested for comparison with the base case $(1 \mathrm{vol} \%)$. As expected, the surfactant concentration was directly related to the oil recovery. The base case simulation with 1 vol\% surfactant concentration had an oil recovery of $27.8 \%$ OOIP whereas the lower concentration ( 0.5 vol\%) and higher concentration (1.5 vol\%) simulations had recoveries 
of $17.5 \%$ and $35.2 \%$, respectively. The simulations had a range in retardation factors from $0.3 \mathrm{PV}$ (1.5 vol\% surfactant) to $0.9 \mathrm{PV}$ (0.5 vol\% surfactant). Since the base case simulation was designed to inject a 0.25 PV surfactant slug, it would be expected that these simulations would have very adverse results. However, recall that the surfactant primarily sweeps the high permeability layers. This means the calculated retardation factors, which were based on the entire reservoir pore volume, gave overestimates according to the actual swept pore volume. Figure B-21 shows the comparison of oil recovery for the surfactant concentration simulations.

The simultaneous change in surfactant mass and oil recovery resulted in differences in chemical efficiency for these simulations. The simulation with higher concentration gave a worse chemical efficiency $(\$ 16.5 / \mathrm{bbl})$ compared to the base case (\$14.5/bbl). Conversely, the simulation with lower concentration resulted in an improved efficiency (\$13.5/bbl). These values were calculated using a surfactant price of $\$ 2.75$ per pound and a polymer price of $\$ 1.00$ per pound. Therefore at these assumed prices, the simulation with the lower injected surfactant concentration was the optimum for this key parameter regardless of the adverse retardation factor.

The economic results for the surfactant concentration simulations are shown in Table B-6. It is shown that the low concentration simulation had the same NPV at low oil price but a higher IRR and GROR. For higher oil price however, the higher surfactant concentration simulation had a slightly higher NPV but lower IRR and GROR. The trend of NPV with surfactant concentration at different assumed oil prices and surfactant costs 
is shown in Fig. B-22. Using this plot, the optimum value for this parameter could be obtained by reading the maximum NPV from the curve. However, in Fig. B-22 the maximum value changes with different assumed oil and surfactant prices. At low oil price and high surfactant price, the optimum value of surfactant concentration was between 0.5 and 1 vol\%. At higher oil price and high surfactant price, the optimum value was around $1.5 \mathrm{vol} \%$. The chemical efficiency values for these simulations indicated that the lower concentration was the optimum value, which was the opposite result given by the DCF result at higher oil price.

Surfactant slug size: Surfactant slug size was another key parameter studied in this sensitivity analysis. The range of slug sizes tested was from $0.15 \mathrm{PV}$ to $0.5 \mathrm{PV}$. The results of these simulations are shown in Table B-5 and a comparison of the cumulative oil recoveries for each are depicted in Figure B-23. Compared to the base case, the simulation with the highest oil recovery was the $0.5 \mathrm{PV}$ slug size case, as expected. This simulation was the only one that injected surfactant long enough to overcome the retardation factor, but as discussed previously this may not be important due to severe channeling. Even though the $0.5 \mathrm{PV}$ simulation had the highest oil recovery, it had the worst chemical efficiency $(\$ 20.1 / \mathrm{bbl})$. The simulation with the best chemical efficiency was the $0.15 \mathrm{PV}$ case, which actually had the lowest recovery.

The economic results for the surfactant slug size simulations are provided in Table B-6. Assuming an oil price of $\$ 30$ per barrel and a surfactant price of $\$ 2.75$ per pound, the simulation with the highest NPV was the 0.15 PV case at \$2.6 million. 
Increases in slug size reduced the NPV at these assumed prices. The trend of NPV's as a function of slug size for different oil and surfactant prices is shown in Figure B-24. The trend was similar to the surfactant concentration simulations in the previous section. At low oil price and high surfactant cost, the optimum value of slug size was a small value. Conversely, the optimum slug size was around 0.35 PV for higher oil price or lower surfactant cost.

Polymer mass: The next key parameter in this sensitivity study was polymer mass, which was important for mobility control during the chemical flood. Compared to the base case, simulations were run with the injected polymer concentration being increased, decreased, and tapered. The results of these simulations are shown in Table B-5 and a comparison of the cumulative oil recoveries for some of the simulations are depicted in Fig. B-25. One result was that the oil recovery was directly related to the injected polymer mass. In addition, the simulation results were less sensitive to changes in polymer mass compared to surfactant mass. The simulation with the highest polymer mass (2,500 ppm polymer for 1.25 PV) had the highest cumulative oil recovery. The simulation with the worst chemical efficiency was the case with 1.25 PV of 500 ppm polymer. This result was different than the surfactant mass simulations where the highest mass had the worst efficiency.

The economic results for the polymer mass simulations are provided in Table B-6. For these simulations, all oil price and surfactant cost scenarios gave the same relative results. Increases in the polymer mass increased the NPV until 2,000 ppm polymer was 
exceeded. At that value, the cost of polymer and the reduction in the injectivity began affecting the economic results regardless of increased oil recovery. Fig. B-26 shows the trend of NPV for all the polymer mass simulations. The constant trend amongst the varying oil and surfactant prices reinforced the importance of mobility control in this heterogeneous reservoir. The optimum polymer mass simulation was the case with 1.25 PV of 2,000 ppm polymer, which resulted in 5.6 million pounds injected for a full fivespot pattern and an NPV of \$3.45 million. 
Salinity gradient: The last design optimization parameter was the salinity gradient. Sensitivity to the salinity gradient was analyzed by running two simulations. One of which was designed with a slightly lower slug salinity and the other with slightly lower polymer drive salinity. These simulations will affect the surfactant phase behavior, polymer viscosity, and permeability reduction. Since these simulations have lower salinity, the polymer viscosity and the permeability reduction will be higher. The results of these simulations are shown in Table B-5. These simulations resulted in nearly identical oil recoveries and chemical efficiencies compared to the base case. The economic results are shown in Table B-6. The NPV of both simulations were a little higher than the base case at all oil price and surfactant cost scenarios. By comparing the results of Simulation 13 (lower surfactant slug salinity) and Simulation 8 (1,500 ppm polymer injected), it is possible that the effect of minor reductions in the salinity is the same as increasing the polymer mass for this reservoir. Simulation 13 and 8 had nearly identical values of NPV, IRR, and GROR at all oil price and surfactant cost.

\section{Uncertainty Analysis}

The parameters used to study the reservoir and chemical uncertainty were surfactant adsorption, polymer adsorption, vertical to horizontal permeability ratio $\left(\mathrm{k}_{\mathrm{v}} / \mathrm{k}_{\mathrm{h}}\right)$, average permeability and the dependence of the oil saturation on capillary number (CDC).

As mentioned previously, the surfactant adsorption was determined in laboratory experiments in a parallel study. As a result of that study, ranges of values for surfactant 
adsorption were presented. In this study, the effect of values within that range and beyond was tested. The primary effects of surfactant adsorption were changes in the retardation factor and the amount of surfactant required.

The polymer adsorption was unknown for this rock and a value of $10 \mu \mathrm{g} / \mathrm{g}$ was assumed for the base case. The effect of this value was changes in concentration effecting mobility control and permeability reduction. To a lesser extent, the retardation factor for polymer can be affected. A value two times higher than the assumed value was tested.

The vertical to horizontal permeability ratio is important for establishing reasonable vertical sweep efficiency during the chemical flooding process. A value for this reservoir was unknown but the field operator suggested a value of 0.05. A lower value of 0.01 was used in this uncertainty analysis.

The permeability is variable within the reservoir in this study. The base case simulation model was based on the "sweet" spot of the reservoir that had the highest permeability. It was expected that lower permeability regions would have similar oil recovery but will have changes in permeability reduction and project life. As a result, the economics of the project would be drastically reduced. For this study, a permeability field with half the average horizontal permeability was simulated.

The last uncertain parameter was the oil capillary desaturation curve, which was unknown for this reservoir. The base case values used for this study were based on Delshad, 1990. To test the effect of this parameter, a more adverse oil CDC was 
simulated by shifting the oil CDC to the right. This can significantly affect oil recovery when low IFT is the primary mechanism.

Surfactant adsorption: The first uncertainty parameter was surfactant adsorption. However, this parameter is the least uncertain because laboratory data was available and a range of values was known. A range of values from $0.1 \mathrm{mg} / \mathrm{g}$ to $0.6 \mathrm{mg} / \mathrm{g}$ was tested. These values suggest a retardation factor ranging from $0.15 \mathrm{PV}$ to $0.9 \mathrm{PV}$, which can be compared to the surfactant slug size of $0.25 \mathrm{PV}$. As expected, the lower adsorption values gave higher oil recovery. The value closest to the most recent laboratory adsorption result using a reservoir core of $0.1 \mathrm{mg} / \mathrm{g}$ resulted in a significantly higher recovery of 39.2\% OOIP. Figure B-27 shows a comparison of cumulative oil recovery for each surfactant adsorption sensitivity. The economic results for these simulations are shown in Table B-6 and in Fig. B-28. The NPV had the same increasing trend as oil recovery for lower values of surfactant adsorption.

Polymer adsorption: The polymer adsorption is highly uncertain for this reservoir. For this study, a value twice the base case value was tested. The result is shown in Table B5. This higher polymer adsorption value actually resulted in higher oil recovery $(29.2 \%$ OOIP). This is due to factors such as higher injectivity and differences in permeability reduction due to lower polymer concentrations during the flood. As shown in Table B-6, the polymer adsorption sensitivity resulted in slightly better economic results. It can be concluded that this study is insensitive to polymer adsorption. 
Vertical permeability: The vertical to horizontal permeability ratio was also an uncertain parameter. A lower value of 0.01 was tested for comparison with the base case value of 0.05 . The result is shown in Table B-5. Similar to the polymer adsorption simulation, a reduction in the $\mathrm{k}_{\mathrm{v}} / \mathrm{k}_{\mathrm{h}}$ resulted in an unexpected increase in oil recovery (29\% OOIP). This simulation had higher channeling effects due to the lower $\mathrm{k}_{\mathrm{v}} / \mathrm{k}_{\mathrm{h}}$ resulting in less cross flow from the high permeability layers into the lower permeability layers. The increase in oil production came primarily from the upper permeability layer, which had improved areal sweep efficiency as a result of increased surfactant and polymer concentration throughout the flood. As shown in Table B-6, the $\mathrm{k}_{\mathrm{v}} / \mathrm{k}_{\mathrm{h}}$ sensitivity resulted in slightly better economic results. It can be concluded that this study might benefit from focusing on chemical flooding the high permeability layers only.

Horizontal permeability: The next uncertainty parameter was the reservoir permeability, which differs throughout the field. For this uncertainty simulation, the permeability used in the base case was reduced by a factor of two. It was expected that two effects would occur: extended simulation time and increased permeability reduction. The result is shown in Table B-5. The oil recovery was only slightly reduced to $27.3 \%$ OOIP but the simulation life was more than doubled. The reduction in permeability and the increase in permeability reduction severely reduced the injectivity. The economic result for this simulation is shown in Table B-6. At low oil price and high surfactant cost, a reduction in permeability resulted in a negative NPV. However, at high oil price the NPV was positive and the economic limit was 25 years. This uncertainty suggests that chemical 
flooding the lower permeability region of this reservoir shows more risk and should be designed carefully.

Capillary desaturation Curve: The last uncertainty parameter was the oil capillary desaturation curve was also unknown. The base case model assumed values provided in Delshad, 1990. For this uncertainty simulation, a more adverse oil desaturation curve was used (lower oil trapping parameter with the curve moved to the right). The result is shown in Table B-5. As expected, the oil recovery was reduced (25.2\% OOIP). However, the reduction in recovery is not as severe as it could have been. As shown in Table B-6, the economics of this simulation were worse compared to the base case, but were still positive.

The results of the uncertainty analysis suggest that the chemical flooding design for this reservoir is very robust and has the opportunity to recover a significant amount of remaining oil reserves. Assuming a price of $\$ 30$ per barrel of oil and $\$ 2.75$ per pound of surfactant, only two simulations gave negative economic results. They were simulations using a surfactant adsorption higher than that reported in the laboratory and using permeability that was reduced by half. On the other hand, assuming $\$ 50$ per barrel of crude oil and \$2.75 per pound of surfactant, all uncertainty simulations had positive economics. Figure B-29 shows the comparison of NPV's for all uncertainty simulations. This is an encouraging result based on several highly adverse uncertainty conditions. 


\section{Determination of the optimum SP design:}

Based on the results of the design optimization and uncertainty analysis, an optimum design can be developed. As shown in Fig. B-30, the highest NPV at all assumed oil and surfactant prices for the sensitivity simulations was injecting a polymer concentration of 2,000 ppm in the surfactant slug and polymer drive. Therefore, the base case should be modified with this optimization. The surfactant mass sensitivities also had results with higher NPV's, but the result depended on the design and oil price. In addition, these increases in NPV were overshadowed by the polymer mass results. It cannot be assumed that changing both polymer and surfactant mass together would optimize the chemical flooding result. Finally, the low value of surfactant adsorption gave much higher values of NPV compared to the increased polymer mass simulation.

There was also a strong impact of reservoir wettability on these results. The main impact was the simulation life. The increased simulation life compared to a water-wet reservoir was due to differences in relative permeability, which affect the injectivity and mobility ratio. The difference in mobility ratio was the main reason for late oil breakthrough and early surfactant breakthrough. 
Table B-1. Reservoir and simulation model properties

\begin{tabular}{|l|l|}
\hline Model physical dimensions & $700^{\prime} \mathrm{x} 800^{\prime} \mathrm{x} 99.1^{\prime}$ \\
\hline Depth & 4,700 feet \\
\hline Porosity & Average $=0.16$ \\
& Min $=0.06, \mathrm{Max}=0.273$ \\
\hline Permeability & $\begin{array}{l}\text { Average }=156 \mathrm{md} \\
\text { Min }=4.4 \mathrm{md} \\
\text { Max }=870 \mathrm{md} \\
\mathrm{k}_{\mathrm{v}} / \mathrm{k}_{\mathrm{h}}=0.05\end{array}$ \\
\hline Residual saturations & Water $=0.3$ \\
& Oil $=0.42$ \\
\hline Corey type relative permeability endpoint & Water $=0.4$ \\
& Oil $=0.6$ \\
\hline Corey type relative permeability exponent & Water $=2$ \\
& Oil $=2$ \\
\hline Simulation model pore volume & $1.610 \mathrm{MMbbl}$ \\
\hline Simulated post waterflood average saturations & Water $=0.53$ \\
& Oil = 0.47 \\
\hline Simulated post waterflood oil in place & $0.75 \mathrm{MMbl}$ \\
\hline Simulated post waterflood average reservoir pressure & $755 \mathrm{psia}$ \\
\hline
\end{tabular}

Table B-2. Fluid properties

\begin{tabular}{||l|l||}
\hline Density & $\begin{array}{l}\text { Oil }=31^{\circ} \mathrm{API}(0.87 \mathrm{~g} / \mathrm{ml}) \\
\text { Water }=1 \mathrm{~g} / \mathrm{cc}\end{array}$ \\
\hline Viscosity & Water $=0.72 \mathrm{cp}$ \\
& Oil $=5 \mathrm{cp}$ \\
\hline Brine & Overall $=1 \mathrm{meq} / \mathrm{mL}$ \\
composition & $\mathrm{Ca}^{+2}=2,066 \mathrm{ppm}$ \\
& $\mathrm{Mg}^{+2}=539 \mathrm{ppm}$ \\
& $\mathrm{Na}^{+}=20,533 \mathrm{ppm}$ \\
& $\mathrm{SO}_{4}^{-2}=4,540 \mathrm{ppm}$ \\
& $\mathrm{Cl}^{-}=32,637 \mathrm{ppm}$ \\
\hline
\end{tabular}


Table B-3. Base case SP design

\begin{tabular}{|c|c|}
\hline Injection well constraints & $\begin{array}{l}\text { Rate constraint }=2,000 \mathrm{bbl} / \text { day }^{1} \\
\text { Pressure control }=2,500 \mathrm{psi}\end{array}$ \\
\hline Production well constraint & Pressure constraint $=300 \mathrm{psi}$ \\
\hline Surfactant slug & $\begin{array}{l}0.25 \mathrm{PV} \\
1 \text { vol\% surfactant } \\
1,000 \mathrm{ppm} \text { polymer } \\
0.365 \mathrm{meq} / \mathrm{mL}(21,000 \mathrm{ppm} \mathrm{TDS})\end{array}$ \\
\hline Polymer drive & $\begin{array}{l}1 \text { PV } \\
1,000 \text { ppm polymer } \\
0.2 \text { meq/mL (11,700 ppm TDS) } \\
\end{array}$ \\
\hline Water postflush & $\begin{array}{l}0.5 \mathrm{PV} \\
0.04 \mathrm{meq} / \mathrm{mL}(2,300 \mathrm{ppm} \text { TDS })\end{array}$ \\
\hline Surfactant adsorption & $0.3 \mathrm{mg}$ surfactant/g rock \\
\hline Polymer adsorption & 10 ug polymer/g rock \\
\hline $\begin{array}{l}\text { Capillary desaturation } \\
\text { parameters }\end{array}$ & $\begin{array}{l}\text { Water }=1,865 \\
\text { Oil }=59,074\end{array}$ \\
\hline Vertical permeability & $\mathrm{k}_{\mathrm{v}} / \mathrm{k}_{\mathrm{h}}=0.05$ \\
\hline
\end{tabular}

${ }^{1}$ Rate constraint is for full 5-spot pattern

Table B-4. Economic analysis input parameters

\begin{tabular}{||l|l|l|}
\hline \multirow{5}{*}{ Capital and Operating Costs } & Equipment Cost & $\$ 100,000$ \\
\cline { 2 - 3 } & Operating Cost & $\$ 5,000$ per month \\
\cline { 2 - 3 } & Chemical Injection Cost & $\$ 0.10$ per barrel \\
\cline { 2 - 3 } & Fluid Treatment Cost & $\$ 0.10$ per barrel \\
\hline \multirow{5}{*}{ Taxation Rates } & Oil Price & $\$ 30-\$ 50$ per barrel \\
\cline { 2 - 3 } & Blended Surfactant Price & $\$ 1.75-\$ 2.75$ per lb \\
\cline { 2 - 3 } & Polymer Price & $\$ 1.00$ per lb \\
\hline \multirow{2}{*}{ General Rates } & Royalty & $0 \%$ \\
\cline { 2 - 3 } & Severance \& Ad valorem & $5 \%$ \\
\cline { 2 - 3 } & Income Tax & $36.64 \%$ \\
\hline & Tax Credit & $15 \%$ \\
\hline & Inflation Rate & $3 \%$ \\
\cline { 2 - 3 } & Real Discount Rate & $10 \%$ \\
\hline
\end{tabular}


Table B-5. Sensitivity simulation designs and results

\begin{tabular}{|c|c|c|c|c|c|c|c|c|c|c|c|c|c|}
\hline $\begin{array}{l}\text { Run } \\
\text { No. }\end{array}$ & $\begin{array}{c}\text { Sensitivity } \\
\text { Variable }\end{array}$ & \begin{tabular}{|c|} 
Surf \\
Slug \\
Size \\
$(\% \mathrm{PV})$ \\
\end{tabular} & $\begin{array}{c}\text { Surf } \\
\text { Conc } \\
\text { (vol\%) }\end{array}$ & $\begin{array}{c}\text { Surf } \\
\text { Mass } \\
(\text { MMlb) }\end{array}$ & \begin{tabular}{|c|} 
Poly \\
Drive \\
Size \\
$(\% \mathrm{PV})$ \\
\end{tabular} & $\begin{array}{l}\text { Poly } \\
\text { Conc } \\
\text { (ppm) }\end{array}$ & \begin{tabular}{|c|} 
Poly \\
Mass \\
$(\text { MMlb })^{1}$
\end{tabular} & $\begin{array}{c}\text { Other } \\
\text { Design } \\
\text { Variable }\end{array}$ & \begin{tabular}{|c|} 
Cum \\
Oil \\
Rec \\
$(\%$ OOIP $)$
\end{tabular} & $\begin{array}{l}\text { Surfactant } \\
\text { Efficiency } \\
\text { (lb/bbl oil) }\end{array}$ & $\begin{array}{l}\text { Polymer } \\
\text { Efficiency } \\
\text { (lb/bbl oil) }\end{array}$ & $\begin{array}{l}\text { Chemical } \\
\text { Cost per } \\
\text { barrel of oil }\end{array}$ & $\begin{array}{c}\text { Run } \\
\text { Length } \\
\text { (years) }\end{array}$ \\
\hline 1 & Base case & 25 & 1 & 5.6 & 100 & 1000 & 2.8 & N/A & $27.8 \%$ & 4.5 & 2.1 & $\$ 14.5$ & 21 \\
\hline 2 & Surf conc & 25 & 0.5 & 2.9 & 100 & 1000 & 2.8 & N/A & $17.5 \%$ & 3.6 & 3.6 & $\$ 13.5$ & 25 \\
\hline 3 & Surf conc & 25 & 1.5 & 8.4 & 100 & 1000 & 2.8 & N/A & $35.2 \%$ & 5.3 & 1.9 & $\$ 16.5$ & 20 \\
\hline 4 & Surf slug & 50 & 1 & 11.2 & 100 & 1000 & 3.4 & N/A & $38.3 \%$ & 6.7 & 1.7 & $\$ 20.1$ & 23 \\
\hline 5 & Surf slug & 35 & 1 & 7.9 & 100 & 1000 & 3 & N/A & $32.7 \%$ & 5.3 & 2.4 & $\$ 17.0$ & 22 \\
\hline 6 & Surf slug & 15 & 1 & 3.4 & 100 & 1000 & 2.6 & N/A & $20.2 \%$ & 4 & 2.7 & $\$ 13.7$ & 22 \\
\hline 7 & Polymer mass & 25 & 1 & 5.6 & 100 & 500 & 1.4 & $\mathrm{~N} / \mathrm{A}$ & $23.5 \%$ & 5.3 & 1.4 & $\$ 16.0$ & 16 \\
\hline 8 & Polymer mass & 25 & 1 & 5.6 & 100 & 1500 & 4.2 & N/A & $30.1 \%$ & 4.1 & 3.1 & $\$ 14.4$ & 31 \\
\hline 9 & Polymer mass & 25 & 1 & 5.6 & 100 & 2000 & 5.6 & N/A & $32.0 \%$ & 3.9 & 3.9 & $\$ 14.6$ & 43 \\
\hline 10 & Polymer mass & 25 & 1 & 5.6 & 100 & 2500 & 7 & N/A & $34.0 \%$ & 3.7 & 4.6 & $\$ 14.8$ & 55 \\
\hline 11 & Polymer mass & 25 & 1 & 5.6 & 50 & 1000 & 1.7 & $\mathrm{~N} / \mathrm{A}$ & $26.2 \%$ & 4.7 & 1.4 & $\$ 14.3$ & 17 \\
\hline 12 & Polymer mass & 25 & 1 & 5.6 & 100 & $\begin{array}{c}1500 / \\
1000 / \\
500 \\
\end{array}$ & 2.5 & $\begin{array}{c}\text { Tapered } \\
\text { concentration }\end{array}$ & $24.8 \%$ & 5 & 2.1 & $\$ 15.9$ & 19 \\
\hline 13 & Salinity & 25 & 1 & 5.6 & 100 & 1000 & 2.8 & $\begin{array}{c}\text { Surf slug } \\
\text { salinity }=0.25 \\
\text { meq/mL }\end{array}$ & $27.9 \%$ & 4.5 & 2.1 & $\$ 14.5$ & 21 \\
\hline 14 & Salinity & 25 & 1 & 5.6 & 100 & 1000 & 2.8 & $\begin{array}{c}\text { Drive salinity = } \\
0.15 \mathrm{meq} / \mathrm{mL}\end{array}$ & $27.8 \%$ & 4.5 & 2.1 & $\$ 14.5$ & 22 \\
\hline 15 & Surf. Ads. & 25 & 1 & 5.6 & 100 & 1000 & 2.8 & $0.1 \mathrm{mg} / \mathrm{g}$ & $39.2 \%$ & 3.3 & 1.7 & $\$ 10.8$ & 19 \\
\hline 16 & Surf. Ads. & 25 & 1 & 5.6 & 100 & 1000 & 2.8 & $0.6 \mathrm{mg} / \mathrm{g}$ & $19.2 \%$ & 7.1 & 2.8 & $\$ 22.3$ & 20 \\
\hline 17 & Surf. Ads. & 25 & 1 & 5.6 & 100 & 1000 & 2.8 & $0.43 \mathrm{mg} / \mathrm{g}$ & $22.9 \%$ & 5.9 & 2.5 & $\$ 18.7$ & 22 \\
\hline 18 & Polymer Ads. & 25 & 1 & 5.6 & 100 & 1000 & 2.8 & $20 \mu \mathrm{g} / \mathrm{g}$ & $29.2 \%$ & 4.3 & 2.1 & $\$ 13.9$ & 19 \\
\hline 19 & $\mathrm{k}_{\mathrm{v}} / \mathrm{k}_{\mathrm{h}}$ & 25 & 1 & 5.6 & 100 & 1000 & 2.8 & $\mathrm{kv} / \mathrm{kh}=0.01$ & $29.0 \%$ & 4.3 & 2.1 & $\$ 13.9$ & 22 \\
\hline 20 & Permeability & 25 & 1 & 5.6 & 100 & 1000 & 2.8 & $\begin{array}{c}\text { Avg Perm }=78 \\
\text { md }\end{array}$ & $27.3 \%$ & 5 & 2.5 & $\$ 16.3$ & 56 \\
\hline 21 & CDC & 25 & 1 & 5.6 & 100 & 1000 & 2.8 & $\begin{array}{c}\text { High oil critical } \\
\text { capillary } \\
\text { number } \\
\end{array}$ & $25.2 \%$ & 5 & 2.7 & $\$ 16.5$ & 22 \\
\hline
\end{tabular}

${ }^{1}$ Quantities shown are for full 5-spot pattern.

${ }^{2}$ Assuming a surfactant cost of $\$ 2.75$ per pound and polymer cost $\$ 1.00$ per pound. 
Table B-6. Sensitivity simulation economic analysis

\begin{tabular}{|c|c|c|c|c|c|c|c|c|c|}
\hline $\begin{array}{c}\text { Run } \\
\text { Number }\end{array}$ & $\begin{array}{l}\text { Sensitivity } \\
\text { Variable }\end{array}$ & $\begin{array}{c}\text { NPV } \\
(\mathrm{MM} \$)^{1}\end{array}$ & $\begin{array}{l}\text { IRR } \\
(\%)^{1}\end{array}$ & $\begin{array}{c}\text { GROR } \\
(\%)^{1}\end{array}$ & $\begin{array}{l}\text { Economic } \\
\text { Limit } \\
\text { (years) }^{1}\end{array}$ & $\begin{array}{l}\text { Cum Oil } \\
\operatorname{Rec}^{2} \\
(\% \text { OIP) }\end{array}$ & $\begin{array}{l}\text { Surfactant } \\
\text { Efficiency }^{2} \\
\text { (lb/bbl oil) }\end{array}$ & $\begin{array}{l}\text { Polymer } \\
\text { Efficiency }^{2} \\
\text { (lb/bbl oil) }\end{array}$ & $\begin{array}{c}\text { Chemical Cost } \\
\text { per barrel of } \\
\text { oil }^{2,3}\end{array}$ \\
\hline 1 & Base case & $2.28-11.2$ & $15.2-34.3$ & $11.3-15.1$ & 15 & $26.5 \%$ & 4.7 & 2.3 & $\$ 15.2$ \\
\hline 2 & Surf conc & $2.27-7.86$ & $20.5-44.4$ & $12.5-17$ & 14 & $17.5 \%$ & 3.8 & 3.2 & $\$ 13.7$ \\
\hline 3 & Surf conc & $0.47-11.9$ & $10.6-26.3$ & $10.1-12.9$ & 20 & $35.2 \%$ & 5.3 & 1.8 & $\$ 16.4$ \\
\hline 4 & Surf slug & $-2.24-10.4$ & $7.2-24.6$ & $9.2-13.7$ & N/A - 19 & $37.3 \%$ & 6.7 & 2.0 & $\$ 20.4$ \\
\hline 5 & Surf slug & $0.90-11.4$ & $11.5-29.6$ & $10.3-14.2$ & 18 & $31.9 \%$ & 5.5 & 2.1 & $\$ 17.2$ \\
\hline 6 & Surf slug & $2.56-9.13$ & $18.9-39.5$ & $12-16$ & 15 & $20.2 \%$ & 3.9 & 2.8 & $\$ 13.5$ \\
\hline 7 & Polymer mass & $0.27-8.0$ & $10.6-26$ & $10.2-13.7$ & 16 & $23.5 \%$ & 5.3 & 1.3 & $\$ 15.9$ \\
\hline 8 & Polymer mass & $3.05-12.5$ & $17-37.8$ & $11.7-15.6$ & 15 & $30.1 \%$ & 4.5 & 2.7 & $\$ 15.1$ \\
\hline 9 & Polymer mass & $3.45-13.3$ & $17.7-39.3$ & $12-16.3$ & 14 & $29.5 \%$ & 4.3 & 1.4 & $\$ 13.2$ \\
\hline 10 & Polymer mass & $3.40-13.2$ & $17.3-38.6$ & $11.9-16.3$ & 14 & $29.2 \%$ & 4.2 & 3.2 & $\$ 14.8$ \\
\hline 11 & Polymer mass & $2.30-11.0$ & $15.3-34.4$ & $11.5-15.9$ & 13 & $25.3 \%$ & 4.9 & 1.5 & $\$ 15.0$ \\
\hline 12 & Polymer mass & $1.78-10.3$ & $14.5-35.8$ & $10.9-14.5$ & 16 & $24.5 \%$ & 5.1 & 2.3 & $\$ 16.3$ \\
\hline 13 & Salinity & $2.87-12.0$ & $17-38.2$ & $11.7-15.9$ & 14 & $26.8 \%$ & 4.7 & 2.2 & $\$ 15.1$ \\
\hline 14 & Salinity & $2.39-11.4$ & $15.4-34.5$ & $11.2-14.5$ & 17 & $27.1 \%$ & 4.6 & 2.3 & $\$ 15.0$ \\
\hline 15 & Surf. Ads. & $6.08-17.4$ & $21.7-42.1$ & $12.4-15.6$ & 19 & $39.2 \%$ & 3.3 & 1.7 & $\$ 10.8$ \\
\hline 16 & Surf. Ads. & $-2.02-5.08$ & $5-22.4$ & $8.6-12.9$ & N/A - 14 & $19.2 \%$ & 6.9 & 2.9 & $\$ 21.9$ \\
\hline 17 & Surf. Ads. & $0.20-7.90$ & $10.5-28.6$ & $10.1-14.2$ & 14 & $23.2 \%$ & 5.7 & 2.6 & $\$ 18.3$ \\
\hline 18 & Polymer Ads. & $2.51-11.7$ & $15.1-32.5$ & $11.3-14.9$ & 16 & $28.6 \%$ & 4.4 & 2.2 & $\$ 14.3$ \\
\hline 19 & $\mathrm{k}_{\mathrm{v}} / \mathrm{k}_{\mathrm{h}}$ & $2.67-11.8$ & $15.9-35.7$ & $11.5-15.5$ & 15 & $27.6 \%$ & 4.5 & 2.2 & $\$ 14.6$ \\
\hline 20 & Permeability & $-0.37-7.31$ & $9.4-22$ & $9.9-12.2$ & N/A - 25 & $26.8 \%$ & 4.7 & 1.8 & $\$ 14.7$ \\
\hline 21 & CDC & $1.34-9.70$ & $13.1-31.9$ & $10.7-14$ & 17 & $24.7 \%$ & 5 & 2.5 & $\$ 16.3$ \\
\hline
\end{tabular}

${ }^{1}$ Low-end values for oil price $=\$ 30$. High-end values for oil price $=\$ 50$. Both values assume a surfactant cost of $\$ 2.75$.

Quantities shown are for full 5-spot pattern.

${ }^{2}$ Values are reported at economic limit.

${ }^{3}$ Assuming a surfactant cost of $\$ 2.75$ and polymer cost $\$ 1.00$. 


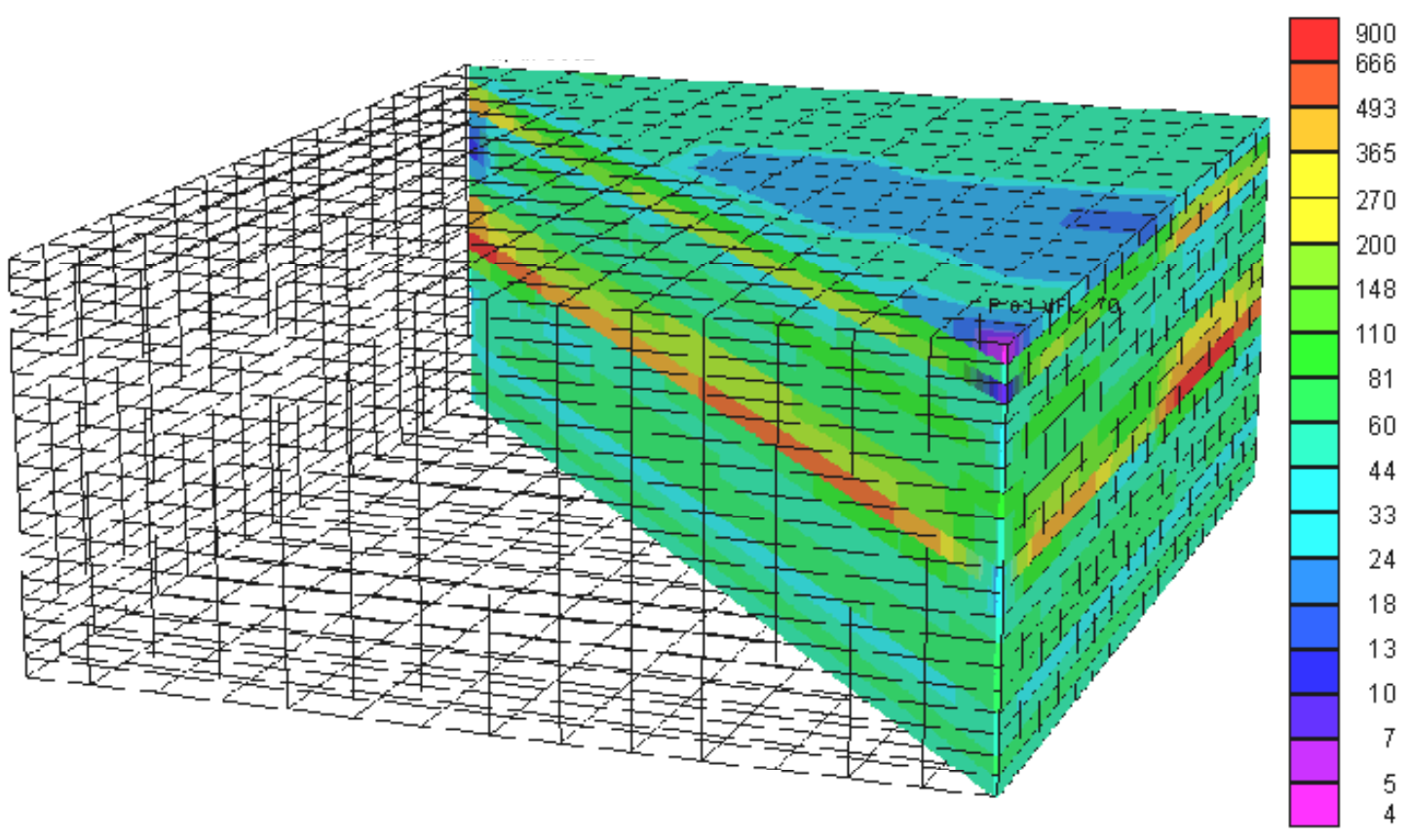

Fig. B-1. Simulation model permeability (md)

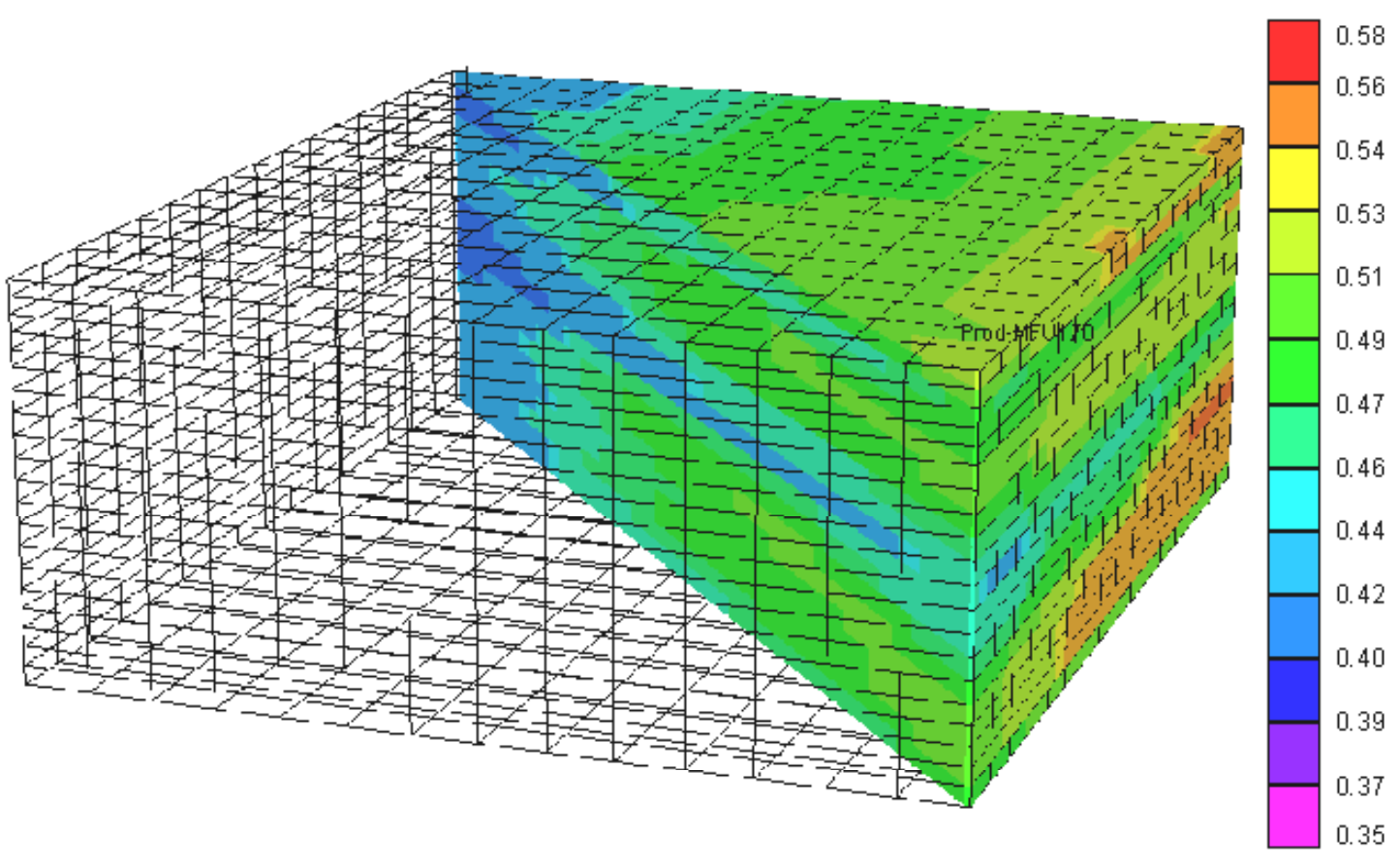

Fig. B-2. Simulation model initial oil saturation 


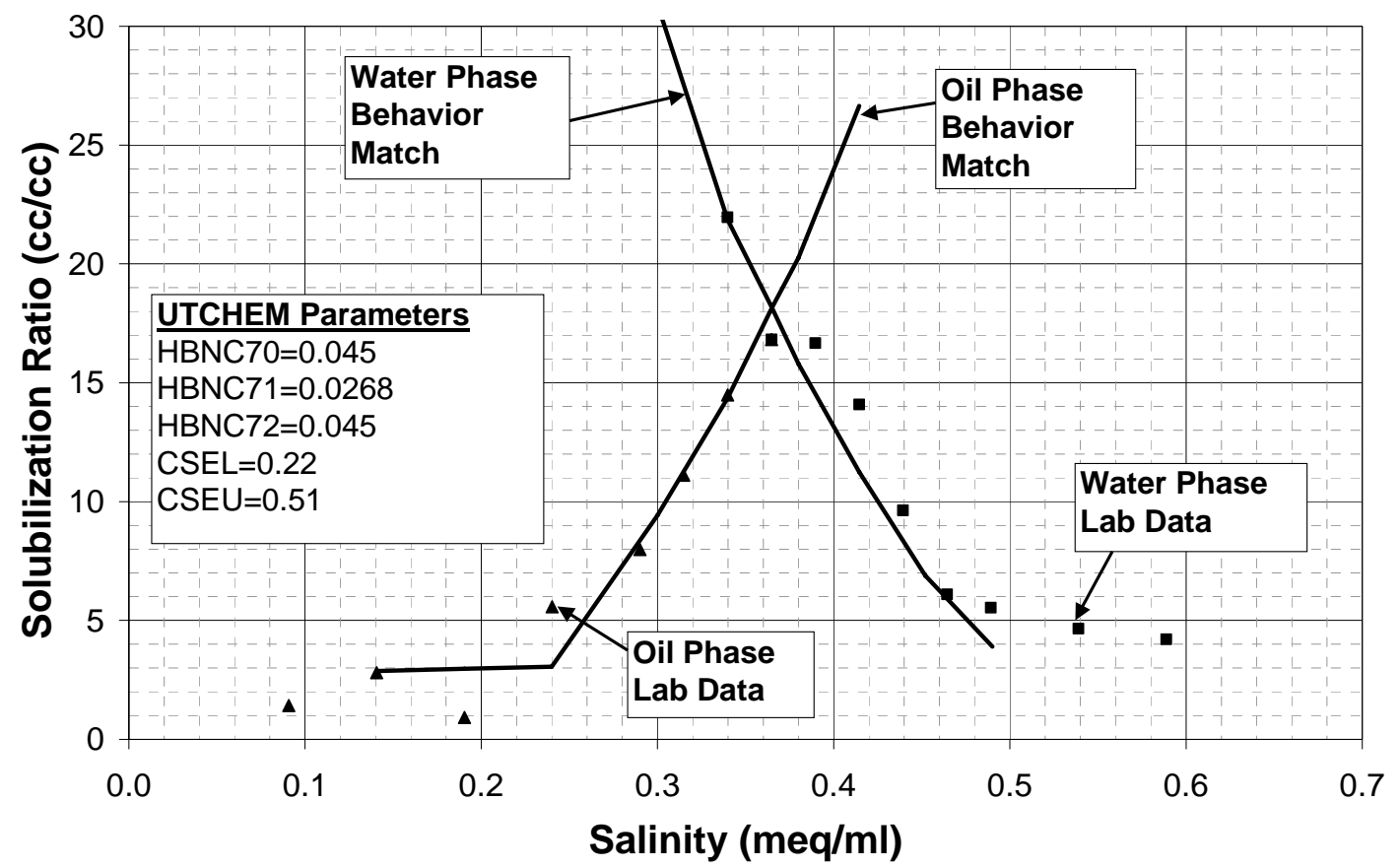

Fig. B-3. Comparison of measured and UTCHEM surfactant phase behavior

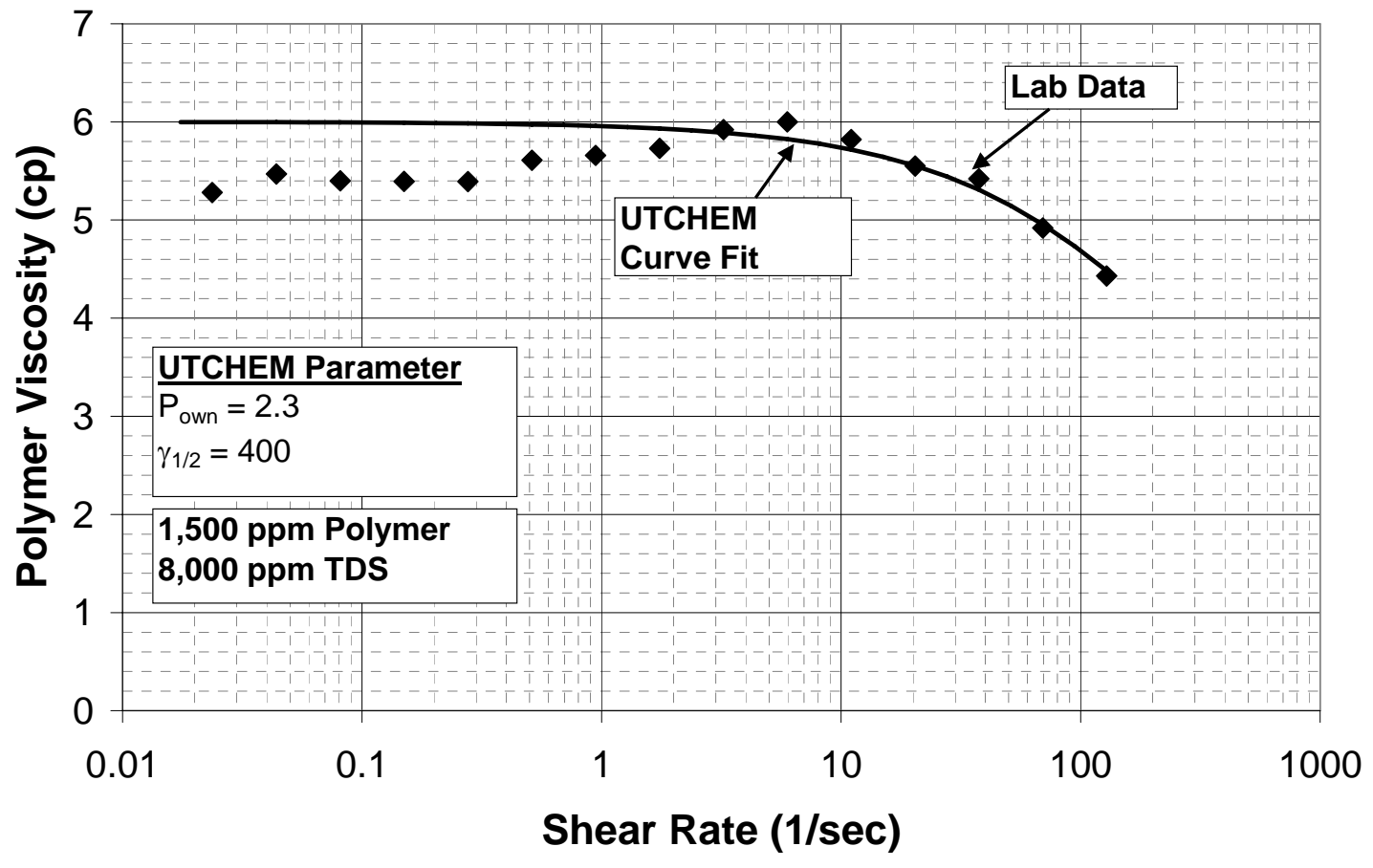

Fig. B-4. Comparison of measured and UTCHEM polymer viscosity vs. shear rate 


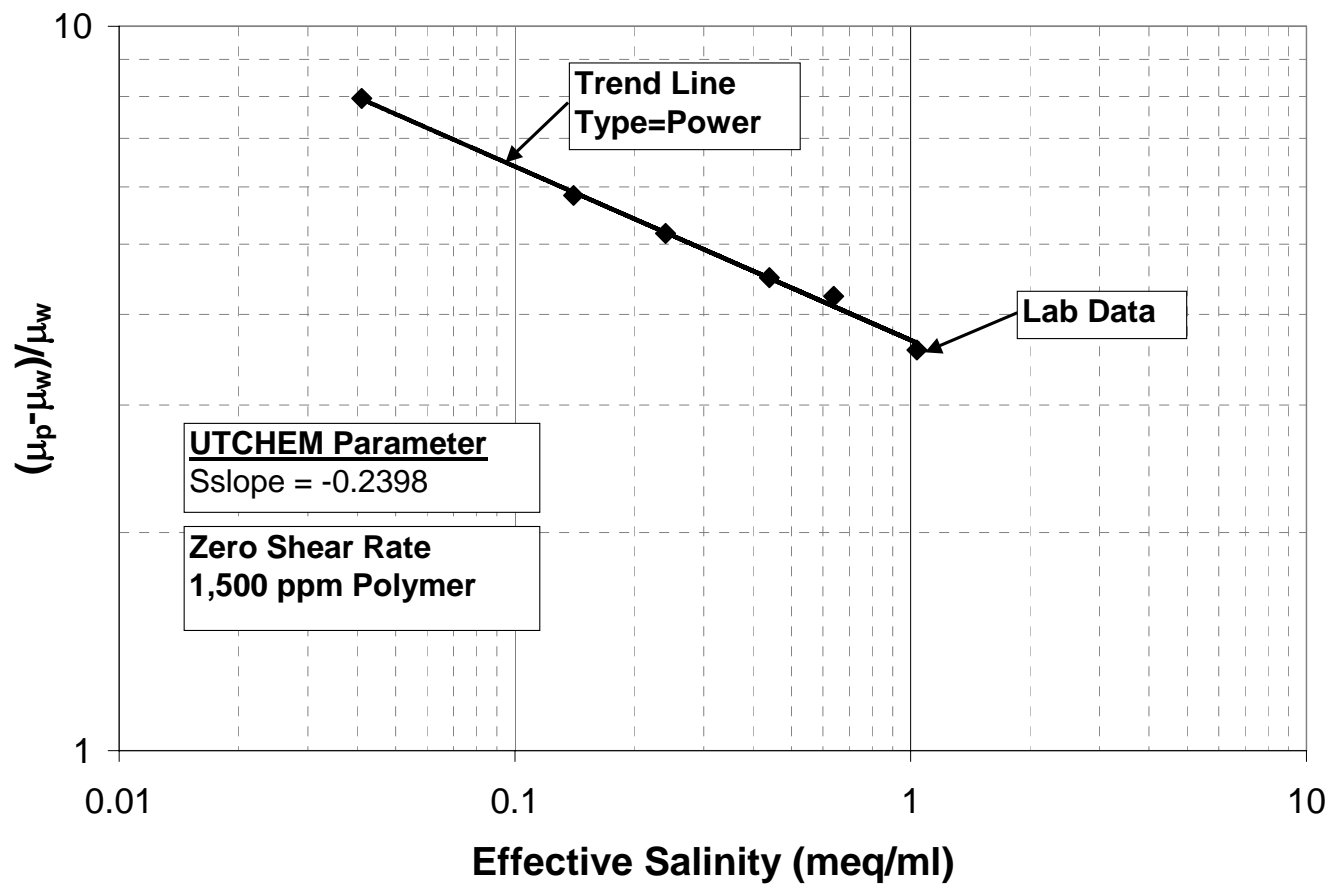

Fig. B-5. Comparison of measured and UTCHEM polymer viscosity vs. salinity

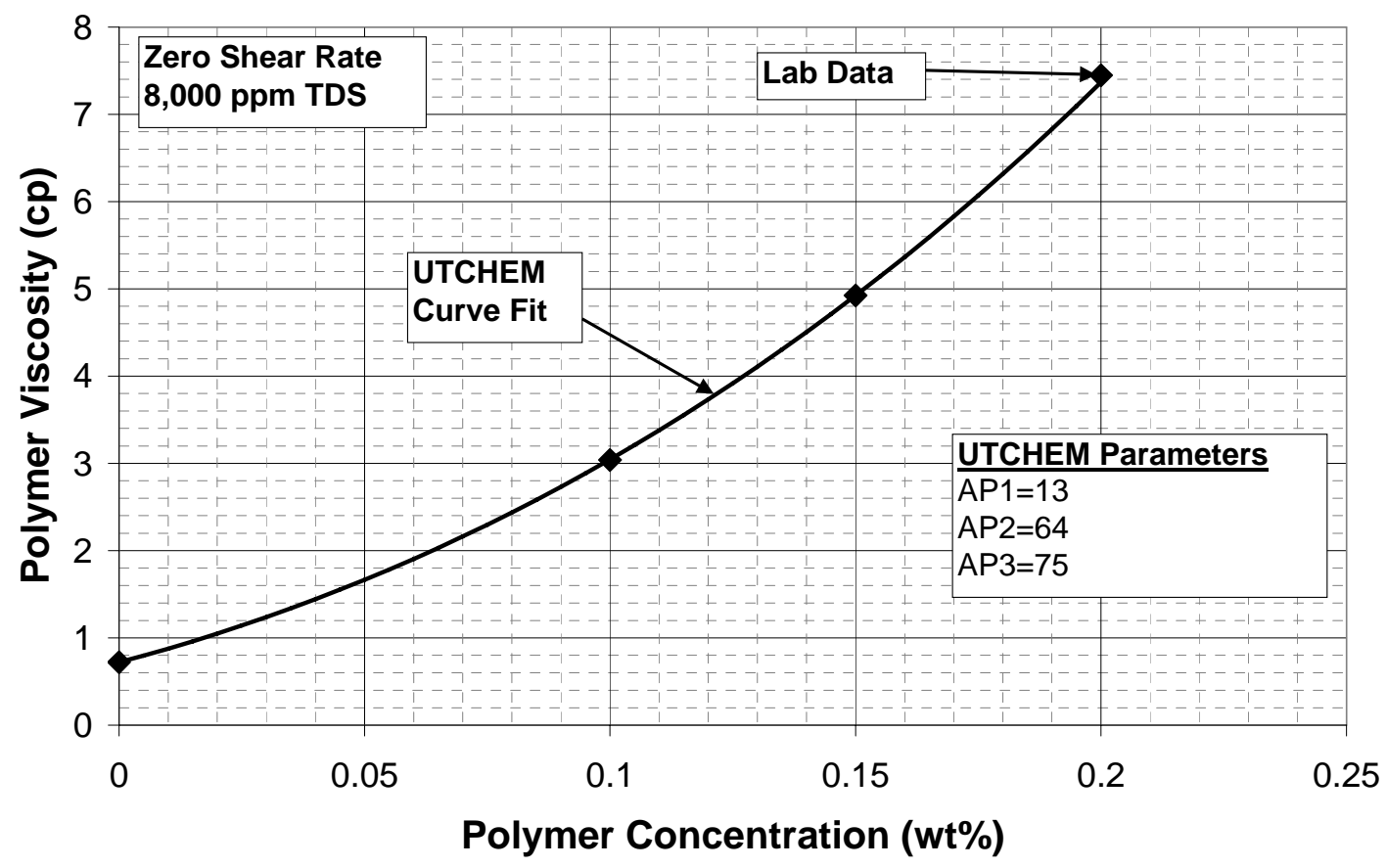

Fig. B-6. Comparison of measured and UTCHEM polymer viscosity vs. concentration 


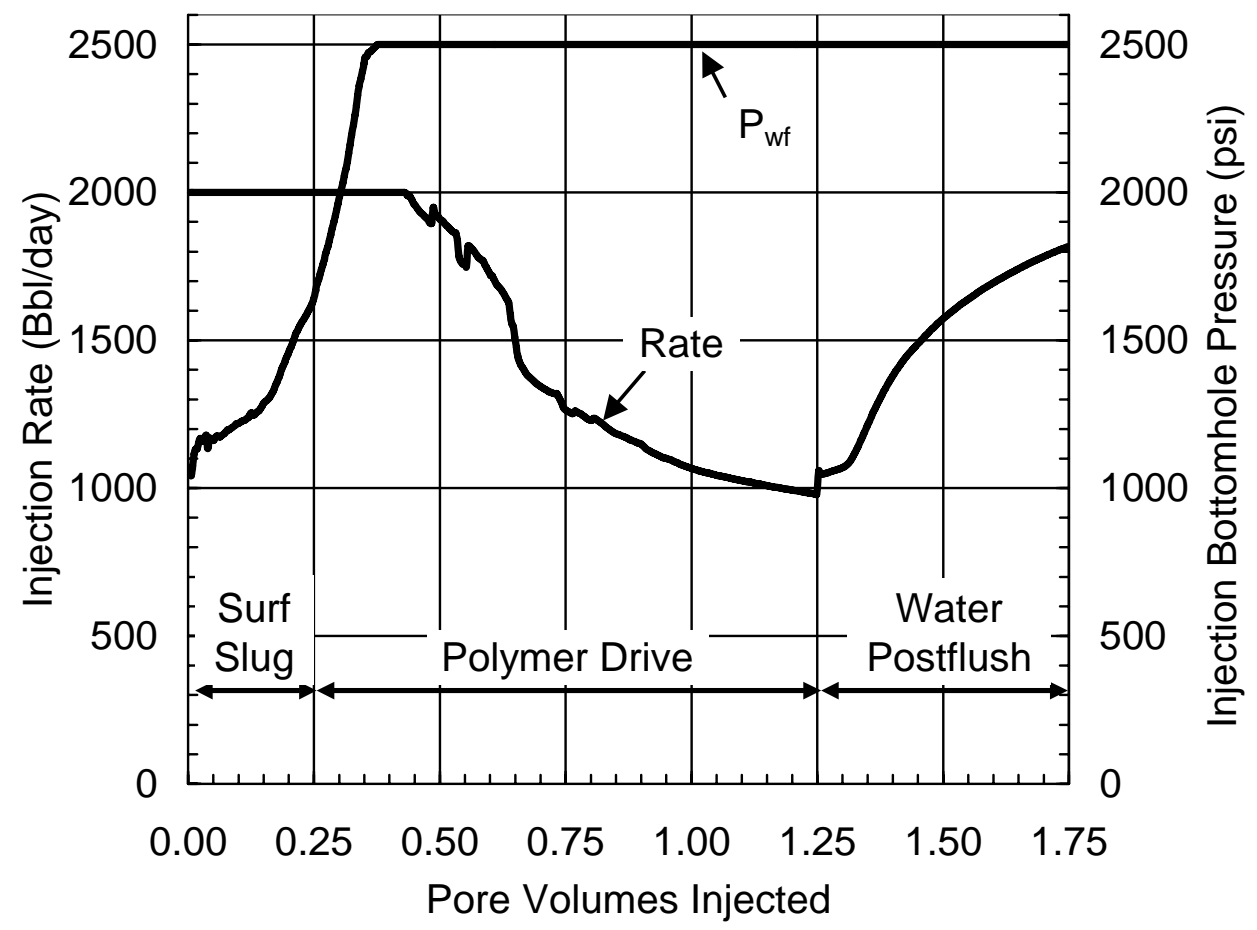

Fig. B-7. Base case simulation injection rate and bottomhole pressure

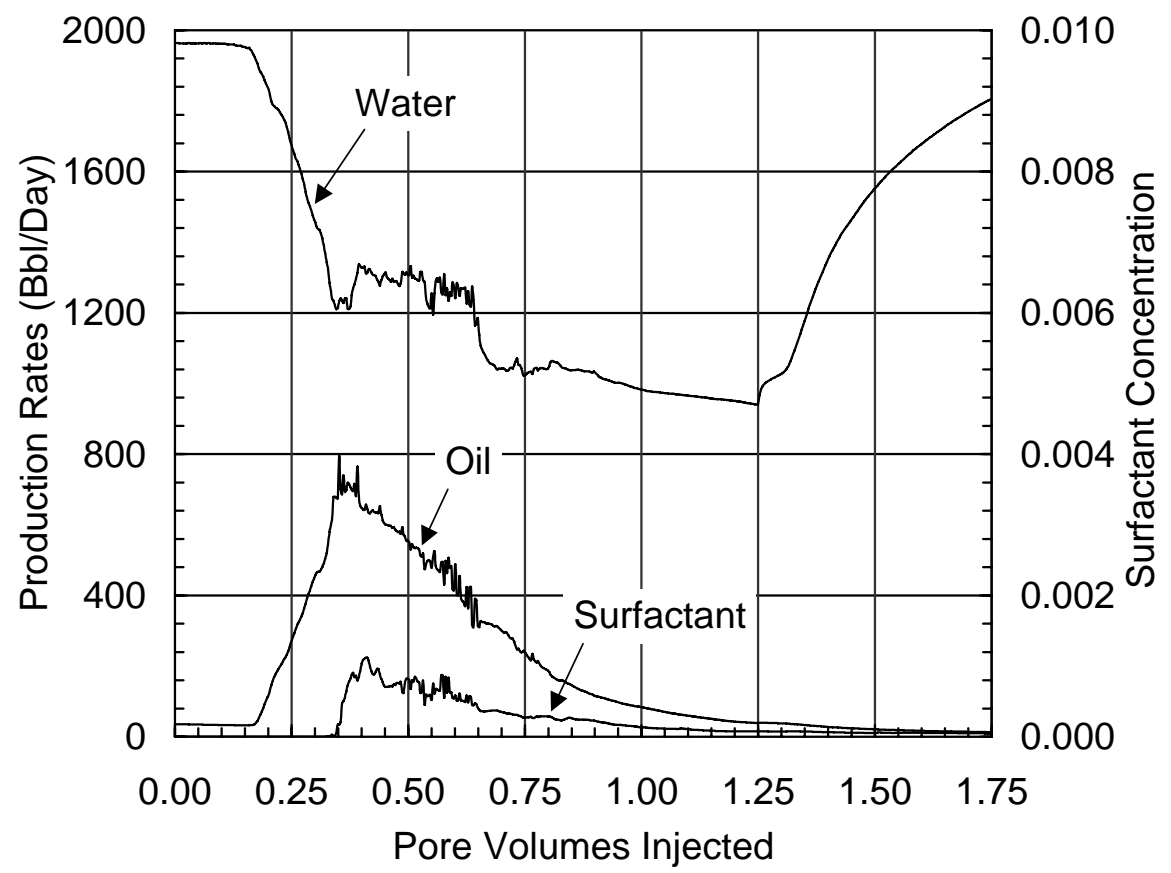

Fig. B-8. Base case simulation production rates and produced surfactant concentration (volume fraction) 

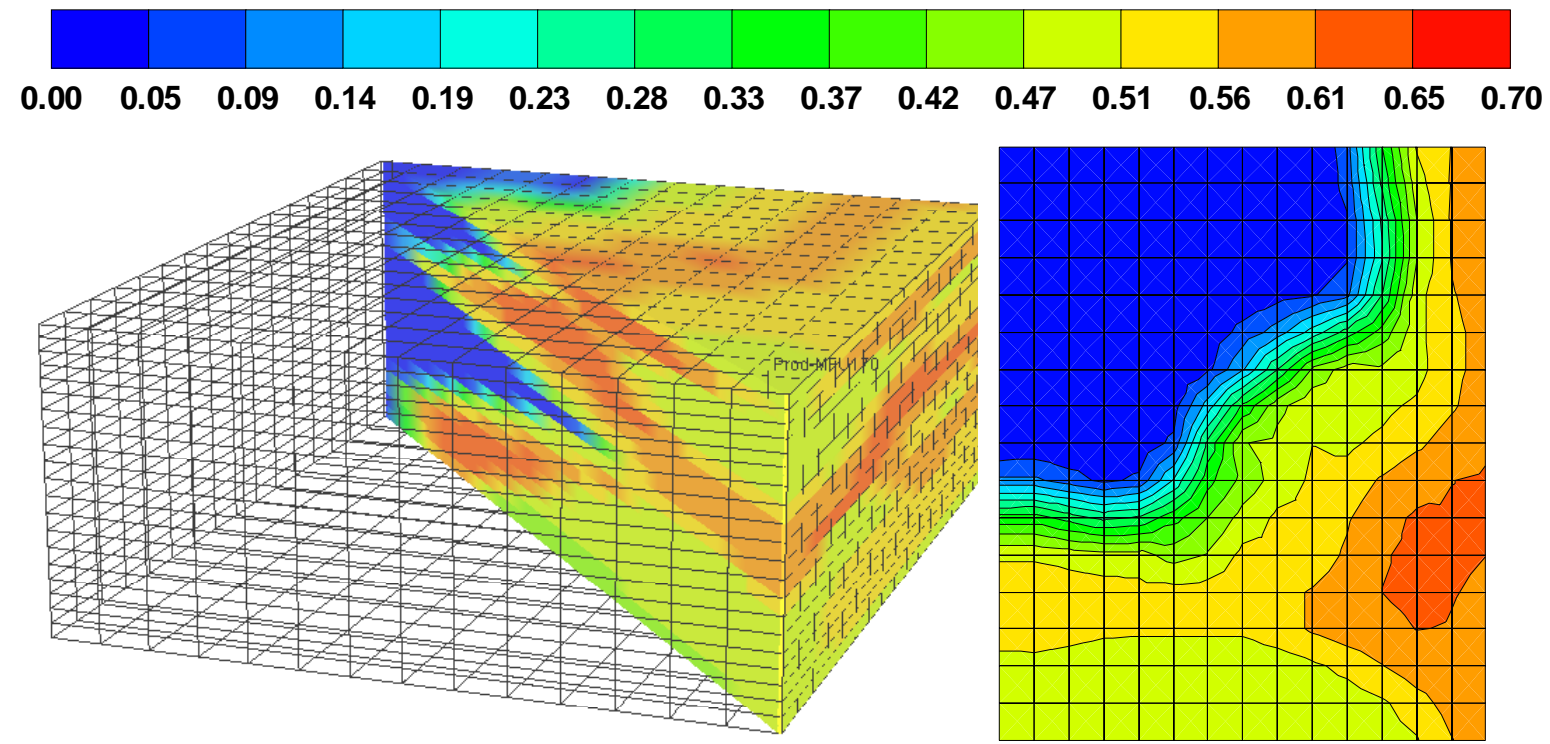

Fig. B-9. Base case oil saturation after 0.2 PV injected
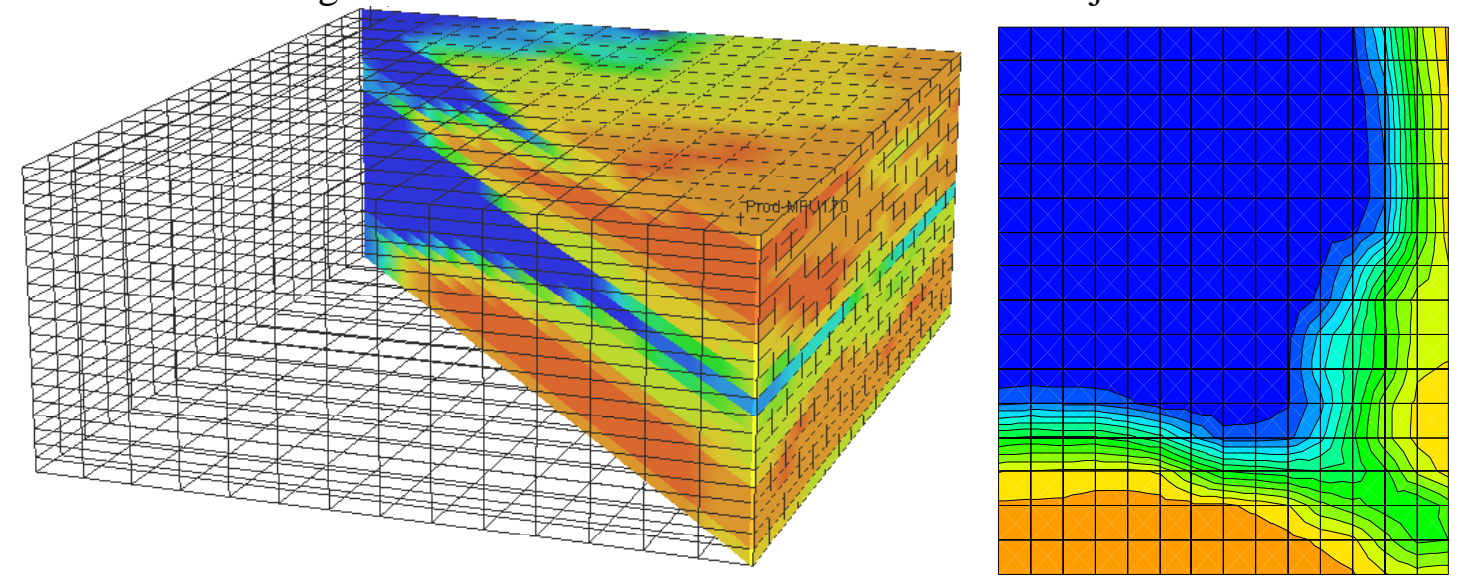

Fig. B-10. Base case oil saturation after 0.35 PV injected
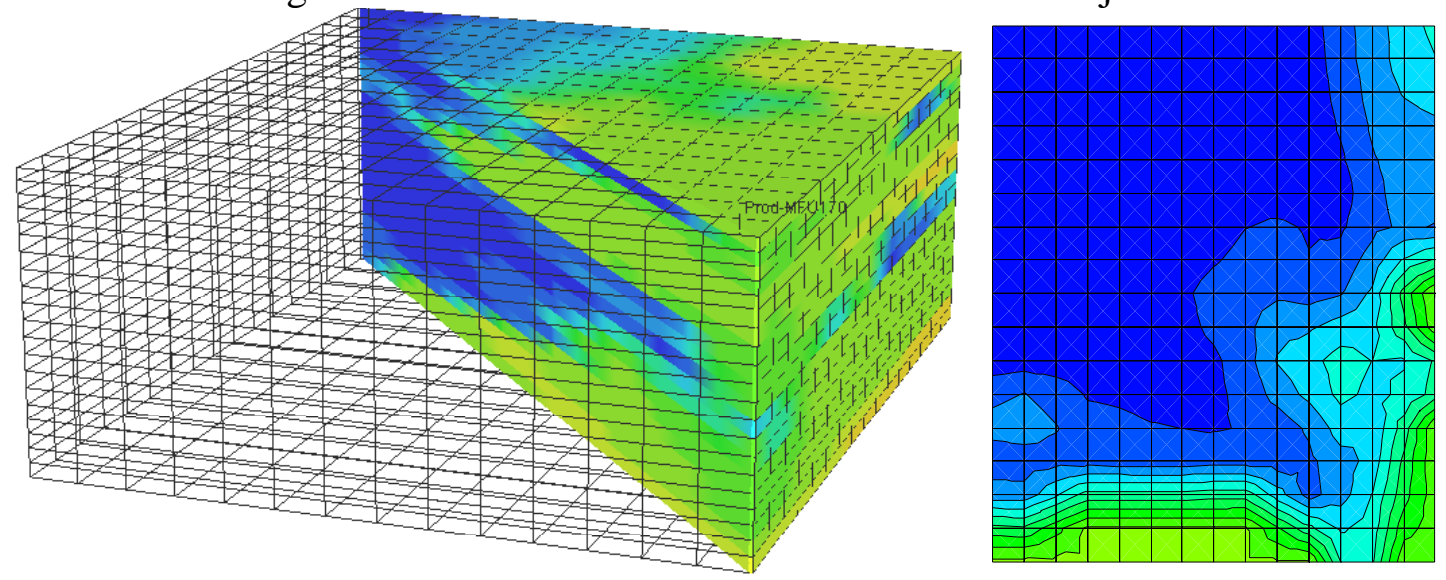

Fig. B-11. Base case oil saturation after 1.75 PV injected 

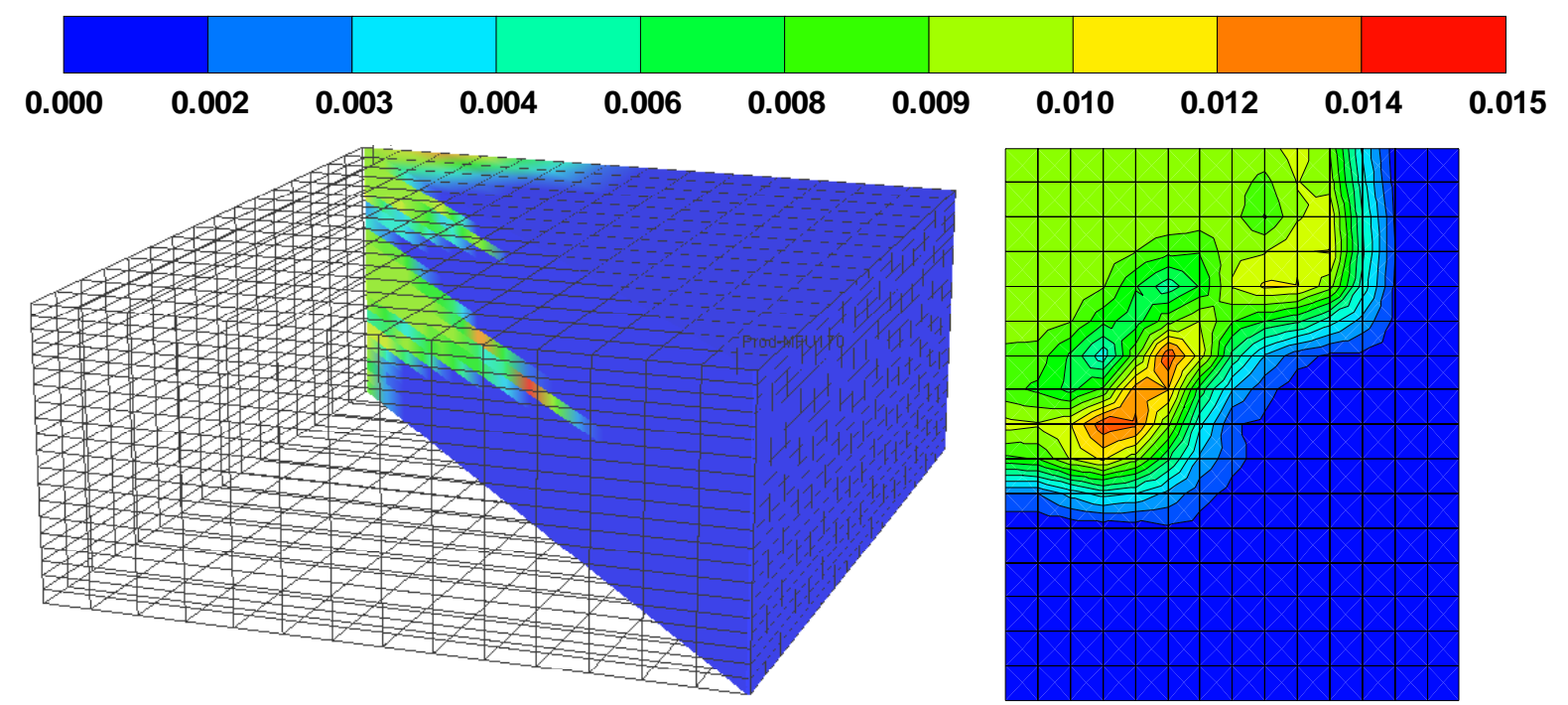

Fig. B-12. Base case surf. conc. (vol. frac.) after 0.2 PV injected
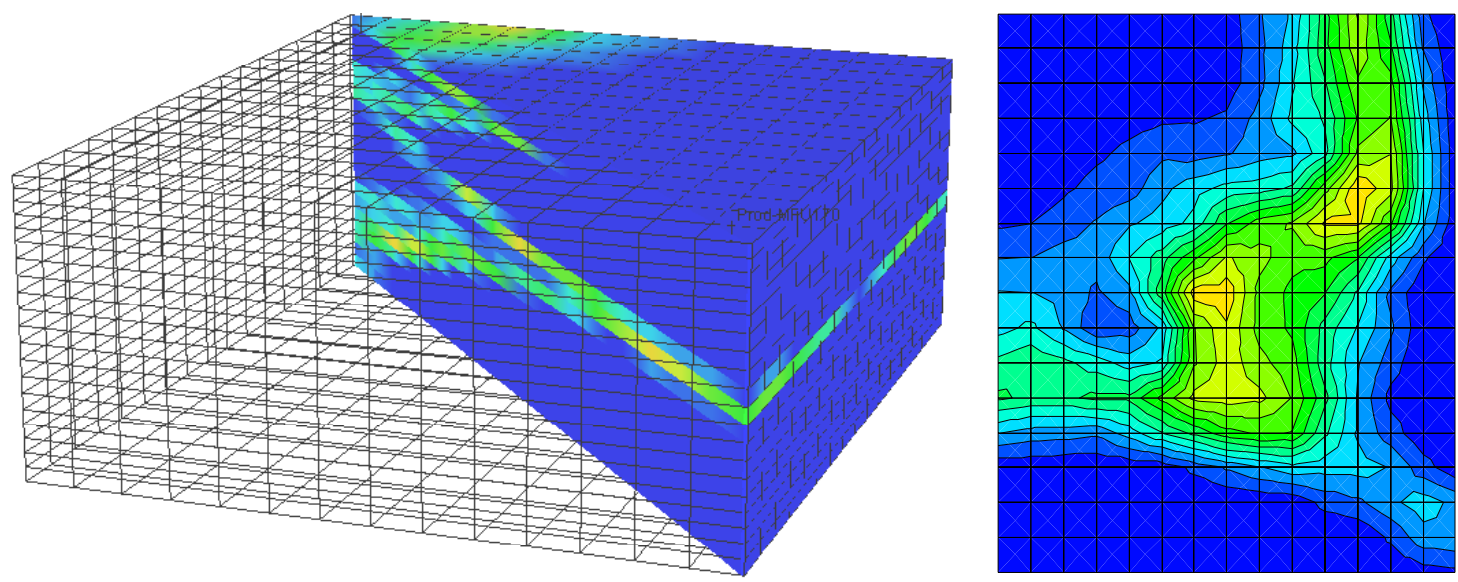

Fig. B-13. Base case surf. conc. (vol. frac.) after 0.35 PV injected

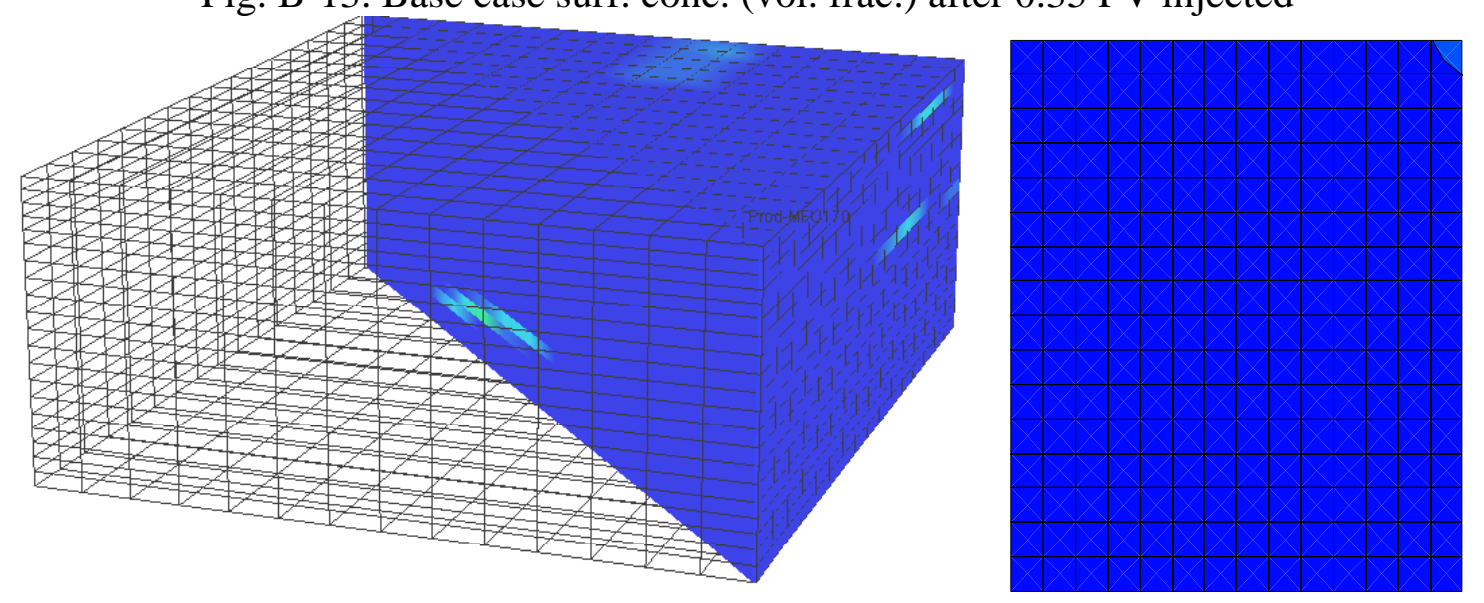

Fig. B-14. Base case surf. conc. (vol. frac.) after 1.75 PV injected 

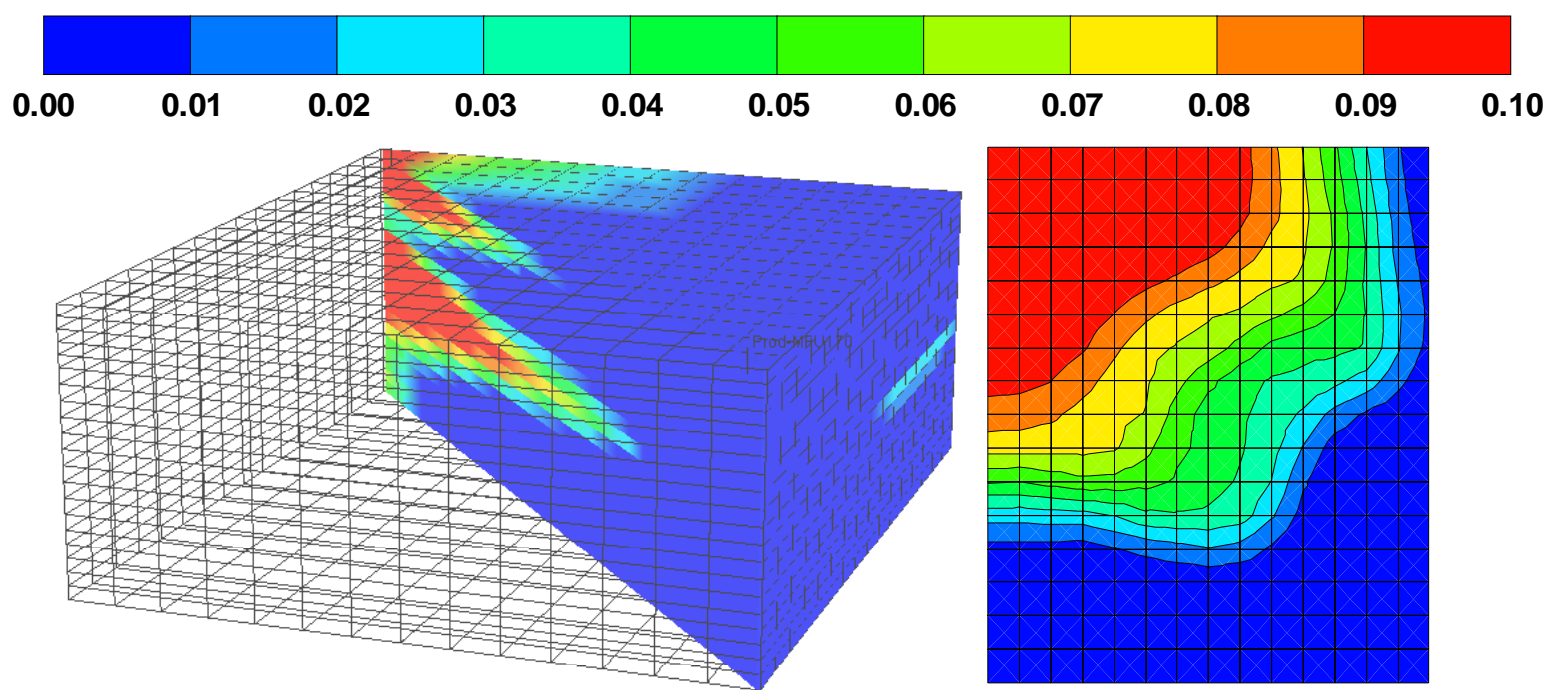

Fig. B-15. Base case polymer conc. (wt\%) after 0.2 PV injected
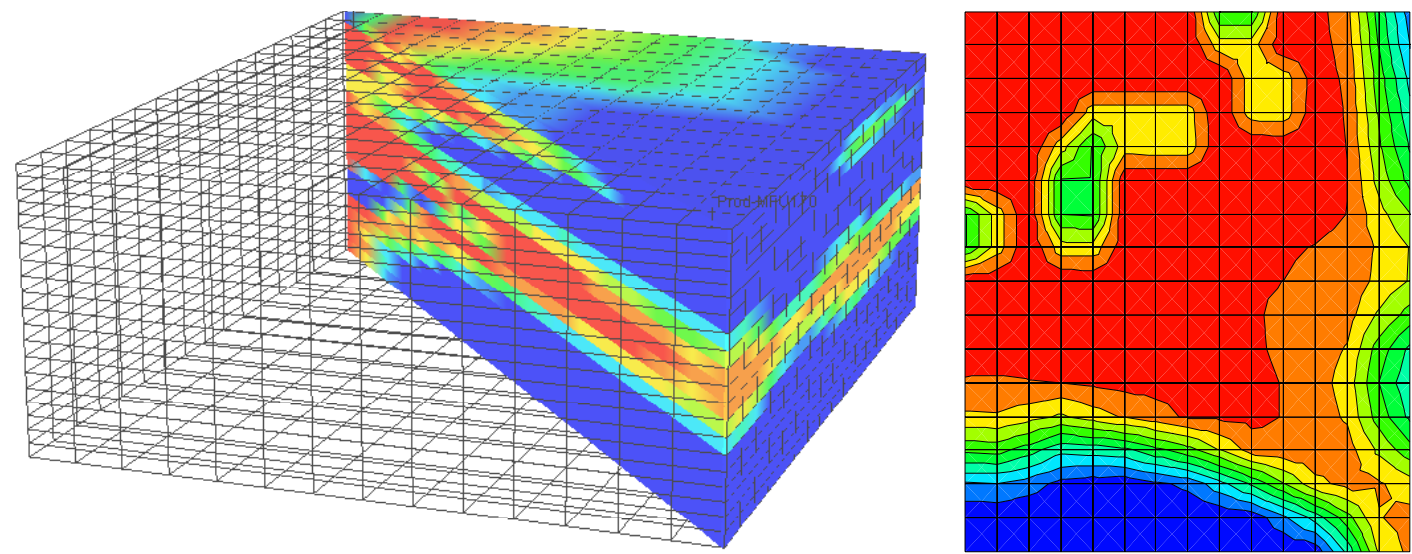

Fig. B-16. Base case polymer conc. (wt\%) after 0.35 PV injected
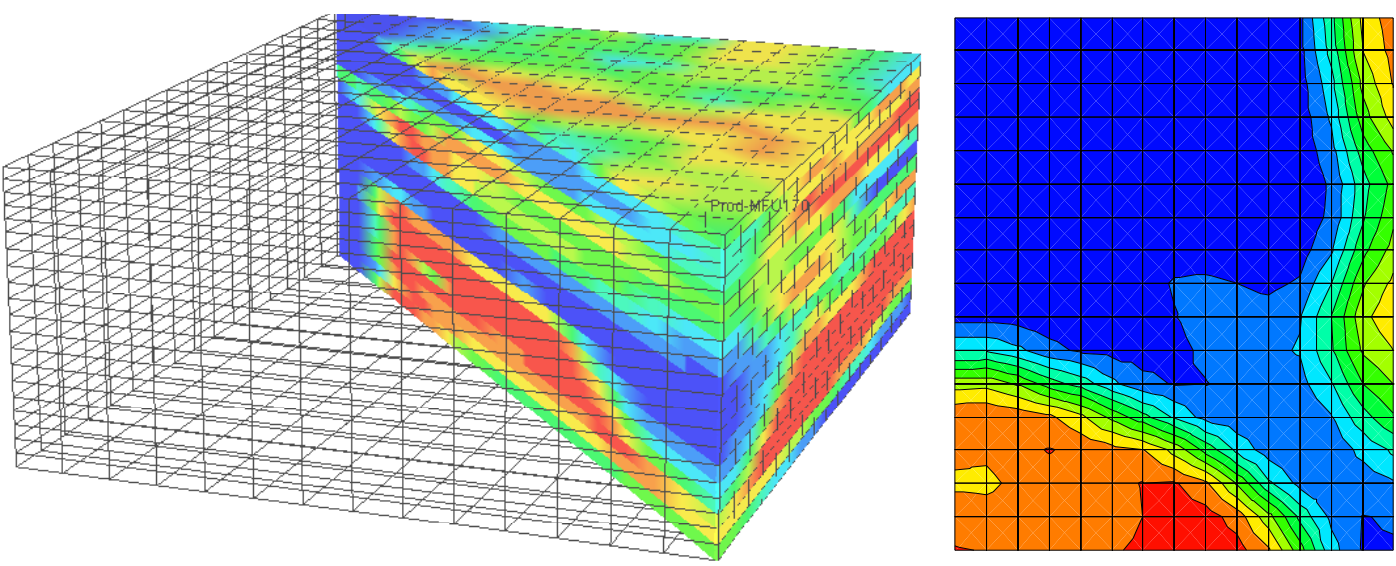

Fig. B-17. Base case polymer conc. (wt\%) after 1.75 PV injected 


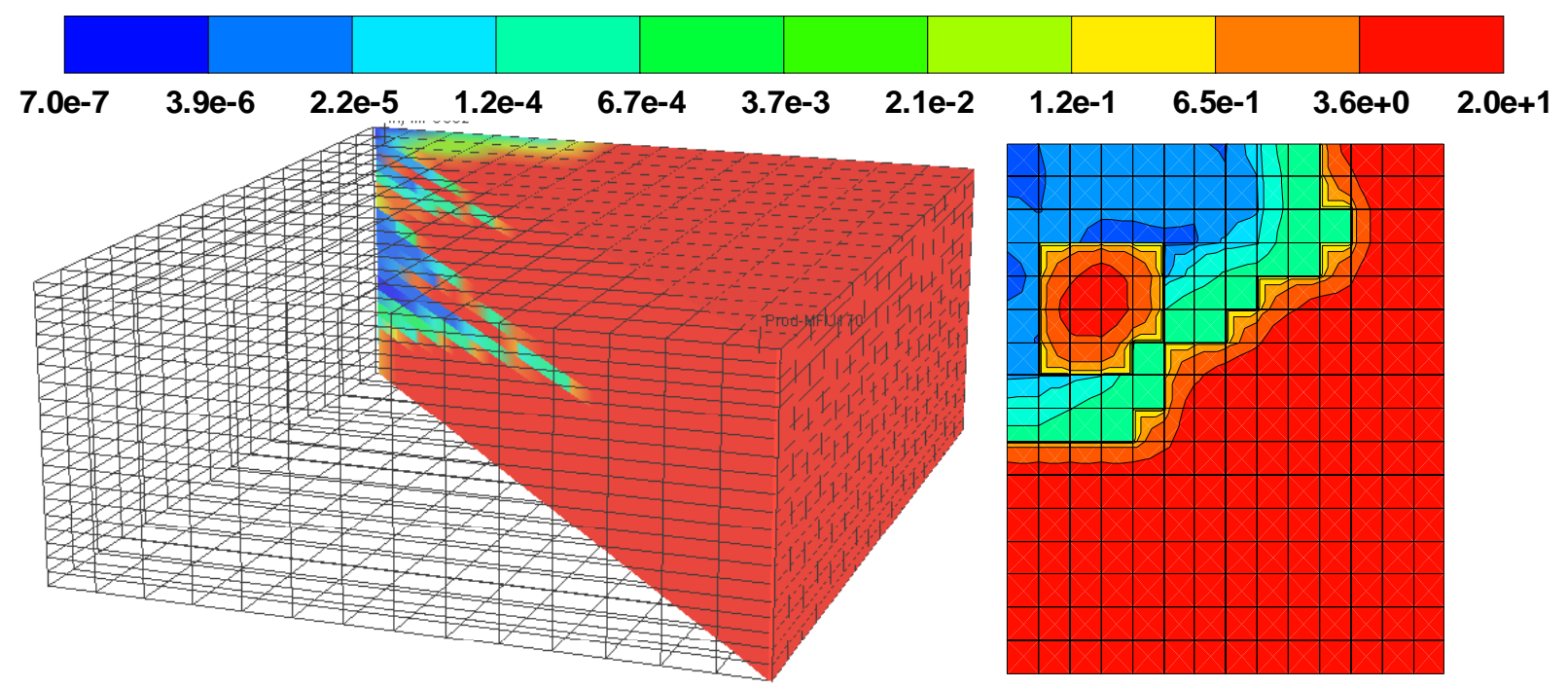

Fig. B-18. Base case IFT (dynes/cm) after 0.2 PV injected
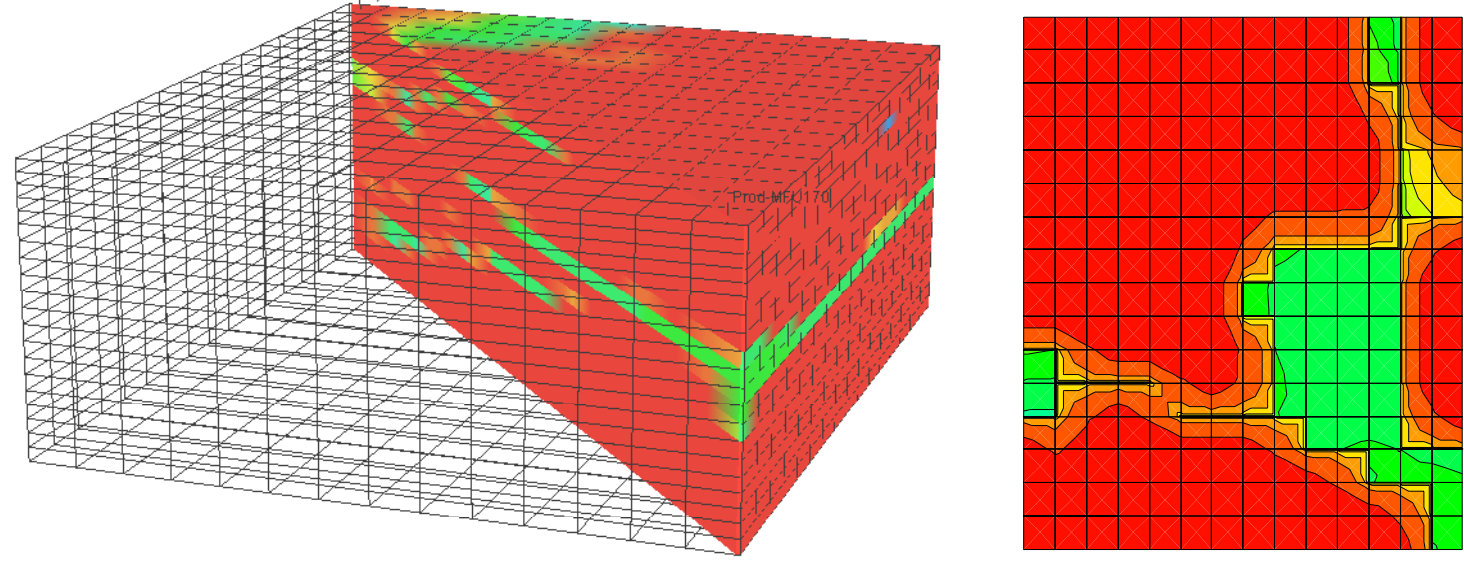

Fig. B-19. Base case IFT (dynes/cm) after 0.35 PV injected
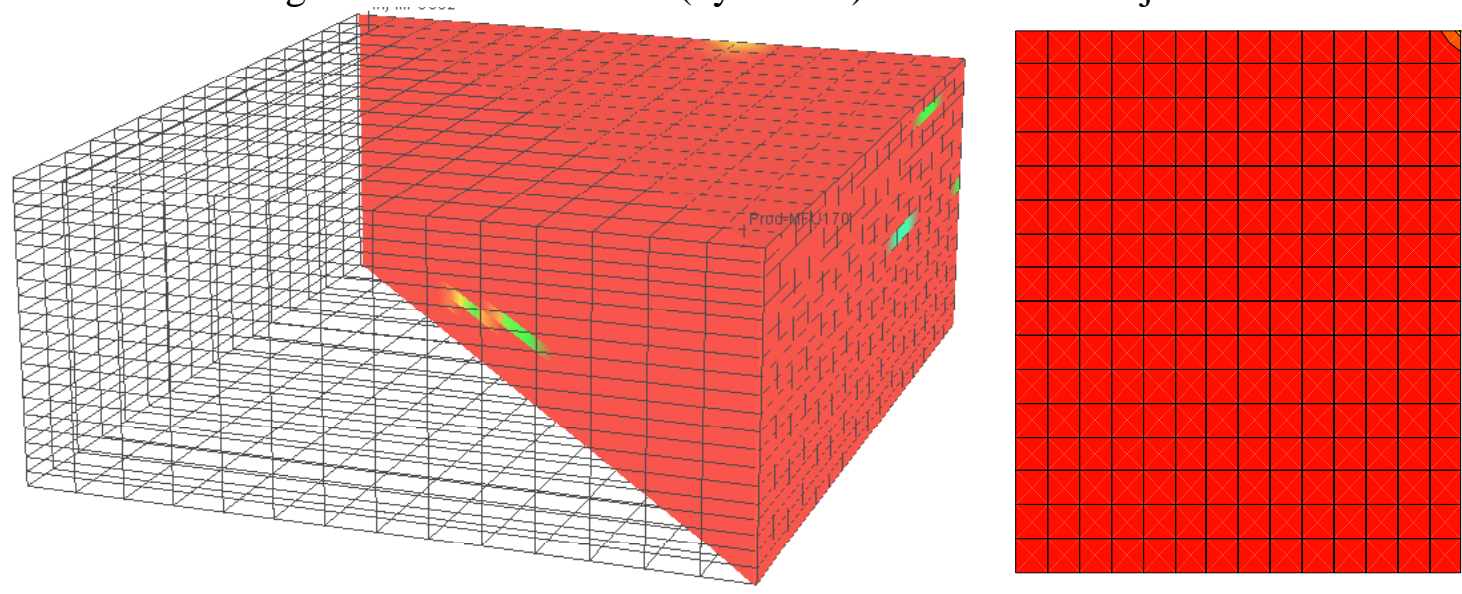

Fig. B-20. Base case IFT (dynes/cm) after 1.75 PV injected 


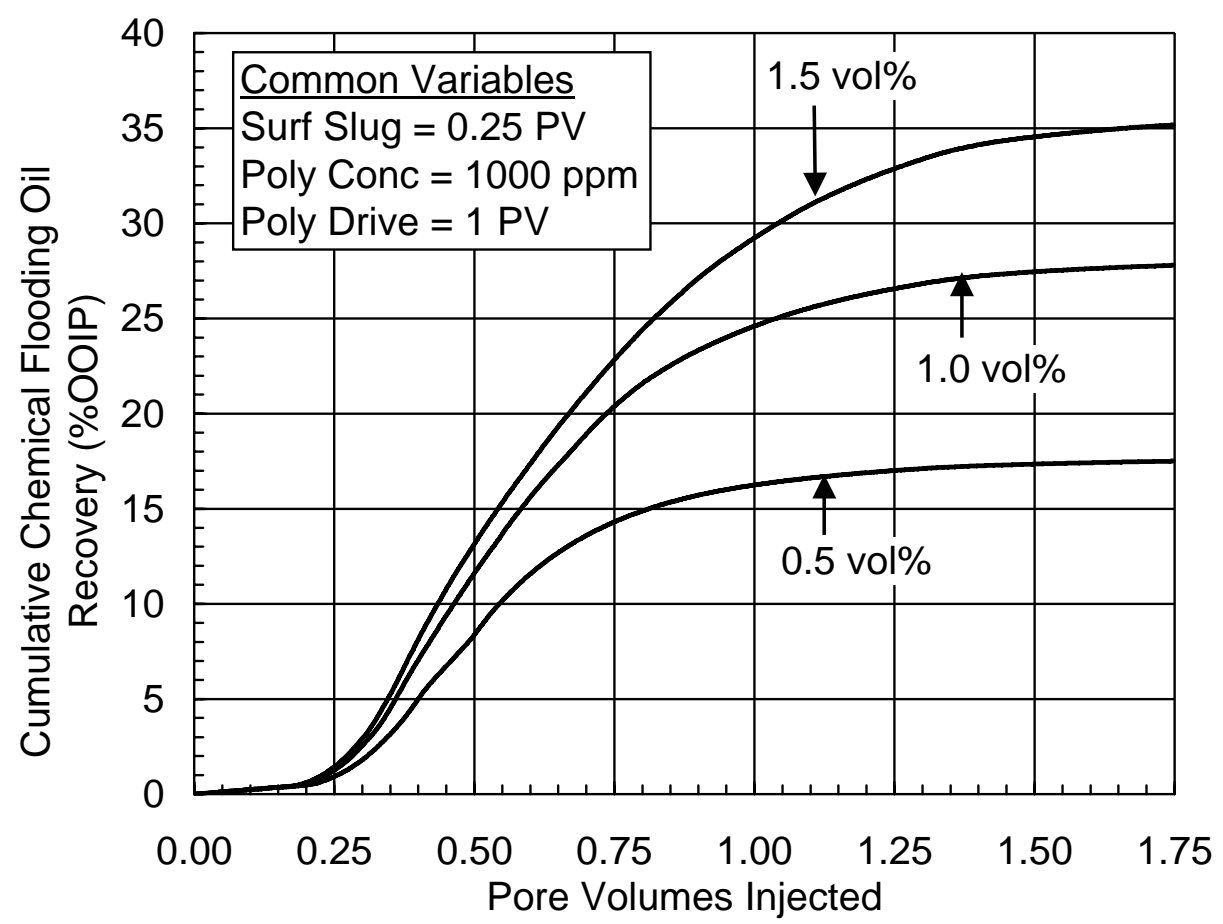

Fig. B-21. Cumulative oil recovery for surfactant concentration simulations

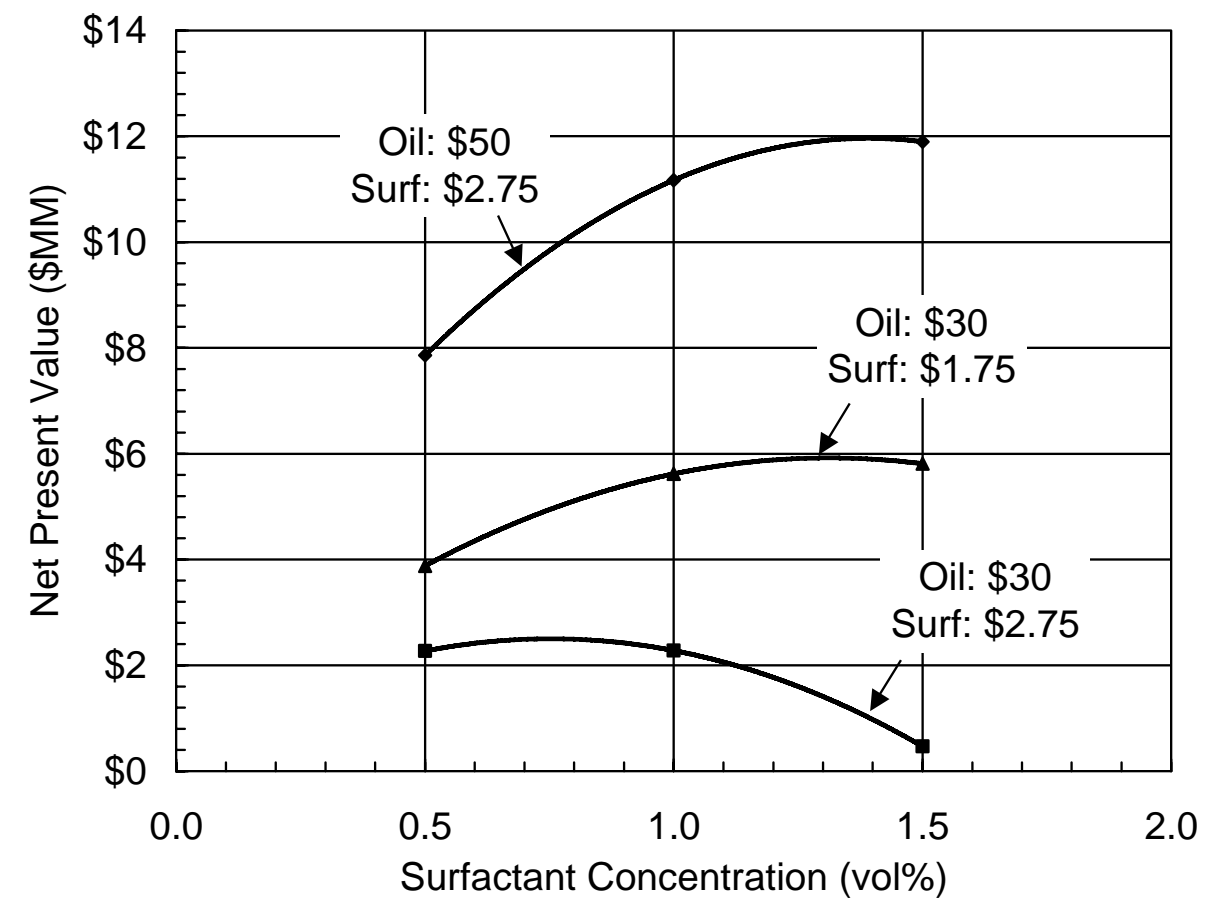

Fig. B-22. Economic results for surfactant concentration simulations 


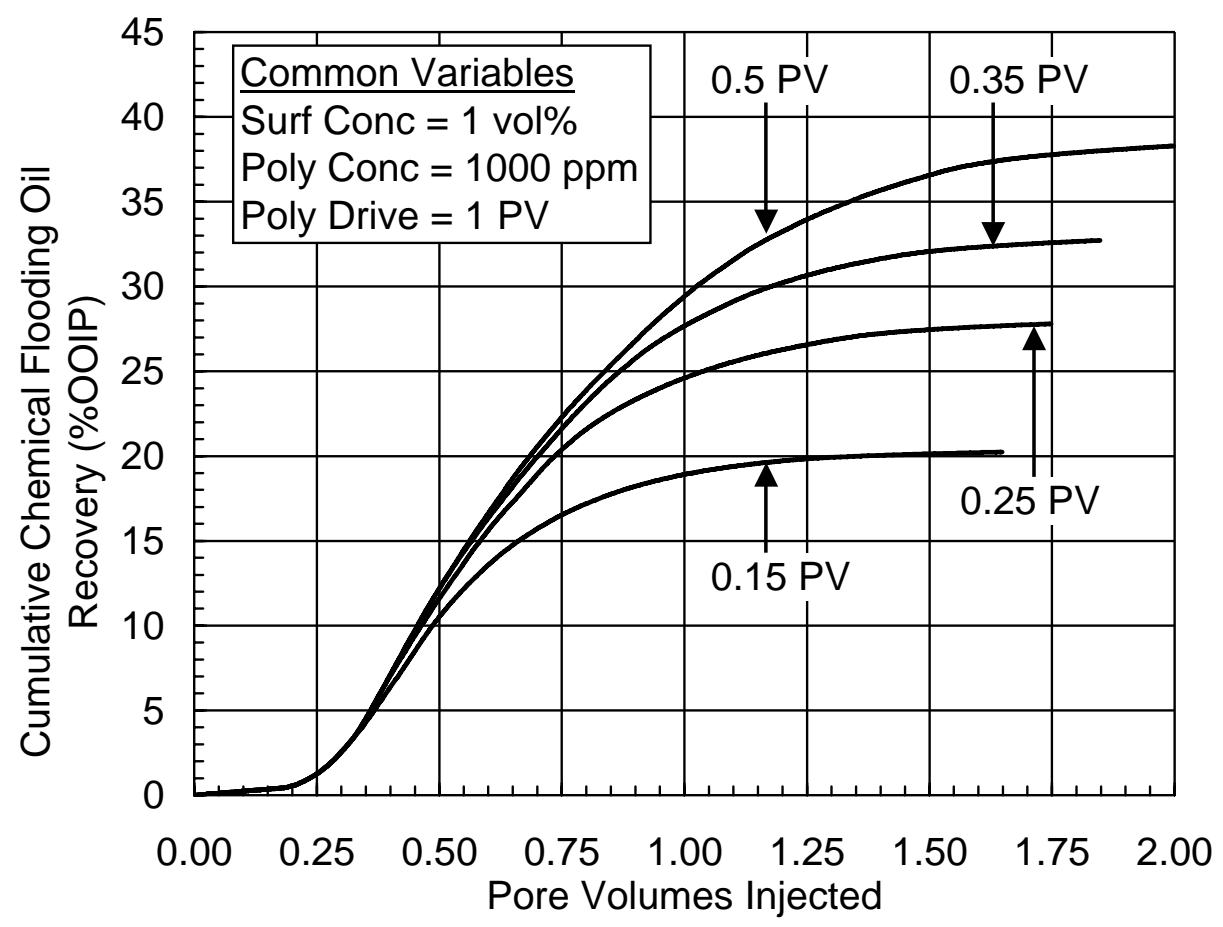

Fig. B-23. Cumulative oil recovery for surfactant slug size simulations

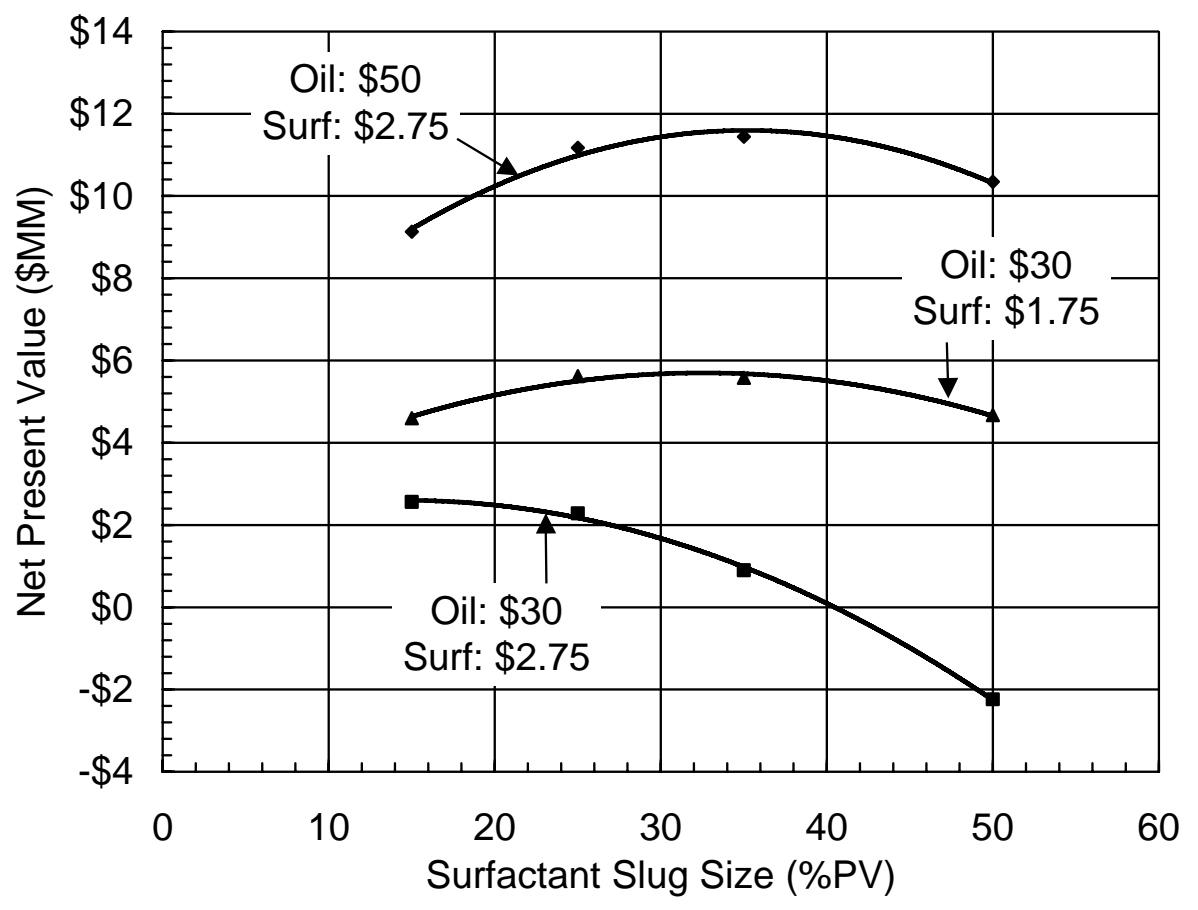

Fig. B-24. Economic results for surfactant slug size simulations 


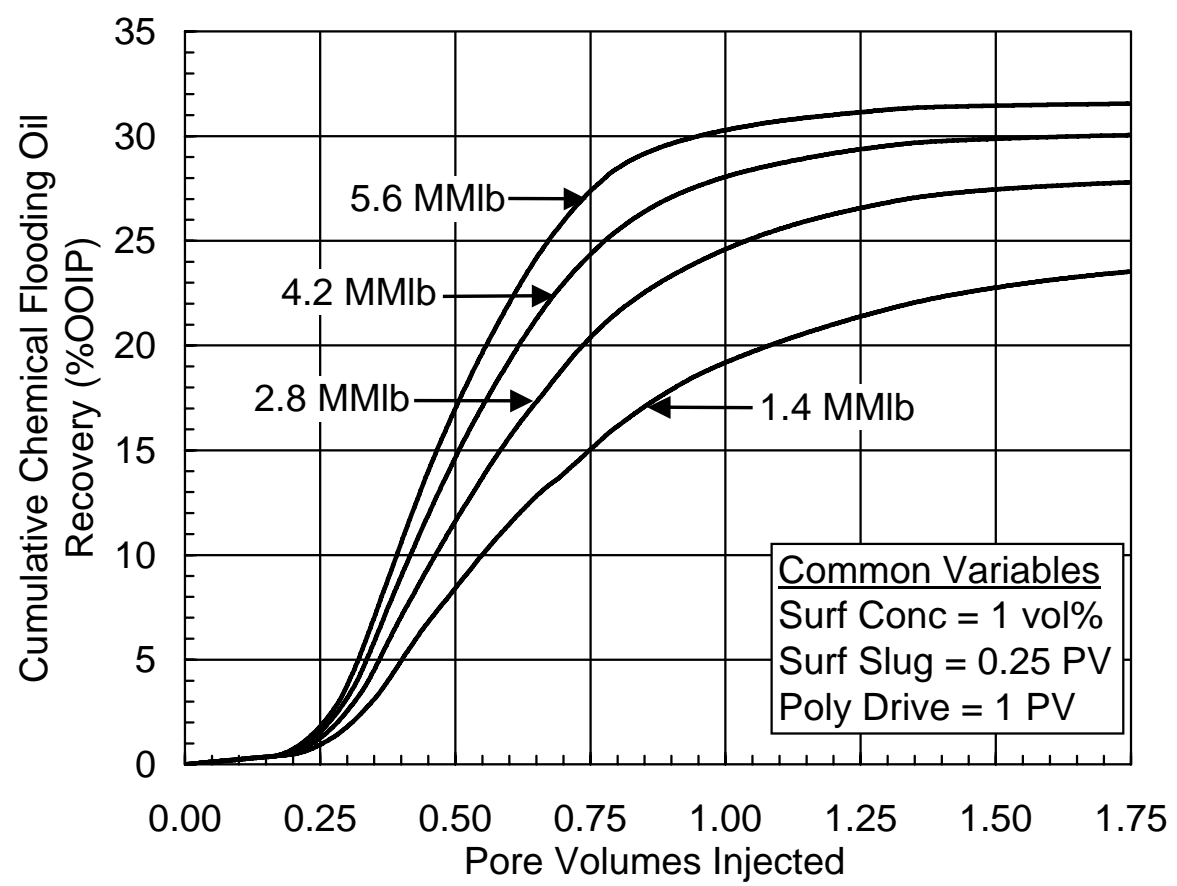

Fig. B-25. Cumulative oil recovery for polymer mass simulations

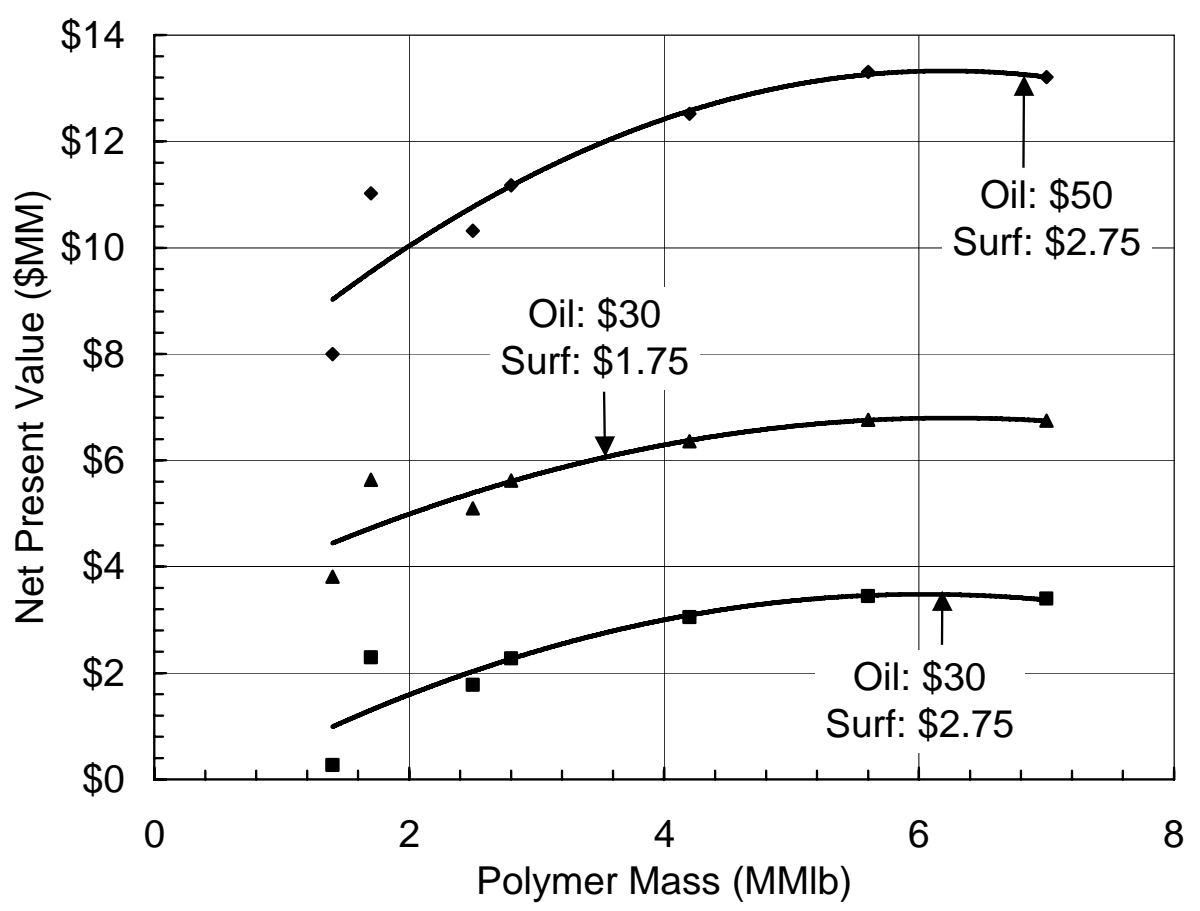

Fig. B-26. Economic results for polymer mass simulations 


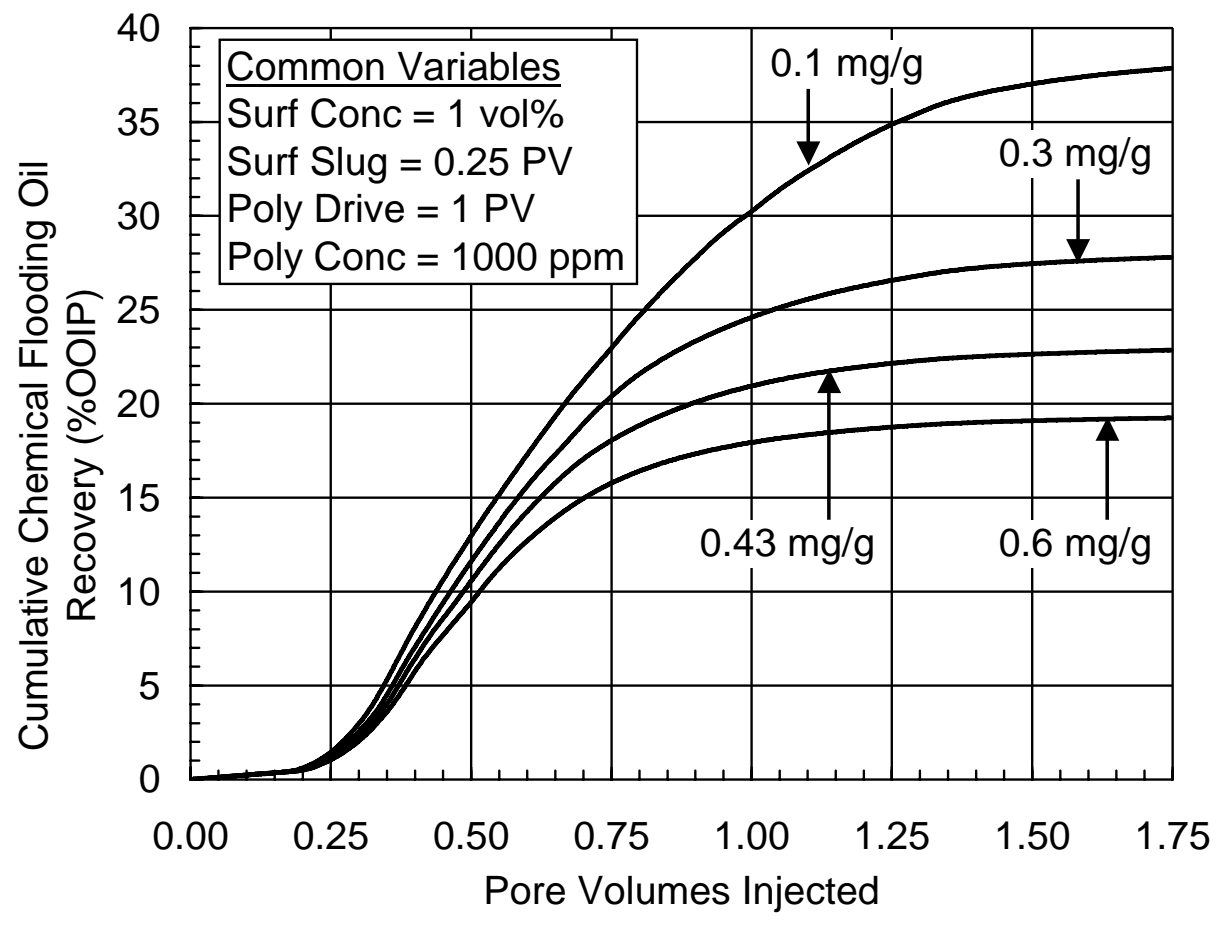

Fig. B-27. Cumulative oil recovery for surfactant adsorption simulations

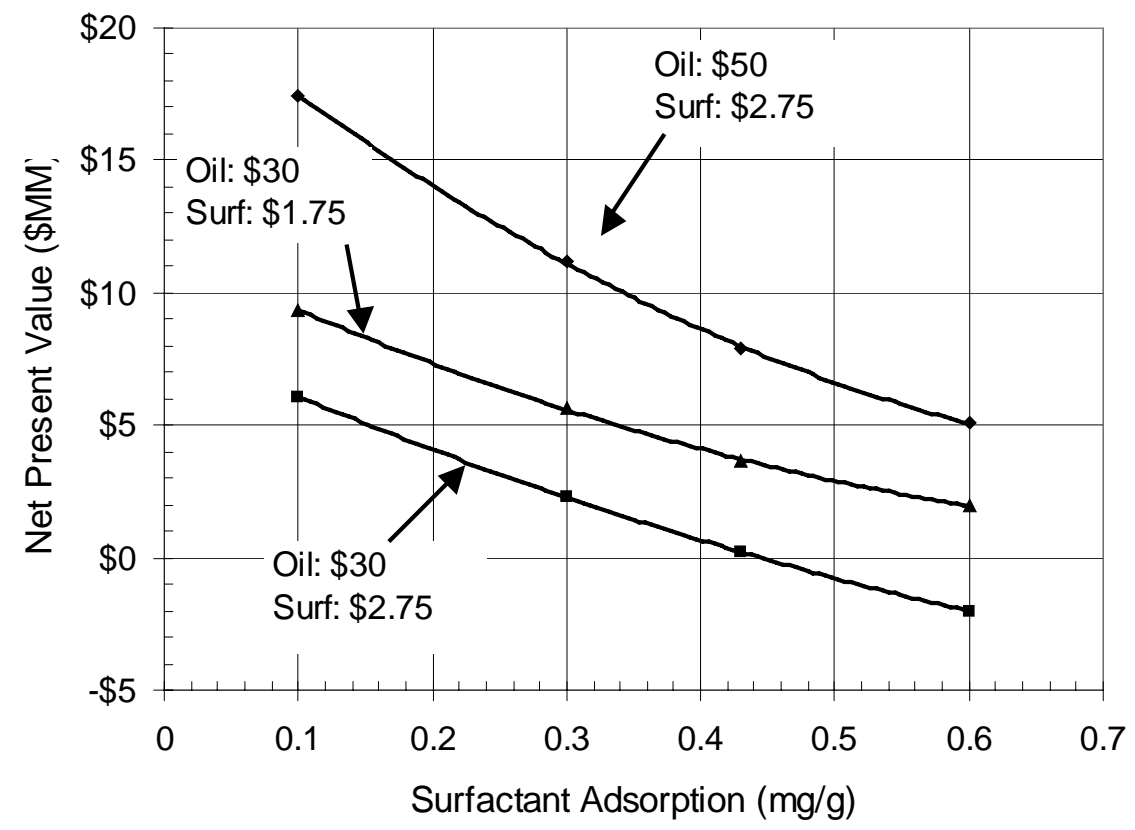

Fig. B-28. Economic results for surfactant adsorption simulations 


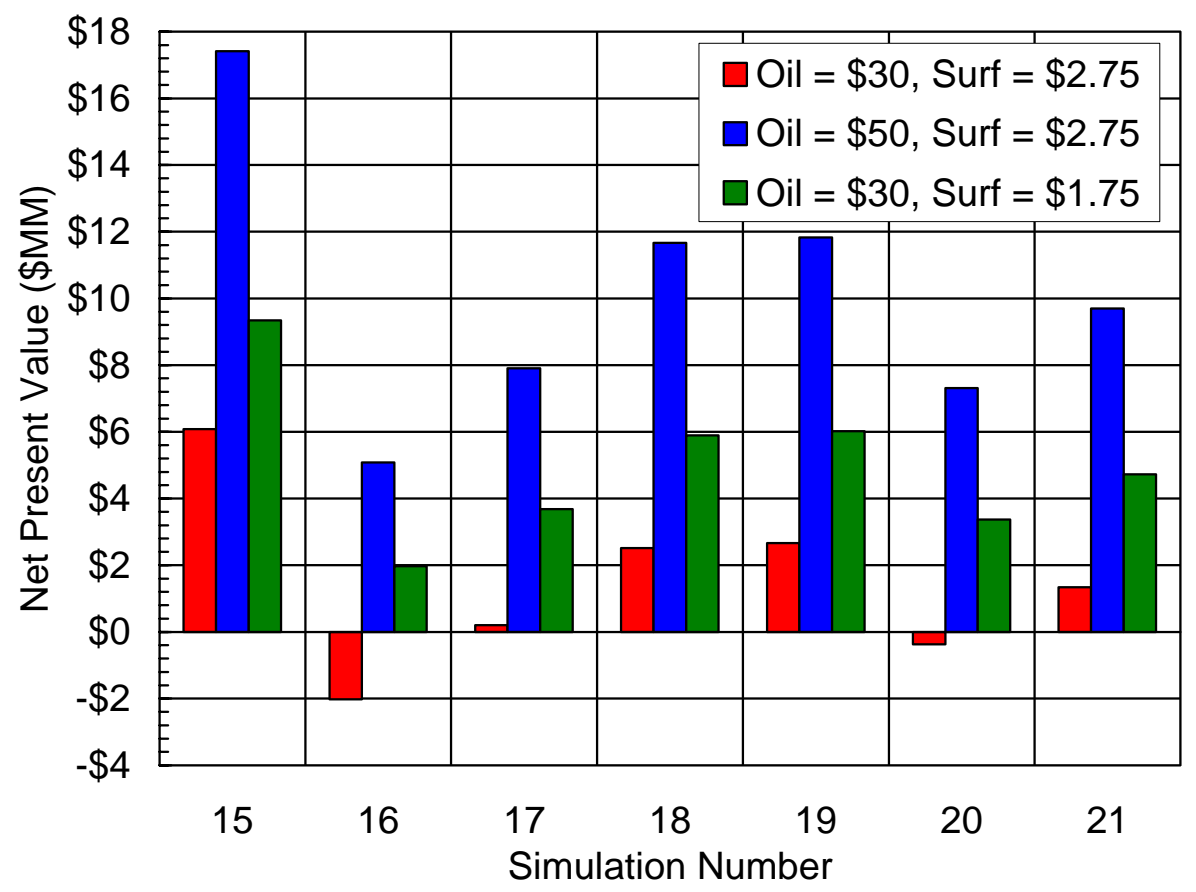

Figure B-29. Comparison of NPV for uncertainty simulations

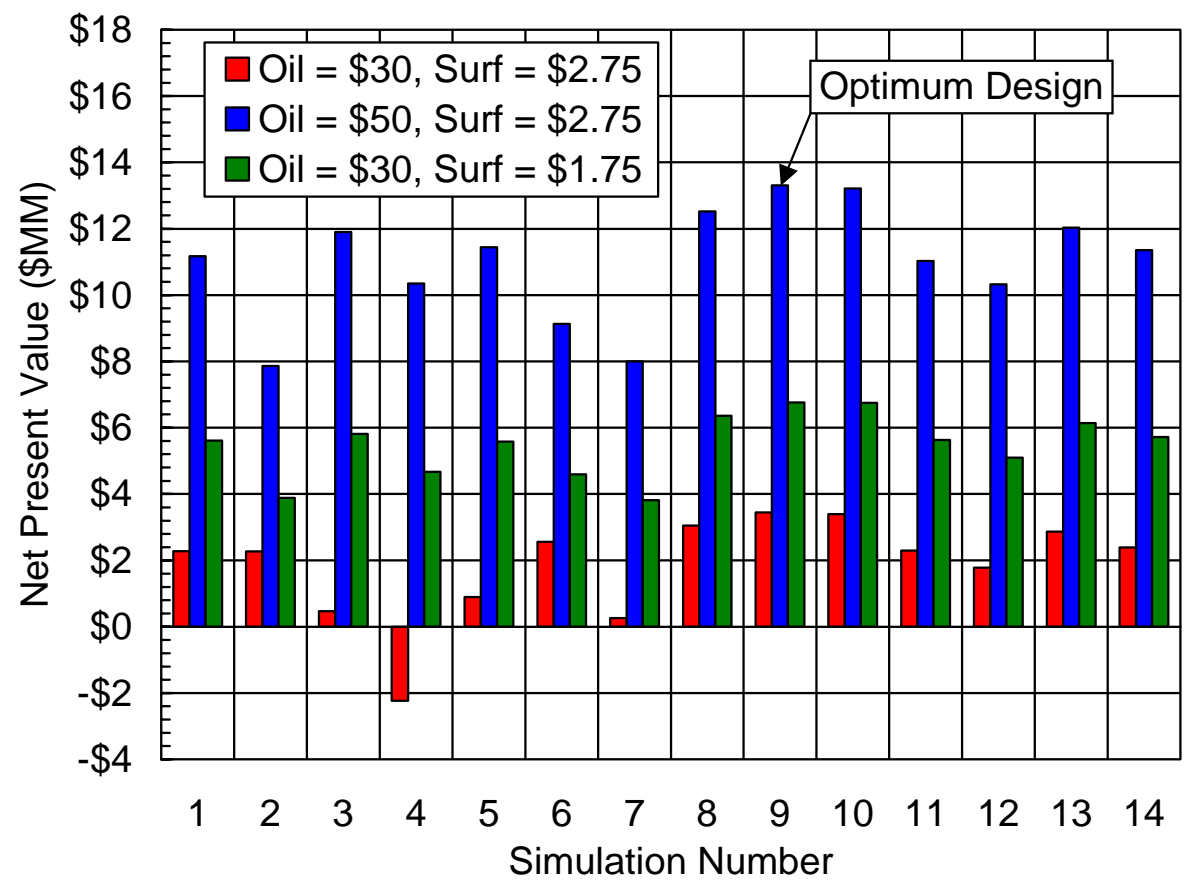

Figure B-30. Comparison of NPV for design optimization simulations 


\section{Summary and Conclusions}

We have developed a user-friendly and efficient platform that integrates an oil reservoir simulator to perform the flow simulations, an economic model for discounted cash flow analysis, an experimental design and response surface methodology, and a Monte Carlo algorithm with a global optimization search engine to identify the optimum design under conditions of uncertainty

A surfactant feasibility simulation study was performed to design and optimize surfactant floods in two US reservoirs. The intent of this study was to help determine whether a surfactant flood could be economically attractive in these fields, given typical performance and consumption of the surfactant. The results indicated that even for heterogeneous mixed wet dolomite reservoirs studies here, a good combination of good surfactant performance based on careful laboratory evaluation, optimization of the design using UTCHEM simulator, and favorable crude oil process gives a high rate of return for the surfactant/polymer EOR process.

\section{REFERENCES}

Anderson, A., "Simulation of Chemical Flood Enhanced Oil Recovery Processes Including the Effects of Reservoir Wettability, "MS Thesis, The University of Texas at Austin, May 2006.

Anderson, G.A., M. Delshad, C.B. King, H. Mohammadi, and G.A. Pope, "Optimization of Chemical Flooding in a Mixed-wet Dolomite Reservoir," SPE 100082 presented at the 2006 SPE/DOE Symposium on Improved Oil Recovery, Tulsa, OK, 22-26 April 2006.

April, J., F. Glover, J. Kelly, and M. Laguna, "A New Optimization Methodology for Portfolio Management," paper SPE 84332 presented at the SPE Annual Technical Conference and Exhibition, Denver, Colorado, Oct 5 - 8, 2003.

April, J., F. Glover, J. Kelly, M. Laguna, M. Erdogan, B. Mudford, and D. Stegemeier, "Advanced Optimization Methodology in the Oil and Gas Industry: The Theory of Scatter Search Techniques with Simple Examples," paper SPE 82009 presented at the 
SPE Hydrocarbon Economics and Evaluation Symposium, Dallas, TX, April 5 - 8, 2003.

Delshad, M., "Trapping of Micellar Fluids in Berea Sandstone," PhD dissertation, The University of Texas at Austin, 1990

Deutsch, C.V. and A. G. Journel, GSLIB, Geostatistical Software Library and User's Guide, Oxford University Press, Second Edition, New York 1998.

Huh, C., "Interfacial Tension and Solubilizing Ability of a Microemulsion Phase That Coexists With Oil and Brine," J. Colloid Interface Sci.(1979), 71, 408-428.

Lake, L.W., Enhanced Oil Recovery, Prentice-Hall, Englewood Cliff, New Jersey, 1989.

Levitt, D. et al., "Identification and Evaluation of High Performance EOR Surfactants," paper SPE 100089 presented at the 2006 SPE/DOE Symposium on Improved Oil Recovery, Tulsa, OK, 22-26 April 2006.

Myers, R.H. and D.C. Montgomery, Response Surface Methodology - Process and Product Optimization Using Designed Experiments, John Wiley \& Sons, New-York, 1995.

Pope, G.A. and R. C. Nelson, "A Chemical Flooding Compositional Simulator," SPEJ (Oct. 1978) 18, pg. 339 - 354.

Vaskas, A.J., "Optimization of Surfactant Flooding: An Economic Approach," Master's thesis, University of Texas at Austin (May 1996).

Yang, A.P., "Stochastic Heterogeneity and Dispersion," Ph.D. dissertation, University of Texas at Austin (Dec. 1990).

Zhang, J., "IRSS: An Integrated Reservoir Simulation System," PhD dissertation, The University of Texas at Austin, August 2005.

Zhang, J., M. Delshad, and K. Sepehrnoori, "A Framework to Design and Optimize Surfactant Enhanced Aquifer Remediation," paper SPE 94222 presented at the 2005 SPE/EPA/DOE Exploration \& Production Environmental Conference, Galveston, Texas, March 7 - 9, 2005.

Zhang, J., M. Delshad, M. and K. Sepehrnoori, and G.A. Pope, "An efficient Reservoir Simulation Approach to Design and Optimize Improved Oil Recovery Processes with Distributed Computing,” paper SPE 94733 presented at the 2005 SPE Latin America and Caribbean Petroleum Engineering Conference, Rio De Janeiro, Brazil, 2-23 June 2005. 